\title{
Reiki Therapy in Social Work Practice
}

\author{
by
}

\section{Cheryl Grant, B.A., B.S.W.}

\author{
A thesis submitted to \\ the Faculty of Graduate Studies \\ in partial fulfillment of \\ the requirement for the degree of \\ Master of Social Work \\ Carleton University \\ Ottawa, ON \\ September 11, 2007 \\ Copyright \\ 2007, Cheryl Grant
}




$\begin{array}{ll}\begin{array}{l}\text { Library and } \\ \text { Archives Canada }\end{array} & \begin{array}{l}\text { Bibliothèque et } \\ \text { Archives Canada }\end{array} \\ \begin{array}{l}\text { Published Heritage } \\ \text { Branch }\end{array} & \begin{array}{l}\text { Direction du } \\ \text { Patrimoine de l'édition }\end{array} \\ \begin{array}{l}\text { 395 Wellington Street } \\ \text { Ottawa ON K1A 0N4 } \\ \text { Canada }\end{array} & \begin{array}{l}\text { 395, rue Wellington } \\ \text { Ottawa ON K1A ON4 }\end{array} \\ \text { Canada }\end{array}$

Your file Votre référence ISBN: 978-0-494-36853-4 Ourfile Notre référence ISBN: 978-0-494-36853-4

\section{NOTICE:}

The author has granted a nonexclusive license allowing Library and Archives Canada to reproduce, publish, archive, preserve, conserve, communicate to the public by telecommunication or on the Internet, loan, distribute and sell theses worldwide, for commercial or noncommercial purposes, in microform, paper, electronic and/or any other formats.

The author retains copyright ownership and moral rights in this thesis. Neither the thesis nor substantial extracts from it may be printed or otherwise reproduced without the author's permission.
AVIS:

L'auteur a accordé une licence non exclusive permettant à la Bibliothèque et Archives Canada de reproduire, publier, archiver, sauvegarder, conserver, transmettre au public par télécommunication ou par l'Internet, prêter, distribuer et vendre des thèses partout dans le monde, à des fins commerciales ou autres, sur support microforme, papier, électronique et/ou autres formats.

L'auteur conserve la propriété du droit d'auteur et des droits moraux qui protège cette thèse. $\mathrm{Ni}$ la thèse ni des extraits substantiels de celle-ci ne doivent être imprimés ou autrement reproduits sans son autorisation.
In compliance with the Canadian

Privacy Act some supporting forms may have been removed from this thesis.

While these forms may be included in the document page count, their removal does not represent any loss of content from the thesis.
Conformément à la loi canadienne sur la protection de la vie privée, quelques formulaires secondaires ont été enlevés de cette thèse.

Bien que ces formulaires aient inclus dans la pagination, il n'y aura aucun contenu manquant.

\section{Canadä}




\section{Table of Contents}

Acknowledgements.................................................Page 3

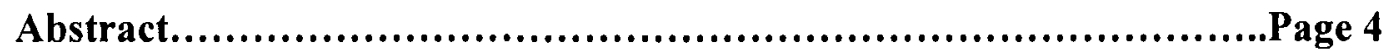

List of Appendices............................................................ 5

Chapter 1: Introduction.............................................Page 6

Chapter 2: Theoretical Framework and Methodology..................Page 35

Chapter 3: The Potential for Integration..............................Page 61

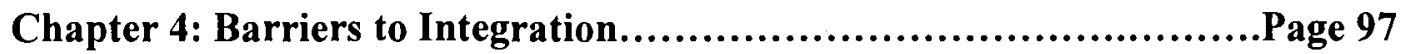

Chapter 5: Conclusions Regarding Integration.........................Page 121

Reference List....................................................Page 131

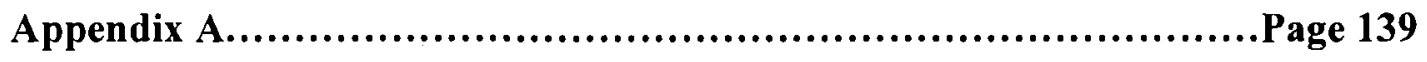

Appendix B......................................................Page 141

Appendix C.....................................................Page 143

Appendix D.............................................................. 145

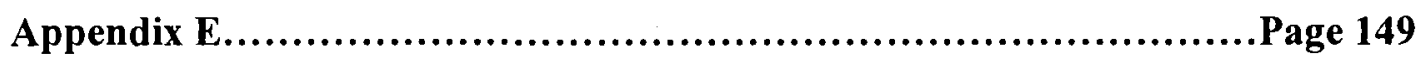

Appendix F................................................................... 151

Appendix G.....................................................Page 154

Appendix H.........................................................Page 157

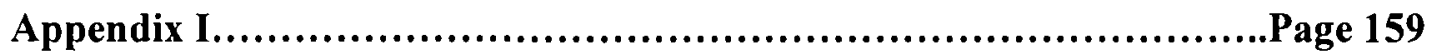

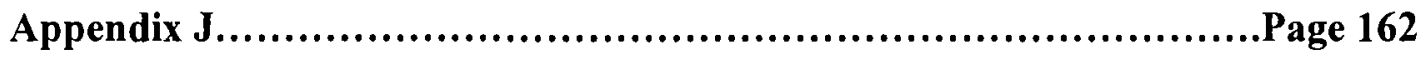




\section{Acknowledgements}

This project may not have come to fruition if it hadn't been for the open and genuine nature of my thesis advisor, Sarah Todd, who encouraged me to pursue an idea that I was interested in, despite my reservations about the parameters of mainstream social work practice and research. Throughout the long and complicated process of undertaking a thesis project, Sarah was endlessly supportive, reliable, and committed to providing continued guidance and quality of education about research in the field of social work and for this I am deeply appreciative. I would be remiss if I did not thank the people who so generously agreed to participate as second readers for my thesis. Betty Taylor, for her enthusiasm and support during the initial stages involved with the proposal and development of this project, and Karen Schwartz, for jumping in and just as enthusiastically agreeing to take on the role of being a second reader when Betty wasn't able to continue. This type of support was very encouraging and helped to make the process more enjoyable.

There are many, many friends and family members that I would also like to thank for their support, caring and encouragement, too many to list here but they are all aware of my appreciation. I would not have been able to complete this thesis without the love, support and patience of my husband, Kevin, and my son, Zachary, who both had to share me with "the thesis" and my late nights at the computer. Last but certainly not least, I would like to extend my respect and sincere appreciation for the participation of the individual professionals that $\mathrm{I}$ had the honour of interviewing for this project. Without their interest in and passion for research, education, and the development of the fields of reiki and social work, this project wouldn't have happened at all! 


\begin{abstract}
This study explores the perspectives of individuals with reiki and social work credentials, or "practitioners", regarding any benefits, risks, and barriers to the integration of reiki therapy and social work practice in the healthcare system. An organizational representative from each the College of Social Workers and Social Service Workers, The Canadian Reiki Association, and The Ontario Health Department was interviewed regarding their response to the prospect of integration and for the purpose of providing an organizational context to the practitioners' responses. Practitioners identified benefits to integration such as relief of physical pain, relaxation and stress reduction, relief of emotional pain, increased mental clarity and self awareness, increased receptivity to therapy, enhanced spiritual connection, and a sense of empowerment. The fit that was described between the two practices demonstrated complementary goals, values, and ethics of practice. Barriers to integration were described to be a lack of standardization in reiki and issues around credibility, financial costs of reiki, lack of education and scientific research about reiki, a Western mind-set, and issues regarding touch in practice. Such barriers demonstrated the impact of cultural differences and social structures due to a conservatism around the East-West paradigm clash and the struggle to establish and maintain boundaries within both CAM groups and within the conventional medical community. None of the participants saw any risks or dangers of integrating social work and reiki therapy. The responses of the organizational representatives demonstrated that the Canadian Reiki Association was very supportive of integration while the College and Ontario Health Department representatives took a more neutral and formalized position. These representatives cited the importance of adhering to standards of practice in their respective fields, which did not allow for an in-depth exploration of potential issues involved with integration.
\end{abstract}




\section{List of Appendices}

Appendix A: Canadian Reiki Association: Code of Ethics

Appendix B: Canadian Reiki Association: Disciplinary Action Policy

Appendix C: Advertisement for Participants

Appendix D: Interview Guide for Individuals with Reiki and Social Work Credentials

Appendix E: Thematic Guide for Telephone Interviews with Organizational Representatives

Appendix F: Letter of Information for Individuals with Reiki and Social Work Credentials

Appendix G: Letter of Information for Organizational Representatives

Appendix H: Standards of Social Work Practice as quoted by the College of Social Workers and Social Service Workers

Appendix I: Letter of Consent for Individuals with Reiki and Social Work Credentials

Appendix J: Letter of Consent for Organizational Representatives 


\section{Reiki and Social Work}

\section{Chapter 1: Introduction}

Questions about healing practices often arise when people are faced with the limits of the medical model that currently predominates in Western ${ }^{1}$ Society. People have been increasingly looking towards alternative treatment modalities to address physical, mental, and emotional health issues (Miles and True, 2003; Wright, 1999; http://nccam.nih.gov.health/). In the Western world, "alternative treatment modalities" fall within a category of healthcare practices referred to as Complementary and Alternative Medicine or CAM (http://nccam.nih.gov.health). CAM practices, often based within Eastern philosophical and spiritual belief systems, operate from a view of health, well-being, and healing that is holistic and that combines physical, mental, emotional, and spiritual dimensions (http://nccam.nih.gov.health/). These practices can either work in combination with conventional medicine, hence the term "complementary", or are separate systems of healing that are used outside of or instead of conventional medicine, hence the term "alternative" (http://nccam.nih.gov.health/) ${ }^{2}$. The holistic healing model espoused in CAM practices differs from and challenges the medical model, which relies solely on using scientific methods to address mental and physical health concerns (Loveland-Cook, Becvar \& Pontious, 2000).

People seek medical treatment and social support to help manage pain resulting from anything from life-threatening illnesses such as cancer and HIV/AIDS to the

\footnotetext{
${ }^{1}$ For the purposes of this paper, the use of the term "Western" refers to Canada, the United States, the countries of Western Europe, Australia and New Zealand.

${ }^{2}$ There are tensions within the Complementary and Alternative healthcare communities, both within and between the individual professions, regarding the use of the term "CAM" and regarding which professions are identified as being part of "CAM". While I acknowledge the existence and importance of these contentions, this is the term and definition that I will use.
} 
cumulative effects of daily stressors faced by those stretching to meet the combined demands of work and family in today's fast-paced, consumer-based society (Walsh, 1999). These demands involve longer working hours, limited time with family, and juggling finances to meet lifestyle standards set by a consumer-based paradigm (Walsh, 1999). The anxiety that results from such cumulative stressors is further compounded for people feeling oppressed by poverty, domestic violence, language barriers, racism, ableism, sexism, and heterosexism (Lundy, 2004). Without the time or energy to manage the stress of living under oppressive conditions and the every day stressors of contemporary life, crises can occur that often have debilitating effects (EII, 1996). People affected by crises may experience difficulty coping, prompting a need to rely on social and medical support services. At times, people move beyond mainstream services and look at alternative services such as CAM.

In response to this growing interest in CAM, in this thesis I explore the benefits and risks of incorporating reiki therapy into social work practice within the healthcare system. The Canadian Healthcare System is a term typically used to refer to the system of publicly-funded, "medically necessary" healthcare services in Canada that include hospitals, mental health institutions, community health centres, and family-based medical practices (http//:www.hc-sc.gc.ca/hcs-sss/alt_formats). This can also include other healthcare services that are provided on an in-home basis or in the community but are not covered under the Canada Healthcare Act. For the purposes of this paper, I use the term "healthcare system" to mean publicly-funded healthcare services, particularly hospitals.

Reiki is a complementary therapy within the category of CAM that promotes well-being and healing of the physical, mental, emotional, and spiritual dimensions by 
applying the concepts of energy and balance that stem from the Eastern philosophies and spiritual practices of Taoism and Buddhism (Miles \& True, 2003). Current literature suggests that research regarding the exploration of complementary and alternative therapies with Western mainstream social and healthcare services is timely because there is an increasing interest in the West regarding holistic approaches to health and wellbeing (Miles and True, 2003; Wright, 1999; http://nccam.nih.gov.health) and a growing interest in including spirituality in social work practice (Coholic, 2002; Canda, 1998; Canda \& Furman, 1999; Epple, 2003).

Questions about the benefits and risks of integrating reiki with social work in healthcare are also significant because they highlight the possibilities for more effective service provision to those struggling with physical, spiritual, mental, and emotional health issues. In addition, I am educated in both reiki therapy and social work practice and I have often questioned the extent of fit between these two areas of practice that use quite different methods for achieving the mutual goal of assisting people to improve their health and well-being.

Social work's theories and practices have continued to evolve and develop over the past century. Its approaches are often quite flexible and adaptable to different practice contexts (Henderson, 2000). It is the awareness of this flexibility, the above-mentioned growing public interest in alternative therapies, and my personal connection to social work and reiki that motivated me to explore the possibilities and risks of incorporating reiki with social work practice within the healthcare system.

In this study, I interviewed six individuals with both reiki and social work credentials regarding their perspectives about the benefits, risks, and barriers involved 
with incorporating reiki and social work practice in the healthcare system. In addition to these interviews, and for the purpose of placing the responses of the above-mentioned individuals within an organizational or institutional context, I spoke with an organizational representative from each the Canadian Reiki Association, the College of Social Workers and Social Service Workers, and the Ontario Health Department respectively regarding their response to the idea of incorporating reiki and social work within the healthcare system. The organizational representatives' responses and the context they provide for the results of the interviews with the practitioners in this study will be discussed below. Interview responses were reviewed for similarities, common threads, and marked differences in terms of responses to a particular question. I then provided an analysis of the responses in terms of the benefits, risks, and barriers described, the types of responses received, and the impact of incorporation on the fields of reiki, social work, and the healthcare system respectively.

\section{Responses of the Organizational Representatives}

Each organizational representative was presented with questions regarding whether or not their organizations have a position on the incorporation of reiki and social work practice and the nature of that position. This was done for the purpose of providing a context for the responses of the practitioners interviewed in this study to the benefits, risks, and barriers involved with the integration of reiki and social work practice in the healthcare system. All organizational representatives saw there being a possibility of integration in the healthcare system and confirmed some of the challenges that such integration would pose. 
Not surprisingly, the representative from the Canadian Reiki Association was enthusiastically in support of integration:

We encourage the use of reiki in all fields including social work. Reiki is non-invasive and used for the Highest Good of the client/patient. It also assists the Reiki "channel" to "tune in" to the person/patient in a much more intuitive way, providing a deeper understanding of their situation without judgment and without ego. As the practitioner uses Reiki to aid in the healing process of their patient/client, they are also receiving healing that enables them to do their job in a much more balanced way with much less stress and much less "burnout". It is truly a win/win situation in every aspect.

This representative not only highlighted the benefit of integration for clients, but also saw integration as having a benefit to practitioners (see also Anne's comment on page 78). The above quote highlights the use of intuitive knowledge in reiki practice that is also common to social work practice but usually referred to as "common sense" practice. The other factor raised about the benefit of integration is the counterbalance that reiki can provide to the practitioner to offset burnout which can often affect social workers in their practice. For the profession of reiki, integration with a well-established and respected profession has clear benefits.

The responses of the organizational representatives from The College of Social Workers and Social Service Workers (hereinafter referred to in this document as "the College") and the Ontario Health Department were similar to each other. While they did not oppose integration, they were concerned that practitioners be appropriately trained and adhere to the standards of their profession (as social workers and as healthcare professionals). The following is an excerpt from the written response provided by the college, thus it is rather formal in its structure and tone:

The Ontario College of Social Workers and Social Service Workers does not have a position on the use of reiki therapy in social work 
practice, nor does the OCSWSSW have a position on the use of any specific therapy or treatment modality.

However, the Standards of Practice set out minimum standards of professional practice and conduct for members of the OCSWSSW. For the purposes of the Social Work and Social Service Work Act, 1998, and the Professional Misconduct Regulation made under the Act, these standards have been approved in a by-law and all members are obliged to practice in accordance with them.

The College representative then proceeded to outline these obligations which can be found in Appendix " $\mathrm{H}$ " of this study. This response is interesting in that it emphasizes standardization and professionalism in accordance with mainstream social work practice. The combination of the representatives' inability to participate in a telephone interview, the provision of written answers to interview questions, and the formal reference to the standards of both the College and the Ontario Health Department did not allow for the type of dialogue required to further explore the tensions and possibilities that may be involved with integrating reiki and social work in the healthcare system.

Unfortunately, it was also difficult to get a sense of the College's level of awareness regarding whether social workers may already be integrating reiki into their social work practice. This information may not be available or documented at this time but would have been interesting information to explore given Henderson's (2000) study indicating the prevalence of social workers' use of alternative therapies in their practice. The references to professional regulations and standards of practice are to ensure that services are provided competently and in a manner that is not beyond the practitioner's scope of practice. Such standards of ethical practice are consistent with those in Section 12 of the Canadian Reiki Association's Code of Ethics (See Appendix "A"). They state that: 
Members must recognize their limits of competence and must not undertake issues for which they have no training. Members will not claim that reiki can cure, nor will they diagnose any medical problems or prescribe, nor will they ever advise a client to stop taking medications, unless qualified to do so. When it is in the client's best interests, members should refer the client on to another practitioner or organization that has the training appropriate to the client's needs.

Currently registration with a regulatory body is neither mandatory for reiki practitioners or required as necessary for one to be able to engage in reiki practice or train others in reiki therapy (Miles, 2003). This factor contributes to the inconsistencies in reiki training and practice that will be discussed in more detail later in this chapter. There are pros and cons to this situation, if flexibility in this context had not been at all permitted, reiki would not be as accessible a therapy as it is today (Miles, 2003). However, as indicated in a majority of the interviews conducted in this project, this flexibility leads to problems with respect to the issue of competency and credibility, particularly given the abstract nature of reiki therapy, and can have a negative impact on how reiki is viewed in society.

The organizational representative from the Ontario Health Department, due to the department in which he is employed and thus knowledgeable about, could only comment on questions regarding the integration of reiki and social work in the healthcare system within the parameters of regulation:

We don't regulate reiki in any regard- that's currently in the public domain. Reiki is not a 'controlled act'. There are $\mathbf{1 3}$ controlled acts that are determined as such because they are considered to be harmful or to present a risk of harm if not practiced by a licensed trained professional authorized to that practice. (Examples provided by the representative included: any procedure below the epidermis; setting a bone; monitoring pregnancy; allergy treatment).

Any incorporation is up to the individual practitioner as long as they have fulfilled their College's expectations in terms of 
training and professional standards which are determined by the professions themselves (such as with social work in the healthcare system).

Ontario recognizes the primary importance in protection of the consumer with that of freedom of consumer choice with healthcare. For example, massage therapy is not a controlled act, reiki can be considered in this category as it involves manipulation of energy where massage therapy involves manipulation of tissue.

Use of therapies that are not considered as harmful or identified as controlled acts is up to the hospital and over-seeing physician as hospitals set their own procedures. The problem is that anybody can perform reiki, it's whether or not a professional is regulated within their profession in order to avoid situations where someone is practicing reiki and recommending reiki in the place of medical treatment versus as a complementary therapy.

Here we see the construction of what is considered to be harmful practice or practices that present a risk of harm. It is clear that reiki does not fit within this category due to the fact that reiki does not involve any intrusion of the physical body. The position that any incorporation is "up to the individual practitioner" unfortunately does not acknowledge the power differential between practitioners in different fields of practice other than medicine in the healthcare system, the ability of medical professionals to veto integration, and the impact of the current policies and procedures regulating practice. This position also does not take into account the existing resistance from medical professionals that do not support the integration of CAM and that present demands for scientific research that are difficult to meet. In short, this position does not demonstrate an in-depth knowledge of systemic and societal barriers that would prevent integration of CAM, much less the integration of reiki and social work in the healthcare system.

In the last section of the above quote, concerns about credibility and lack of standardization in reiki training and practice are more clearly stated. Again we see a 
reliance on a system designed to maintain the authoritative status of its powerholders (for e.g., hospital administrators and medical physicians) who make the decisions about what treatments are acceptable or not, particularly in the case of complementary and alternative therapies. Despite government claims to recognize and strive to meet the needs of the public, consumer choice is still restricted by the standards set by current powerholders within the healthcare system.

The following response illustrates what the Ontario Health Department representative felt would have to change in order to facilitate integration of social work and reiki in the healthcare system:

Again, reiki therapy would have to be considered harmful or as presenting a risk of harm. It would be beneficial to formally regulate the use of reiki in the healthcare system given there are so many different and individual cases. Individuals may or may not want the service, hospitals or medical professionals may want to incorporate the therapy on a compassion basis for the client's situation and request - it would get clumsy. Social workers in hospitals would be permitted to incorporate within the standards and expectations of their profession and in accordance with the hospital's standards.

It is incongruous to abide by standards under which reiki would not be considered harmful, while concluding that the resolution for achieving integration of reiki with social work in the healthcare system would necessitate the construction of reiki as harmful. In light of earlier discussions regarding the status of medical professionals as powerholders within the healthcare system and their demands for CAM therapies such as reiki to provide scientific research, this contradiction raises the question of whose interests are ultimately being served.

Although the above position raises doubt regarding an unbiased position, there are some legitimate concerns raised about the parameters of practice standards and procedure 
around service provision. The concern raised in the above quote supports that voiced by the practitioners of this study around the problem of the lack of standardization of reiki training and practice. However, given this concern, the primary standards that would need to be considered regarding integration of reiki and social work in the healthcare system come back to safety and efficacy, which link back to the controversy around the definitions of harm, safety, and efficacy and how these are measured. In this context, the organizational representative suggested formal regulation of reiki to facilitate the possibility of integration.

In addition to the above recommendation, there would need to be a transformation of the current role that social workers play in the healthcare system, particularly hospitals. The current role of a social worker does not allow for the space, time, and environment necessary for an integrated reiki and social work service to be provided. There would also need to be changes made in policies and procedures regarding the process involved with the provision of integrated services within the healthcare system. Any service without some planning as to the process of service provision would get clumsy. Social workers are familiar with the breadth of diversity that comes with working with individuals in various situations. Social workers often have to work on a case by case basis within the confines of the institution they work for. This is the reality of mainstream services. What social workers can do to facilitate individualized service is to tailor their approach and referral of resources to the individual and advocate for change or special considerations to be made when referrals to other resources are not going to be effective. This helps to ensure that a person gets appropriate services and appropriate access to services. This concept is not completely foreign to a healthcare system that 
claims to be moving towards more individualized services and use of community resources to better meet healthcare needs in a cost-efficient manner.

\section{The Evolution of Social Work}

To understand contemporary possibilities for integrating reiki and social work, it is helpful to understand the evolution of social work as a profession. The profession of social work is concerned with intervening in the lives of individuals, groups and communities and strives to enhance individual and collective well-being (www.casw acts.ca). In addition, broader social issues are targeted in an effort to evoke social change for the overall benefit of society (Canadian Association of Social Workers: www.casw acts.ca; http://www.ocswssw.org, 01/04/2006). The origins of social work, beginning in the early 1900's, were rooted in religious sentiment and the quest for service to benefit humanity on behalf of various Christian organizations during the social gospel movement (Canda \& Furman, 1999; Wills, 1992; Richmond, 1969). The social gospel movement was a movement within the Protestant churches inspired by Christian socialism and operating under the concepts of interdependence, a sense of brotherhood, democracy, and social reform with regards to the marginalizing impact of a capitalist society (Wills, 1992). Religious institutions were the first sponsors of social service programs, via the Charity Organization Society. Workers at the time were originally referred to as "Friendly Visitors" and shared a sense of spiritual mission (Richmond, 1969). While this religious initiative may have been prompted in the spirit of helping others, it unfortunately also imposed religious values and judgments that may not have been shared by all (Canda \& Furman, 1999). 
In the late 1920's there began a shift in social work practice towards professionalization and secularization, and a shift away from the religious and spiritual initiatives (Wills, 1992). Further, the gradual, interrelated processes of secularization and professionalization resulted in social work emulating psychiatry and its medical model (Holland, 1989) and embracing a scientific worldview (Canda \& Furman, 1999; Kilpatrick \& Holland, 1990). The move towards a secular practice was made on the grounds that spirituality was viewed as unnecessary, irrelevant, and even illogical and pathological (Spencer, 1961). As the rift between secularity and spirituality grew in the interest of achieving a clinically objective and scientifically credible therapeutic environment, issues pertaining to spiritual distress were viewed as being personal and private and to be discussed with clergy members in a spiritual or religious context (Walsh, 1999).

However, in more recent years, the rigid secular nature of the profession has been challenged as shoring up a consumer-based economy without fulfillment (Walsh, 1999). Walsh argues that the industrial and political campaign for people to work towards obtaining material goods to achieve success and happiness undermines the individual sense of identity and well-being. In addition, increasing uncertainty in the context of job security, future retirement benefits, and media regarding war and financial crisis fosters a sense of chaos and instability and an ensuing desire for meaning and moral integrity (Walsh, 1999; Kabat Zinn, 1990).

Literature indicates a positive correlation between stress and physical health difficulties, leading people to seek relief of both anxiety and physical health concerns from healthcare services (Ell, 1996; Loveland Cook, Becvar \& Pontious, 2000; Finger \& 
Mayfield Arnold, 2002; Henderson, 2000). This anxiety includes the existential anxiety described above by Walsh (1999). Stress reduction and a focus on holistic well-being are factors that have been identified as contributing to the popularity of CAM (Astin, 1998). It is from this position that $I$ argue there is value in incorporating Eastern spiritual and philosophically-based practices such as reiki into both social work practice and a healthcare system that is based within a scientific model. Social work, particularly in the healthcare system, may well be in the best position to find a balance between spirituality and secularity that can meet the existential needs of people.

\section{Conceptual Framework}

To better understand this topic of research and the basis for the research question, I will introduce and discuss the concepts below and why they are central to my research question.

\section{Spirituality}

Spirituality, as a dimension of human functioning is an important concept for thinking about the integration of social work and reiki. It is important to note that a distinction often needs to be made between the concept of spirituality versus the concept of religion as the boundaries between the two can often become blurred or oversimplified and can impact on work with clients (Canda \& Furman, 1999; Walsh, 1999).

Religion involves a belief in, and a carrying out of, traditional practices that adhere to morals and standards as defined within an organized, and usually institutionalized, belief system. This system usually includes beliefs about a particular God, deity, or Higher Power, and emphasizes involvement in a faith community (Walsh, 1999; Canda \& Furman, 1999). 
The definition of spirituality is one that is more general and abstract in nature than that of religion, which can contribute to confusion and a misinterpretation of the differences between the two constructs (Walsh, 1999; Canda \& Furman, 1999). Spirituality is often defined as beliefs and practices that are inherently more personal in nature and that can occur either within or outside of formal religious structures (Walsh, 1999; Canda \& Furman, 1999). Spirituality involves an active investment in an internal set of values in the search for a sense of purpose and for moral frameworks for relating to self, others, and the ultimate reality, which can involve a connection with a God, or a divine or natural order (Canda \& Furman, 1999). This investment fosters a sense of wholeness and meaning for the individual as well as a sense of connection with other people and with nature, or all life as a whole (Walsh, 1999, Griffith \& Griffith, 1999; Canda \& Furman, 1999).

For the purposes of this project, the broader context of spirituality is used to speak to the existential needs of people in Western society as well as the individual's search for meaning and for connection with self, others, and with a divine or natural order. In addition, the notion of spirituality used values respect for the individual, for selfdetermination, and connection with others, which in turn correspond to goals of social work practice (Canda \& Furman, 1999) as well as reiki therapy (Miles \& True, 2003).

Reiki therapy is largely influenced by the Eastern philosophical and spiritual belief systems of Buddhism and Taoism. As such, there is an emphasis on spiritual healing as part of a holistic approach to health and well-being (Miles, 2003; Miles and True, 2003; Lubeck, Petter and Rand, 2000). A number of writers have argued that there is a revival in the West towards spirituality and living a meaningful life (Walsh, 1999; 
Roof, 1993). Science and medicine have long been relied upon to provide answers to problems in Western society, yet when crisis, death, and war continue in spite of medical and technological breakthroughs, people cease to be satisfied with the answers that are presented. Various authors have noted that as people age and experience loss they begin to reflect on their lives and where they are going within an existential context (Roof, 1993; Walsh, 1999; Kissman \& Mauer, 2002). In particular, Walsh (1999) states that people are most likely to ask themselves these questions when faced with life and death issues after the loss of loved ones, when ill, or when facing the possibility of their own death. She notes that this has been particularly relevant with the loss of people to AIDS, which has had a profound impact on queer communities (1999).

As people face mortality they start to think about what life means, which often leads to spiritual questions and the search for answers and meaning in life. Roof (1993) writes about this within the context of the "baby boom" generation, people born between the years of 1946 and 1964. The "baby-boom" generation represents the people born during the period after World War II who comprise a large component of the North American population. This cluster of people now range from age 41 to 59 years. People in this period of life are more likely to reflect forward to their mortality and to reflect back on the life they have lived which demonstrates another dimension to the growing interest in Western society in spirituality and alternative healthcare (Roof, 1993).

Walsh (1999) and Epple (2003), in their respective studies, note that aside from those people seeking meaningful lives, many who seek help for physical, emotional, or interpersonal problems are also in spiritual distress. While writing in different contexts, both discuss the importance of research that has begun to document the benefits of faith 
and congregational support with regards to individual well-being and longevity, as well as recovery from illness, loss, substance abuse, and trauma. Both Walsh (1999) and Epple (2003) come to similar conclusions that it is crucial to explore the social work clients' spiritual beliefs and practices in order to address the spiritual sources of their distress. It is also important to encourage clients to draw on their spirituality for inner strength and problem resolution (Walsh, 1999; Epple, 2003). In addition, Walsh (1999) notes that it is important for the social worker to understand a client's spiritual perspective in the context of how it would influence the manner in which that person communicates about their pain and of their attitudes towards the helping profession and the type of treatment they seek (Walsh, 1999). These authors build an argument that incorporating spirituality and social work is key to healing. In turn, the spirituality literature provides a foundation from which to consider the possibilities of integrating reiki practice within social work. Yet, such trends are not without dangers. Some authors have suggested that the integration of spirituality, if not carefully constructed, could result in religious oppression if considerations about the diverse cultural and spiritual beliefs are not adequately represented (Canda \& Furman, 1999).

The work on spirituality is no longer on the fringe of social work. There are a number of studies that have been looking into the fit between spirituality and social work (Canda, 1998; Canda \& Furman, 1999; Canda, \& Furman, 2004; Coholic, 2002; Epple, 2003; Kissman \& Mauer, 2002). In addition, the Canadian Society for Spirituality in Social Work has now held four annual conferences since its inception in 2002. Journals such as Currents: New Scholarship in the Human Services, Critical Social Work (2005, Volume 6, No. 2), have also explored the connection between spirituality and social 
work. The first North American Conference on Spirituality and Social Work, a joint conference between the Canadian Society for Spirituality and Social Work and the Society for Spirituality and Social Work in the United States recently took place in May, 2006 (http://people.stu.ca/ jeoates/cnssw/overview2006.html/). This is the broader discussion into which the questions explored in this thesis are situated.

Part of the trend towards integrating spirituality and social work is linked to the increasing cultural and ethnic diversity of Western society (Canda \& Furman, 1999). This diversity can be attributed to people from various cultures immigrating to the West, First Nations communities, and people traveling to other countries, meeting people and experiencing other cultures (Canda and Furman, 1999). Inter-faith and inter-cultural marriages have introduced new spiritual and religious belief systems to the West, from which many alternative healing practices originate. This population change is noted by Canda and Furman (1999) when they describe the historical trends with regards to the development of spiritual diversity in the United States. They outline the introduction of Eastern spiritual belief systems and philosophies such as Buddhism and Hinduism as largely stemming from emigration from Asia, which has been increasing since the 1970's. Canda and Furman note that many European Americans have also become converts to offshoots of spiritual belief systems such as Hinduism and Buddhism and that the New Age movement of the 1970's and 1980's brought about alternative approaches to humanism. Canda and Furman (1999) state that these changes have contributed to new paradigm scientific thinking and opened the door to Eastern and Western mystical practices. It is within this context that we have the responsibility to explore the possibility of providing health care services from a spiritually and culturally diverse perspective. 


\section{Complementary and Alternative Medicine}

The concepts of complementary and alternative medicine are also central to this discussion. The National Center for Complementary and Alternative Medicine (NCCAM), a component of the National Institute of Health in the United States, defines complementary and alternative medicine (CAM) as a group of diverse medical and healthcare systems, practices, and products that are not presently considered to be part of conventional medicine (http://nccam.nih.gov/health/). Complementary medicine is defined as a medicine or therapeutic technique that can be used together with conventional (or allopathic) medicine, whereas alternative medicine would be used instead of conventional medicine (http://nccam.nih.gov/health/).

There are tensions within the CAM community regarding what professions are identified as being within this general category of "complementary and alternative medicine" versus operating as separate systems of healthcare (Kelner, Wellman, Boon \& Welsh, 2004b; Kelner, Boon, Wellman \& Welsh, 2002). Some complementary and alternative healthcare professions do not agree with the position that they need to organize themselves and conduct the type of research that meets the requirements of evidence-based medicine in order to professionalize or to become associated with the medical model as it exists within the healthcare system (Kelner, Wellman, Boon \& Welsh, 2004b; Kelner, Boon, Wellman \& Welsh, 2002). Furthermore, some of these groups are splintered, lack an organizational leader or regulatory body, and experience tensions within their own professional communities with regards to the above (Kelner, Wellman, Boon \& Welsh, 2004b; Kelner, Boon, Wellman \& Welsh, 2002). While acknowledging these tensions, for the purposes of this project I will still use the term 
CAM to differentiate this group of healthcare practices from the conventional medical professions that are part of the Canadian healthcare system. Although reiki is one of the modalities considered to be the least organized and to be divided regarding individual practitioners' views on professionalization (Kelner, Wellman, Boon \& Welsh, 2004b; Kelner, Boon, Wellman \& Welsh, 2002), I will refer to reiki in this paper as being a modality within CAM healthcare services. I have chosen to do this due to the fact that reiki is considered, within its own profession, to be a complementary therapy and is often referred to as such in literature within the category of both CAM and reiki (Miles \& True, 2003; http://www.reiki.ca/faq.htm; Kelner, Boon, Wellman \& Welsh, 2002).

Many of the alternative therapies in CAM are built upon systems of theory and practice, often having evolved apart from and earlier than the conventional medical approach used in Western society today. An example of a system that has developed in non-Western culture would be traditional Chinese medicine (TCM). Traditional Chinese medicine (TCM) is the current name for a Chinese ancient system of health care. TCM is based on a concept of balanced qi, or vital energy, that is believed to flow throughout the body. This concept is also relevant to reiki therapy and stems from the influences of Taoism and Buddhism (Miles \& True, 2003) that will be discussed in further detail in the context of the theoretical framework behind reiki.

NCCAM classifies CAM therapies into five categories or domains:

- Alternative medical systems - such as homeopathic and naturopathic medicine and traditional Chinese and Aruvedic medicine.

- Mind-Body Interventions - such as meditation, prayer, mental healing and art, music and dance therapies. 
- Biologically-Based Therapies - such as those that would use substances found in nature such as herbs, foods, dietary supplements, and vitamins.

- Manipulative and Body-Based Methods - such as would be seen with chiropractic, osteopathic and massage therapies.

- Energy therapies - which are divided into two categories: Biofield Therapies and Bioelectromagnetic-based therapies (http://nccam.nih.gov/health/; Cook, Becvar, \& Pontious, 2000).

Biofield therapies are described as therapies that are designed to manipulate the fields of energy that surround and penetrate the human body (http://nccam.nih.gov/health/; Miles and True, 2003). Some forms of energy therapy work include qi gong, reiki, and therapeutic touch (http://nccam.nih.gov/health/; Miles, 2003; Miles and True, 2003). Biofield therapies such as reiki work with biofields by applying light touch and by placing hands in, and through, these energetic fields (Miles \& True, 2003). Reiki can be explained as stemming either directly from TCM practices or the philosophy behind TCM given the emphasis in this healing system on qi (Miles, 2003). Qi (life force energy) is proposed to regulate a person's spiritual, emotional, mental, and physical balance and is influenced by the opposing forces of yin (negative energy) and yang (positive energy) (http://nccam.nih.gov/health/; Lubeck, Petter \& Rand, 2000; Yip, 2005). TCM, as previously mentioned, can be mainly described through Taoist principles centered around the premise of "the way"- a universal order to all things and all systems that involve the balance of yin and yang, or what we tend to describe as "opposites" (hot/cold; up/down; male/female; internal/external). Disease is proposed to 
result from the flow of qi being disrupted and yin and yang becoming imbalanced (http://nccam.nih.gov/health/; Lubeck, Petter \& Rand, 2000).

In Western medicine, practitioners tend to introduce something external, synthetic, and otherwise foreign to the body to counteract or fight off the biochemical or biologically-based mechanism that is causing the imbalance. This also includes removing body parts that are impacted. While this is a generalist interpretation of Western medical practice, and there has been some incorporation within the medical system of practices that acknowledge the importance of a mind-body connection (such as with mindfulness based therapy) (Kabat Zinn, 1990), there remains a general paradigm difference with regards to Eastern and Western approaches to health and well-being (Chan, Ho, \& Chow, 2001; Kelner, Wellman, Boon \& Welsh, 2004a). The Eastern approach interprets symptoms of illness or disturbance to be the marker that the client is experiencing "imbalance". This comes from the presumption that there is to be balance between all things and functions within the Universe, including within the person. The body is considered already an efficient system of various natural functions that strive towards balance for maximum effectiveness. The emphasis is on working from the standpoint that the body already knows how to heal itself naturally and signifies when things are out of balance within the systems (http://nccam.nih.gov/health/). One works with the body's natural system by providing natural resources in accordance to what a system needs in a certain area in order to restore its balance.

The concept of energy work, or "energy medine", such as that used in reiki, proceeds in much the same manner however the focus is mainly on the systems of energy in and around the body (Miles, 2003; Miles and True, 2003). While Western science has 
evolved from identifying that universal matter is made up of particles charged with protons and neutrons to identifying electromagnetic fields and exploring space-time continuums, the concept (specifically stemming from Eastern philosophies) that the entire universe exists within energetic fields has continued to impact healing therapies in the Eastern world (Brennan, 1987). Energy medicine works with the energetic layers surrounding and penetrating a person's body in order to nourish and maintain the balance of a person's physical, mental, emotional, and spiritual state. Whereas energy medicine in general focuses on an individual's physical health, alternative/complementary energy therapies such as reiki also focus on the emotional, mental, and spiritual aspects of balance, healing within these energy fields as well.

\section{Reiki}

Pamela Miles and Gala True (2003) describe reiki as a subtle energy therapy that is believed to balance the biofield and strengthen the body's natural ability to heal itself. Although reiki is said to be a therapy most commonly facilitated by light touch, actual physical touching is not necessary for healing to occur. (Miles \& True, 2003; Lubeck, Petter \& Rand, 2003) Reiki is a system of healing that is said to have originated by the spiritual inspiration of Dr. Mikao Usui, a Buddhist monk from Japan. Miles and True (2003) note that originally, Dr. Usui's teaching was intended as a system of spiritual practice and that any physical, mental, or emotional healing that might occur was seen as a natural by-product. Reiki was introduced to the United States through the teachings of Mrs. Hawayo Takata (Lubeck, Petter and Rand, 2000; Miles and True, 2003; Ellis, 1999). Reiki has since been passed on to many individuals across the world and the traditional methods of teachings have changed over time to allow for increased accessibility to this 
growing system of healing. Such changes include decreasing or eliminating fees and required timelines for training and apprenticeship (Lubeck, Petter and Rand, 2000; Miles and True, 2003). While this has increased the number of people able to access this form of therapy, it has also contributed to many interpretations of training and a decrease in standardization in training and practice (Lubeck, Petter and Rand, 2000; Miles and True, 2003; Miles, 2003).

Reiki is growing rapidly and is being used in health care settings in the United States (Miles, 2003). While reiki has made great advances into American health care institutions and is becoming increasingly popular at health spas, it is still not considered a form of therapy to use in mainstream Western society. Furthermore, it is not generally found in Canadian hospitals (Kelner, Wellman, Boon and Welsh, 2004a; Miles, 2003). This is likely due to the mystical aspects of reiki and some difficulties in quantifiably measuring its success, particularly by Western scientific standards (Miles and True, 2003; Miles, 2003; Kelner, Wellman, Boon and Welsh, 2004a; http://nccam.nih.gov/health/).

In the United States, there are two major groups that focus on the standardization of reiki therapy: The Reiki Alliance and the International Centre for Reiki Training. The Canadian Reiki Association (CRA) is currently trying to establish standards around training and practice of reiki, however, involvement is not mandatory or necessary for one to either practice or teach reiki. The CRA is a national non-profit registry of reiki practitioners and teachers representative of various styles of reiki (http://www.reiki.ca/whois.htm) that is committed to promoting ethical practices and teaching, encouraging educational standards, and providing the public with referrals to practitioners and teachers (http://www.reiki.ca/commitment.htm). Criteria for 
membership includes that one must have been attuned to the first level of reiki, can produce a Level 1 certificate and must sign and abide by the CRA Code of Ethics and the CRA Disciplinary Action Policy (See as appendices "A" and "B" respectively) (http://www.reiki.ca/criteria.htm).

The Canadian Reiki Association endorses a code of ethics for teachers and practitioners that parallels the social work code of ethics with regards to respecting clients' rights to "truth, confidentiality, and the respect of their human dignity" and that outlines expectations regarding the practitioner's professional manner of dress and conduct with a client (See Appendix "A", numbers $6 \& 7$ respectively). Practitioners and teachers are to practice within the parameters of their professional competency, ensure up-to-date training, and refer to relevant services if they cannot provide the service in a competent manner (http://www.reiki.ca/ethics.htm). This includes the principal that one is not to provide a medical diagnosis or prescription within their role as reiki practitioner or teacher. Particular attention is paid to outlining parameters around touch and ensuring services are not provided in a manner that could be construed as sexual. A breach in the code of ethics surrounding professional conduct and inappropriate provision of services would result in immediate termination of CRA membership (http://www.reiki.ca/ethics.htm).

In addition to the CRA code of ethics is the expectation of adherence to or respect of the five principles of reiki, influenced by Buddhist philosophy, that are meant to offer a simple guideline for daily conduct with self and others:

- Just for today, I will not anger

- Just for today, I will not worry 
- Just for today, I will be grateful

- Just for today, I will work hard on myself

- Just for today, I will be kind to others (http://www.reiki.ca/faq.htm)

This philosophy is relevant in the context of its contribution to the benefits of reiki therapy, which will be discussed further in the section regarding the theoretical framework of this study.

\section{Reiki Treatment}

To provide reiki therapy, the reiki practitioner channels the life force energy through their body, out of their hands and to the client, either through a direct laying on of hands or by way of touching the energy field, or aura, surrounding the person. The energy flows around and throughout the body via the field surrounding the body referred to as the aura, throughout channels running through the body (also referred to as meridians in the practice of acupuncture), and through major energy centers or vortices (referred to as chakras) throughout the body (Lubeck, Petter and Rand, 2000; Gala and True, 2003; Miles, 2003; Ellis, 1999).

Reiki work includes an energetic and bio-psycho-spiritual healing focus on the above-mentioned chakras. Effects of reiki are typically similar to that of massage: relaxing, peaceful, refreshing, and energizing (Ellis, 1999; Miles and True, 2003; Miles, 2003 and 2004; MacDermott and Epstein, 2001). Many people describe feeling sensations such as heat or coolness emanating from the practitioners hands as well as feeling tingles, buzzing, pins and needles, and pulsations in the areas over which the practitioners hands are covering (Miles, 2003). Furthermore, as previously indicated, the universal energy being channeled is "intelligent" and it knows where to go (Miles and 
True, 2003). The areas of the body where the above sensations are reported to be felt by clients are often consistent with areas where they may be feeling discomfort or having difficulties within their bodies. As mentioned previously, it has been difficult to prove the efficacy of Reiki therapy through scientific testing although efforts to do so continue. Many of the results and benefits of reiki therapy are anecdotal, which presents a challenge in terms of being validated in the science-based Western medical model.

\section{The Canadian Healthcare System}

In considering the possibilities and dangers of integrating reiki and social work, it is also important to establish a context in which to think about this question. For the purpose of this study, I decided that it would be most helpful to consider integration within hospitals. This provides some important parameters for the study. I am only considering the integration of reiki with respect to health issues and am considering it within the institutional contexts of hospitals, community health centers, and doctor's offices, rather than society as a whole. Integration of reiki and social work in the healthcare system could benefit people seeking treatment for physical as well as emotional health issues, particularly with regards to problems related to stress and anxiety felt by patients seeking healthcare services. It is possible to hypothesize that, given the links between stress reduction and improved physical health, social workers incorporating reiki into their practice in healthcare settings could help to alleviate overloaded hospital conditions as well as other healthcare professionals. However it is also important to consider the position of mainstream healthcare professionals regarding CAM services such as reiki. 
The Canadian healthcare system is widely known for it's publicly funded "medicare", a system that provides universal access to medical and physician services free of charge (http//:www.nc-sc.gc.ca/ncs-sss/alt_formats/hpb-dgps/pdf/pubs/2005-hcssss_e.pdf ). Funding for this system is mainly the responsibility of provincial and regional governments, with assistance from the federal government (http//:www.nc-sc.gc.ca/ncssss/alt_formats/hpb-dgps/pdf/pubs/2005-hcs-sss_e.pdf). As a result of an ageing population, increasing consumption of healthcare services, and rising numbers of healthcare professionals, the cost of healthcare has risen exponentially, prompting ongoing shifts and transformations within the healthcare system (Coyte, 2001). The increasing use of healthcare resources, in combination with changes in structure and funding of services, has contributed to a system that is strained from the pressures of high costs, restructuring of primary care and an insufficient number of medical and nursing staff to meet demands (Kelner, Wellman, Boon \& Welsh, 2004a; Coyte, 2001). Coyte (2001) notes that over the last 25 years there has been a notable shift away from funding hospital care towards the funding of other health services such as the pharmaceutical industry and home and community care. Emphasis on physicians has decreased slightly to accommodate service from other healthcare professionals.

The concern remains that the healthcare system will continue to struggle to meet the more intensive care demands of a growing ageing population, particularly as the baby boomer generation enters old age (Coyte, 2001). Hospitals have been impacted by the shifting priorities of healthcare funding by experiencing closures and mergers, as well as restructuring to accommodate a more intense focus in community care and integrated delivery systems of care (Michalski, Creighton and Jackson, 1999). More hospitals have 
adopted an organizational framework that has shifted away from specific professional departments towards multi-disciplinary programs, emphasizing "patient-focused care" as defined and promoted by the government (Michalski, Creighton and Jackson, 1999).

The emergence of CAM has posed several issues of concern that add to the already existing pressures involved with the ongoing restructuring of the healthcare system. Pressures from the general public's demand for CAM services and from CAM groups to integrate into the healthcare system are offset by resistance from the medical community to the integration of CAM, tensions amongst CAM groups to regulate or professionalize, and tensions between the municipal, provincial, and federal government regarding the allocation of funds within the healthcare system (Kelner, Wellman, Boon and Welsh, 2004a; Kelner et al., 2004b).

The emphasis placed on factors such as health promotion in a holistic manner and the reduction of anxiety have been identified as primary reasons for people's choice to use CAM (Astin, 1998; Eisenburg, 1998). However, these are factors that do not necessarily have to be addressed solely by healthcare professionals. As intermediaries between emotional and physical health needs within the medical care system, particularly with regards to stress management, it would be beneficial for social workers to have an appropriate knowledge base of CAM services (Loveland Cook, Becvar \& Pontious, 2000; Finger \& Mayfield Arnold, 2002). A study by Henderson (2000) indicates that there are social workers who have been either utilizing or referring to CAM services within the scope of their social work practice, which suggests an existing interest in, and comfort with, integrating complementary and alternative therapies as tools for use in social work and which highlights an area for further research. Interventions focused on alleviating or 
resolving the debilitating impact of stress, trauma, and oppression of individuals, groups, and communities fall within the objectives and values of the field of social work (Lundy, 2004; Ell, 1996). The use of CAM therapies, such as reiki, in social work and healthcare settings could be of benefit to the current healthcare system, provided that any risks or dangers involved in such incorporation are also explored and taken into account.

In this chapter, I have discussed a growing trend in the West towards spirituality, including a movement towards incorporating spirituality in social work practice and an increasing use of CAM services that promote a holistic approach to health and wellbeing. Literature reviewed for this study provides an argument that this renewed interest in spirituality stems from factors such as the increasing cultural and ethnic diversity of the North American population and the need to address emotional and physical health issues related to existential anxieties that arise from living within the oppressive and demanding parameters of a capitalist society. The above factors all combine to provide a rationale for exploring the integration of alternative holistic healthcare practices, such as reiki, within social work practice in the healthcare system. The issue of spirituality and its importance to human functioning and development, CAM, reiki, and the return of spirituality in social work are all key concepts that have been detailed with respect to their relevance to this project. In the following chapter, I will discuss the theoretical framework that I rely upon to ground the above information and research within the broader context of the fields of reiki and social work practice. 


\section{Chapter 2: Theoretical Framework and Methodology}

Due to the abstract nature of reiki and the broad scope of social work, it is important to provide a theoretical framework to ground the research in this study and understand the connections between the two practices that allow for the exploration into possibilities related to the integration of reiki and social work practice within the healthcare system.

Based on a review of the literature, my own knowledge and experience, and the context for the issue being studied, I will be drawing upon a combination of transpersonal theory (Leight, 2001; Canda and Smith, 1998) and the Eastern philosophies of Taoism (Cleary, 1998; Yip, 2005; Koenig \& Spano, 1998; Creel, 1970; Kohn, 1991) and Buddhism (Saso, 1977; Canda \& Phoabtang, 1992) to establish connections within the larger theoretical framework of social work and reiki respectively. While I realize that there are other Eastern philosophical and spiritual belief systems that are relevant, for the purposes of this project, I will be attending to only Taoism and Buddhism with regards to their contribution to the practice and philosophy behind reiki as well as links with both transpersonal theory and social work practice.

\section{Transpersonal Theory}

I will be drawing upon Transpersonal Theory, a psychological, humanistic approach, as this social work theory speaks clearly in support of integrating spirituality and social work (Leight, 2001; Canda \& Smith, 1998). In this thesis, I will use transpersonal theory as the foundation from which to explore the relevance of spirituality for healing emotionally as well as physically. Transpersonal theory is relevant to this project in that it's focus on transcendence and the concept of connection to a higher self 
or divine order establishes links with the Eastern philosophies of Taoism and Buddhism that underpin reiki practice (Canda \& Furman, 1999; Cowley, 1999; Cowley, 1993). While this theory is limited with respect to its ability to speak to the impact and resolution of structural barriers on individuals in society, it does allow for an in-depth exploration of working with individuals to assist them in identifying and resolving issues of concern as well as responds to the individual's search for meaning and desire for a higher level of consciousness (Canda \& Furman, 1999; Cowley, 1996; Leight, 2001).. This study is being conducted for the purpose of exploring possibilities for service provision that may better meet the existential needs of people in Western society. As such, this study is limited to speaking about the dimension of social work practice that works with the individual and the individual's relation to self and society with the hope that this can possibly open the door to future studies regarding the impact of structures on accessibility and consumer choice about healthcare services in Western society. It is with this foundation that we can begin to consider links between reiki and social work.

The transpersonal approach to psychotherapy is influenced by both Eastern and Western thought and it involves the conventional process of understanding the psychological forces that influence the body and the mind, as well as incorporating treatment goals such as symptom reduction and behavioural modification (Cowley, 1999). While this focus does not directly address the oppressive conditions that structural social workers aim to change, it assists with part of that process by working to mitigate the impacts of internalized oppression. The ensuing change in the individual's concept of self, personally and in relation to society, opens up possibilities for empowerment to the point of social action. 
Eastern-based techniques such as meditation and visualization are used in order to help the client dis-identify from negative thoughts and feelings, including those that have been influenced by societal standards, and thus be empowered to assign new meaning to their concept of self (Canda, 1998). Such techniques and philosophy regarding treatment goals are similar to those used in reiki practice (Lubeck, Petter \& Rand, 2003; Miles \& True, 2003). For example, reiki practitioners are taught to follow 5 guidelines, influenced by Buddhist philosophy, for daily living that encourage dis-identification from stressful or anxiety producing thoughts and behaviours. Practitioners are encouraged to meditate upon and adopt these guidelines (Lubeck, Petter \& Rand, 2003).

Canda (1998) asserts that the context of transpersonal theory supports basic social work priorities regarding the need to start where the client is, respect client selfdetermination, and honour the client's perspective. These views, as mentioned previously, are also reflected in the code of ethics for reiki practice as established by the Canadian Reiki Association (See Appendix "A"). The healthcare system in Canada acknowledges the importance of addressing healthcare issues and maintaining a sense of well-being, however it tends to employ strategies that demonstrate an over-reliance on the medical model to address these issues. This adherence to the medical model runs the risk of not sufficiently identifying or addressing factors in a person's life that contribute to anxiety and related health problems (Tataryn \& Verhoef, 2001). Such risk could include an impact to the client such as a lack of acknowledgement with regards to the client's overall situation, knowledge, perspective, ability to decide what they need, and ability to access services in an equitable manner (Tataryn \& Verhoef, 2001). Which is 
important to consider in light of a person's spiritual needs and potential for self-reflection and self-actualization (Canda \& Furman, 1999; Kabat Zinn, 1999).

Canda (1998), Cowley (1993 \& 1996), and Leight (2001) all discuss the use of transpersonal theory with regards to assisting individuals to extend, or transcend, beyond the ego and the goal of self-actualization and to establish a connection and awareness of the interdependence between the self, the world, and the universe. "Transpersonal" has been described by Leight (2001) as meaning "beyond the person or beyond the ego" ( $\mathrm{p}$. 65 ) and is based on the assumption that there is an inner self, distinct and "higher" than the ego. Transpersonal theory has been labeled as the "Fourth Force" in psychology, following the First Force (based on dynamic psychology), the Second Force (behavioural psychology), and Third Force (experiential, humanistic, and existential psychologies) (Cowley, 1993 and 1999; Smith, 1995). The development of transpersonal theory is described by Cowley (1999) to have grown out of work by psychologists such as Abraham Maslow, Stanislov Grof, Anthony Sutich, and others.

Goldberg (1980), states that transpersonal theory was named and conceived in the late sixties, when theorists of the time were beginning to explore a larger context for human potential. It continued to develop in the 1970's and 1980's in response to the prevalent reports to professionals from people regarding a sense of "spiritual malaise". Transpersonal psychology is described to emphasize spiritual growth and transformation of consciousness which includes the search for ultimate values, peak or mystical experiences, unitive or universal consciousness, and the legitimation of spiritual connection (Cowley, 1993). Transpersonalists, looking to the spiritual dimension as the missing piece in a Western understanding of human development, began to re-examine 
Eastern influences that had been introduced to Western culture during the late 1800 's (Cowley, 1993). The development of transpersonal theory involved the incorporation of Eastern contemplative practices with Western psychological theories. Today we see that the relevance of this incorporation still exists as evidenced by the resurgence of interest in practices such as yoga and meditation, as well as CAM healthcare services, to minimize stress and release from the daily stressors and oppressive conditions of a capitalist society (Kelner \& Wellman, 1997; Miles \& True, 2003; Cook, Becvar \& Pontious, 2000). Within the context of relevance to this project, transpersonal theory speaks to the spiritual dimension and existential need of the person that is beyond the physical and emotional, a dimension that is important to human development and well-being. The Eastern influences that have contributed to this spiritual aspect of well-being are also inherent in reiki and will be discussed further in a description of the theoretical underpinnings of reiki practice.

Cowley (1993) explains that understanding the transpersonal approach in the Western world requires a paradigm shift from the Western goals of self-integration and actualization to the less conventional aim of Eastern approaches to self-transcendence. The concept of transcendence is relevant in this project in the sense of being able to reach beyond oppressive conditions and sense of disconnection to find the strength, resilience, and perspective needed to address problems arising from these conditions (Aponte, 1999). This same paradigm shift is required when considering the relevance, benefits, and legitimation of Eastern-based CAM therapies within the current science-based medical healthcare system in the West. The transpersonal approach unites the above-mentioned 
goals to include more traditional goals such as relief of emotional and behavioural issues (Cowley, 1993).

Achieving the connection between the self and the universe involves strengthening one's intuition, creativity, and holistic thinking (Canda, 1998). Transpersonal theory supports a concept of self that is interdependent and united with others, highlighting self-determination and implying a responsibility to respect the freedom and perspective of other people (Canda, 1998). This perspective is in line with the values as stated in the social work code of ethics and is also parallel to the philosophy and ethics inherent in reiki therapy as stemming from Taoist and Buddhist philosophies.

\section{Theoretical Underpinnings of Reiki}

I will be discussing both Buddhism and Taoism in the context of providing understanding as to the theoretical framework behind reiki as a healing practice. Both Buddhism and Taoism provide direct links to the principles and practice of reiki in their emphasis on the concepts of connecting with self and the universe and on detaching from material sources of stress identified through increased self-awareness. In addition to these direct links are the concepts of flow and balance inherent in Taoism, which effectively captures the philosophy about the energy healing that is central to reiki therapy. In addition to the direct links between Taoism, Buddhism and reiki, there is a direct link with regards to the interconnectedness between self and universe that is inherent in Buddhism and Taoism (Yip, 2005; Creel, 1970; Welch, 1965) and that is encouraged in transpersonal theory (Cowley, 1996). Additional connections between Taoism and Buddhism and goals of social work practice will be discussed below. These links help to 
provide the groundwork for the theoretical basis for considering the possible benefits and limits of integrating reiki and social work.

\section{Taoism and Social Work}

In their explanation of the fit between Taoism and the strengths perspective in social work, Koenig \& Spano (1998) describe the congruence between Taoist thought and traditional social work values. This congruence is reflected in values such as respect, mutuality, justice, and trust that provide the context necessary for mutuality between the client and worker in the process of exploring self in relation to the universe. A central theme in Taoist philosophy is the importance of balance, or holistic dualism, in the context of the constant flow and change of the universe (Cleary, 1998; Koenig \& Spano, 1998). Holistic dualism refers to the recognition of the complementarity and interrelatedness of opposites, encapsulated in the well-known symbol of the Yin and Yang (Koenig \& Spano, 1998).

In the context of health and well-being, mind, body, and spirit are viewed as interconnected (Chan, Ho, \& Chow, 2001). Treatment is thus focused on assisting a person to achieve balance in all of these areas. This is generally in contrast to the Western medical approach where body and mind are treated separately (Chan, Ho, \& Chow, 2001). According to Taoist philosophy, reality, or one's lived experience, needs to be understood in terms of whole patterns, versus being broken down into parts. In short, one needs to look at the bigger picture in terms of how everything is interconnected. If reality is reduced to parts and responded to as such, imbalance will occur (Koenig \& Spano, 1998). The above perspective can be exemplified in the comparison of the compartmentalized, bio-physical medical model used in the West versus the holistic 
nature of complementary and alternative healthcare services that stem from the East. Intelligence and the wisdom of the natural body are valued in Taoist philosophy with regards to the care of each person (Koenig \& Spano, 1998). This perspective correlates with the above-mentioned social work values regarding respect and self-determination, providing the conditions conducive to the self-actualization valued in transpersonal psychology. Studies have linked this philosophy of health and well-being to the popularity of CAM services (Kelner \& Wellman, 1997; Astin, 1998; Cook, Becvar \& Pontious, 2000).

\section{Taoism}

Taoist philosophy originated around 500 B.C. (Yip, 2005; Welch, 1965; Creel, 1970). The writings of Lao Tzu and Chuan Tzu had a profound influence in Chinese culture and continue to be well-referenced sources for studying classical Taoism today (Yip, 2005; Creel, 1970). Their writings laid the foundation for later development in Taoism as well as the Tao religion, which branched out from its philosophical roots. Taoist and Buddhist philosophies emphasize the link between self and universe as key for managing and transcending human suffering. Opposite to the prevalent Western culture in its capitalist regime, Taoism and Buddhism emphasize detachment from material desires as well as emphasize internal awareness and connection with the universe. Similar to the benefits of incorporating spirituality into social work practice as described by authors such as Walsh (1993) and Canda (1998), this practice enhances a perspective that allows a person to re-organize some of the priorities or factors in their daily lives that can lead to stress and possible illness. One cannot re-organize oppressive factors such as poverty or domestic violence, however one may be able to see more clearly what 
contributes to these factors, to see what is and is not beyond their control, and to look for potential supports that may be able to assist with these issues. The benefit of such practice is the enhancement of a cognitive framework that refutes the impact of internalized oppression by allowing one to see more clearly the external impacts of various factors in their lives and how they are managing them. It is this perspective, a psycho-social form of addressing problems that can lead to stress and ensuing health difficulties, that influenced my choice to explore the possible benefits and risks or dangers to incorporating reiki and social work practice within the health care system.

Taoism priorizes the goal of transcendence as the ultimate state of being (Yip, 2005; Creel, 1970; Welch, 1965). In comparison to the Western goal of self-development and self-actualization, Taoist philosophy promotes the goal of transcendence from secular standards, gratification, honour, disgrace, and the influence and perception of others (Yip, 2005; Koenig \& Spano, 1998). In addition to transcendence from secular influences, traditional Taoism stresses the dynamic revertism of nature (the philosophy of the balance of opposites), integration with nature, and the pursuit of the infinite in connecting with the universe, or Tao, in doing all of these things (Yip, 2005; Koenig \& Spano, 1998; Creel, 1970; Welch, 1965).

The nature of Tao is best understood by interpreting it on two levels simultaneously. In a universal context, it is the source of life and change. As well, it can be understood at a spiritual level as a radiance that is available psychologically for the pursuit of salvation through connection with the infinite (Kohn, 1991). This provides a framework for priorizing and managing life issues and any dischord as the result of 
giving into the demands of a material world. It offers a broader view based on balance and connection with a divine or natural order.

Reality is defined not merely by isolated or superficial events, but by a deep understanding of the patterns and processes that connect these events as well as the meaning of these events (Koenig \& Spano, 1998). Koenig \& Spano (1998) discuss five general themes of Taoism: 1) Reality as a process of constant flow and change; 2) Holistic dualism - or the blending of two aspects into one whole (also referred to as dynamic revertism, everything in the world is relative to its complement (Yip, 2005); 3) Nonaction as a way of action that maintains harmony with an everchanging universe; 4) All at one time knowledge and 5) Virtue - representing internal power central to healing.

In this manner, this perspective could work to counteract the effect of a hectic, fast-paced, acquisition-based society, placing more emphasis on slowing down and disengaging from micro-cosmic pressures as a way of self-care and self-preservation, and placing more value on one's internal wisdom and self-determination than the current Western paradigm allows for. While this perspective may be effective for helping one to reduce stress and enhancing one's emotional capacity to manage with the abovementioned stressors, it would not be able to resolve the actual need for the basic materials necessary for survival. To be of maximum benefit, this perspective could be combined with existing services that advocate for appropriate living conditions and material needs of underprivileged people and that enhance the capacity for the empowerment valued in such practice. 


\section{Buddhism}

Similarities and differences have been noted between the Eastern philosophies of Taoism and Buddhism (Saso, 1977). With respect to this paper, both are relevant for their contribution to highlighting the goal of transcendence and their influence on the philosophy behind reiki therapy. Buddhism was established about 2,500 years ago in India. A man by the name of Siddhartha Gautama developed the concept that human existence is filled with suffering as long as people are attached to desires, because desires cannot be realistically fulfilled (Canda \& Phoabtang, 1992). He concluded that the way to overcome suffering is to cultivate a correct lifestyle and meditation in order to learn freedom from desire. Gautama is more commonly referred to as Buddha, meaning "the enlightened one", as his teachings emanated from his own spiritual enlightenment.

Compassion and loving kindness are described as the motivations behind alleviating human suffering and thus the necessary starting points for human service (Canda \& Phoabtang, 1992). The Buddhist perspective operates from a spiritual conception of human existence; all forms of trouble are perceived as manifestations of the existential problem of human suffering from attachment to self and desires. The ultimate goal of Buddhism is to liberate people from the root causes and superficial manifestations of this suffering (Canda \& Phoabtang, 1992). To facilitate this liberation, a high degree of consciousness is required, as well as the use of techniques that have been developed for training the mind. The concept of compassion and ultimate goal of liberating people from suffering is also inherent in the values and practice goals that form the foundation for social work practice (Canda \& Furman, 1999). 
Although both religious philosophies have commonalities in their emphasis on transcendence, their approach to transcendence differs (Saso, 1977). The Buddhist approach emphasizes non-attachment as key to transcending suffering, is more concerned with the afterlife, and holds a monistic view in that only the world of union with the cosmos is real and the present material world is based on illusion (Saso, 1977).

With respect to this project, links have been made to the material demands of a capitalist society and anxiety, and between the experience of anxiety and the impact it has on physical, mental, spiritual, and emotional well-being. With this view, one would see the effects of human suffering, such as spiritual malaise and stressors in meeting the material demands as caused by values imposed by and inherent in a capitalist society. Resolution would involve detaching from the material, freeing oneself from the oppressive nature of the current paradigm and transcending beyond externally imposed values to a point of self-actualization, maximizing human potential to a broader connection with the universe.

Detachment from the material, within a social work perspective, could be facilitated by education and consciousness-raising regarding the construction and maintenance of oppression (in this case, the denial of the right to access healthcare that is consistent with ones personal belief system). Detachment, with regards to the incorporation of reiki and social work, would also be achieved with a combination of the above strategies with: relaxation techniques, the re-balancing of the energy in and around the body, and techniques such as visualization and meditation.

Transpersonal theory and the Eastern philosophies of Taoism and Buddhism work together to provide a framework for the relevance of incorporating reiki and social work 
practice with respect to a focus on assisting the individual to obtain a connection with self, others, and the universe (or a divine or natural order), and to transcend suffering caused by structural oppression or attachment to material desires inherent in a capitalist society. The values of respect for the client or individual, client self-determination, and client as expert are reflected in the above approaches and correspond to values inherent in goals of both reiki and social work practice (Miles, 2003; Canda \& Furman, 1999). Furthermore, the motivating factor of compassion and desire to help humanity provides another link between Transpersonal theory, Taoism and Buddhism as a theoretical framework from which to explore the integration of reiki and social work practice (Miles \& True, 2003; Lubeck, Petter, \& Rand, 2003; Canda \& Furman, 1999).

\section{Methodology}

\section{Qualitative Research}

Given the limited literature to ground the research question, I chose an explorative, qualitative method as the most appropriate means for gathering the necessary data. Qualitative studies are largely used for the purposes of securing descriptive and meaningful information, which is beneficial in the context of studying situations that are not particularly quantifiable (Dilley, 2004; Yegidis, Weinbach, Morrison-Rodriguez, 1999; Neuman and Kreuger, 2003). Research in social work and the social sciences is often used to reflect descriptive, or qualitative, information gathered from people regarding their personal experiences and perspectives. With this descriptive information and research approach, I was able to offer various interpretive analyses regarding the possibilities and risks of incorporating reiki and social work that could prompt more specific studies related to this topic (Broom, 2005). 
Yegidis, Weinbach, and Morrisson-Rodriguez (1999) describe that an exploratory research design is an appropriate approach to use when a problem has been identified and when knowledge on how to both understand and address this problem is limited. In this case, the abstract nature of reiki therapy has contributed to the difficulty of developing studies that adequately assess its limitations and effectiveness. This lack of information has made it difficult to establish a reliable body of literature for discussing the incorporation of reiki into the healthcare system and other fields of practice. Therefore, an exploratory research design seemed the most appropriate for the topic area.

Exploratory designs are based on the assumption that we need to know more about something before we begin to understand it or attempt to confront it successfully using intervention methods (Yegidis, Weinbach, and Morrisson-Rodriguez, 1999; Neuman and Kreuger, 2003). The benefit of an exploratory research design is its flexibility with regard to the scope of observation and interpretation of results (Broom, 2005; Yegidis, Weinbach, and Morrisson-Rodriguez, 1999; Neuman and Kreuger, 2003). With regards to this study, information was gathered to narrow the scope of observation and possibly contribute to further research. Questions were posed to gather experiential information and opinions from individuals who have credentials in both fields of reiki therapy and social work (hereinafter referred to as "practitioners") to understand their opinions regarding the possible benefits, limits and barriers to the incorporation of the two practices in the healthcare system. In order to provide context to the practitioners' responses, it was recommended by my thesis committee that questions would also be posed to organizational representative from the College of Social Workers and Social Service Workers, the Canadian Reiki Association, and the Ontario Health Department 
regarding their response to the integration of reiki and social work in the healthcare system.

\section{Sampling/Selection}

Practitioners were recruited through advertisements placed in Ottawa's Tone magazine, on the Canadian Reiki Association Website, and in the Ontario Association of Social Work newsletter (See Appendix "C"). Tone is a local magazine that is geared for the "consciousness raising community" in Ottawa and features articles and advertisements from various "alternative" and holistic health practitioners, including reiki, from diverse spiritual perspectives. I also contacted several community service agencies in the Ottawa area to request that an advertisement of the study be placed in their staff rooms. It was anticipated that practitioners would also be identified through word of mouth by others who learned about the project and referred it to them, by original participants identifying others that fit the study's recruitment criteria, and the ensuing "snowball sampling" effect of referrals among reiki practitioners and social workers upon learning about this study (Neuman and Kreuger, 2003). Organizational representatives were contacted by telephone with the request to participate in the study.

\section{Subjects}

The number of people who responded to this study with the above-described criteria was limited as only 3 individuals that responded from Ottawa had credentials in both reiki and social work. As such, I opened the study to include 2 individuals with counselling credentials and one person residing outside of Ottawa who wished to participate in the study and who had both social work and reiki credentials and practice experience. Overall there were 6 practitioners interviewed. The small number of 
practitioners presents a limitation in this study in terms of not being able to generalize the study results to the overall population of people with both reiki and social work credentials in Ottawa. The lack of a larger response to participate in the study may have been impacted by the fact that advertisements were only posted for one month. In addition to these 6 practitioners, interviews were conducted with a representative from each the College of Social Workers and Social Service Workers, the Canadian Reiki Association, and the Ontario Health Department (hereinafter referred to as "organizational representatives") respectively to provide context to the practitioners' responses. In total, 9 individuals participated in the study.

Participants consisted of 2 men and 4 women in the practitioner category, and 1 man and 2 women in the organizational representative category. Of the practitioners, 5 individuals appeared to be Caucasian (the race and ethnicity of the sixth practitioner is unknown due to the fact that the interview occurred over the telephone). The participants were not asked about their race or ethnicity and did not identify such in their interviews. The race and ethnicity of the organizational representatives is unknown because the interviews took place by email and over the telephone. Given their professional roles, participants appeared to be functioning within middle to upper-middle socioeconomic status. I did not ask probing questions with regards to these demographics because I wanted to focus on the broader aspects and narrative stories of the practitioners regarding benefits, barriers and risks involved with integration. However, it is important to note that such demographics could influence their response and observations should they be making observations about financial or cultural barriers from a position of privilege. 
It should be mentioned that additional individuals contacted me to participate in the study however they did not fit the criteria required to participate, even after the expansions made to the sample parameters. This indicates a greater interest in the research topic than the small sample size suggests and points to the possibility of more success in obtaining a larger sample size in a study with wider parameters regarding participant qualifications (such as location and type of professional credentials/experience). Additional individuals, upon learning about the study, also contacted me with an interest in obtaining results of the study, which again demonstrates a broader interest in this topic and possible usefulness of further studies. Research Instrument

The data for this study was collected through the use of in-depth, semi-structured interviews. Interviews are a popular method utilized in qualitative research (Anastas, 1999; Broom, 2005; Dilley, 2004; Rubin \& Babbie, 1997). To elicit the authenticity of the practitioner's experience and the descriptive information of their story, an interview guide was used so that open conversation could be facilitated (Anastas, 1997; Broom, 2005; Rubin \& Babbie, 1997) (See Appendix “D”). This dialogic approach provided the opportunity for practitioners to explore conflict, tensions, and ongoing struggles involved in the practices of reiki and social work as well as with regards to the possibility of integrating the two practices (Broom, 2005). This in-depth, subjective approach sacrifices the generalizability of results often valued in research with large samples, however it captures an enhanced quality of information collected in and specific to each interview, which was the goal of this project (Broom, 2005; Yegidis, Weinbach \& MorissonRodriguez, 1999). 
Information gathered from organizational representatives occurred in a different manner. I contacted the organizations by telephone to request participation in a spontaneous telephone interview for the purposes of the study. The representatives were informed of the letters of information and consent that would be mailed or emailed to them for their review and consent. It was intended that an interview guide be used to conduct interviews that were semi-structured in nature to allow for such subsequent information to be obtained as guided by the conversation that occurred (See Appendix "E") however this did occur as hoped. It is often during the thought process, voiced in a face to face or spontaneous interview, that important factors are identified that could guide the present or future research (Dilley, 2004). A combination of reasons such as long distance, time constraints, and the need to check for authorization to participate in the study resulted in correspondence and interview answers from two of the participants via email. This unfortunately meant the responses were more scripted than those that would have been obtained through face to face interviews. The third organizational representative responded to a voice mail message I left regarding the study, so would also have had the opportunity to reflect on and prepare for the topic prior to the telephone interview.

\section{Confidentiality and Anonymity}

The proposal and research instruments for this project were approved by the Carleton University Ethics Committee. Individuals wishing to participate in the study were not identified by their own name in this paper. People, referred to the study through another professional or participant, were provided with my contact information in the event that they wished to contact me on their own in order to participate in the study. All 
participants were advised that, although the above steps would be taken, their comments would not be confidential given that the information from the participant in question may be familiar to the referent, despite the removal of their names and other identifying information.

All participants were provided with a letter describing the research being conducted and stipulating that their involvement in the study was voluntary, that their identity would not be revealed, and that the information they provided would be relayed in an anonymous manner. Interviews with the practitioners were conducted in a location agreed upon between myself and the practitioner. This was done in the interest of maintaining the privacy and anonymity of the practitioner and respecting their schedules. The interviews took approximately 1-2 hours to complete and occurred either in the practitioners' homes or place of employment as per their choice. The interview with the practitioner residing outside of Ottawa took place over the telephone, all others were face-to-face. Participation in the study was voluntary and no remuneration was offered. The interviews were taped and then transcribed. Any notes taken regarding the interviews, as well as the tapes and transcriptions of the interviews, have been contained in a locked filing cabinet in my home and will be destroyed after final submission of this project.

\section{Data Analysis}

A grounded theory approach was used for the purpose of allowing relevant information to rise out of the data and to guide the analysis of results as this study does not aim to prove or disprove a particular hypothesis (Strauss and Corbin, 1990). The term "grounded theory" is used to describe the method of inductively arriving at a conclusion 
from identifying themes derived from the data and developing a theory that is relevant to the issue being studied (Strauss and Corbin, 1990). As this study is exploratory in nature, grounded theory method was used in a first-level manner to compare participants' responses and to formulate an information base regarding possible benefits, limits, and barriers to incorporating the two practices, in hopes of contributing to future research in reiki and social work as well as the larger field of complementary and alternative medicine.

In the grounded theory approach, conclusions stemming from study results should be faithful to the everyday reality of the participants, should fit that substantive area, and should make sense to both the subjects of the study and the recipients of the research data (Strauss and Corbin, 1990). The data in this study is based on the personal and professional experiences and perspectives of reiki and social work practitioners, as well as on the standards of the organizations in social work, reiki, and healthcare quoted in the organizational representatives' interviews.

I focused my analysis of the data on my interpretations of interview responses and on my recognition of any similarities and irregularities in the meanings associated with particular events. I reviewed information from each interview and collated this information according to similarities and marked differences in responses to questions regarding the benefits and limits of incorporating reiki and social work in the healthcare system for the practitioners as well as their clients. I also reviewed information pertaining to the hopes and desires of the participants regarding research and the future direction of reiki and social work practice, and issues related to the credibility of reiki practice. These were themes that reflected commonalities between the transcripts. 
My role as both interviewer and as a graduate student with professional experience in both reiki and social work practice contributed to the ability to manage questions and information from the participants in this study. Because I was able to identify with the experiences and observations of practitioners regarding both fields of practice, interviews occurred in an open manner, facilitating important in-depth conversation given the abstract nature of the topic. However this knowledge could have also contributed to either a restriction of a more critical perspective or a bias in the interview results due to the level of familiarity with and passion for the fields of practice, particularly towards the incorporation of the two practices.

\section{Validity/ Reliability}

Literature on research methodology differentiates issues pertaining to the validity and reliability of data obtained through qualitative versus quantitative research. The manner in which information is obtained is important to consider in terms of reliability and validity in qualitative studies (Yegidis, Weinbach \& Morrison-Rodriguez, 1999; Anastas, 1999). With respect to this project, the interviews that were conducted demonstrate the personal opinions of the practitioners regarding any possibilities, limits, benefits, and barriers to the integration of reiki and social work practice as based from their own personal and professional experience in both fields. My perspective as the researcher and of that of the practitioners were taken into consideration in terms of the possible impact to study results. Also considered was the location of the study, the position of my role as researcher in relation to that of the practitioner, and the amount of contact between myself and the practitioners (Anastas, 1999; Rubin \& Babbie, 1997). 
Practitioners were noted to be very passionate about their experiences with reiki and provided a majority of positive examples of healing in their interviews, thus presenting more likelihood of a positive bias rather than a restricted, critical voice. In an effort to counter this bias, which reflected my own bias and prompted fears that the study would not be balanced, I worked hard to also gather information from them regarding their thoughts and experiences about the limits of and barriers to an integration of services. Probing questions that I asked about barriers included the issue of touch as a barrier, given my own practice observations and conversations with practitioners prior to commencing this study, I was surprised that touch had not been explicitly identified as a barrier. It is important to note that in my efforts to address one form of bias, I may have created another in terms of encouraging the exploration of barriers that participants may not have otherwise discussed in their interviews. Practitioners did not feel that there were any risks or dangers to integrating reiki and social work practice, stating that reiki is a non-invasive form of therapy with no contraindications. This response corresponds with literature regarding reiki therapy (Miles \& True, 2003; Miles, 2003).

Reliability refers to the consistency of (or ability to replicate) observations made. Ideally, different researchers would be able to conduct the same research and obtain the same information each time. Enhancing the reliability, or trustworthiness, of the data can require lengthy contact between the researcher and participants that extends beyond the traditional 1-2 hour interviews utilized in social work research (Anastas, 1999). Practitioners presented their information and perspectives fairly consistently throughout the interview as various questions would often elicit similar information given in previous responses. In terms of the consistency of responses within each interview and 
the conviction of the responses, it would be fair to say that the research information is reliable as it is highly likely that, if interviewed again, the practitioners would respond in a similar manner as in the original interview.

Validity refers to the truthfulness of research results, or the consistency with which theoretical concepts and observations from the data are to each other (Neuman \& Kreuger, 2003). The more positive a relationship between theory and results, the more valid or credible the research is considered (Anastas, 1999; Royce, 1991). A clear explanation of what the results mean, both in the context of the conditions in which the results were obtained and the content of explanations offered to interpret study results, contributes to assessing the validity of the research (Anastas, 1999; Royce, 1991). With regards to this study, I noted that practitioners were consistent in their responses to various questions, offering the same information regarding their perspectives on benefits, risks and barriers to integration. This consistency would, in a larger sample, contribute to the reliability of the research as it would suggest a greater likelihood that results could be repeated with different participants in additional studies and thus validate patterns found in the information obtained. However, as mentioned previously, due to the small sample size and personal nature of this research, results could not be generalized to a larger population but could contribute to the development of future studies.

\section{Conclusion}

In this chapter, I explored interconnecting factors between reiki and social work related to the focus on individual connection with the universe, holistic well-being, and detachment from material stressors as common to both transpersonal theory and the philosophies and spiritual belief systems inherent in Taoism and Buddhism. I also 
discussed similarities regarding respect for the individual and self-determination as cornerstones of the code of ethics for both social work and reiki practice. Other important links were mentioned such as the goals of self-actualization and transcendence, the benefits of living a meaningful life, and the value of the process one goes through to achieve this, which is apparent in transpersonal theory and reflected in the philosophical practices of Taoism and Buddhism.

The resurgence of interest in spirituality has paralleled the increasing popularity of Complementary and Alternative Medicine (CAM). CAM therapies, such as reiki, reintroduce the spiritual dimension as an aspect of human development and an avenue for healing and living a balanced life. Proponents of incorporating spirituality in social work practice as well as health care services discuss benefits such as stress reduction, relief of physical and mental health difficulties, and the ability to enhance resilience by operating from a spiritual perspective. However there is tension within the healthcare system regarding the integration of CAM services. With the above-mentioned information and theoretical and practice links between reiki and social work, I conducted interviews to explore the perspectives of individuals with reiki and social work experience and credentials regarding their perspectives on the benefits, risks, and barriers related to the integration of reiki with social work practice in the healthcare system. Participants were obtained through the use of advertisements placed in the Ontario Association of Social Work newsletter, on the Canadian Reiki Association website, and in Tone, a local magazine advertising alternative and holistic health practitioners in Ottawa. In addition to this, advertisements were placed in staffrooms in several community service agencies in Ottawa. Difficulties presented with regards to obtaining participants in Ottawa that had 
both reiki and social work credentials specifically, as such, the sample parameters were expanded to include two individuals with counseling credentials, and one individual in Ottawa that had both reiki and social work practice experience and credentials. For the purpose of providing context for the responses of the above-mentioned practitioners, questions were also posed over the telephone to an organizational representative from each the Canadian Reiki Association, the College of Social Workers and Social Service Workers, and The Ontario Health Department respectively to gain information from a systems perspective. Names and other identifying information regarding the practitioners were removed and pseudonyms were used. Grounded theory analysis was used for the purpose of allowing relevant information to rise from the data, identifying similarities or common threads throughout the interviews. Despite the fact that the small sample size precludes the possibility of generalizing the results of this study to the larger population, there is value in analyzing the rich, contextual responses of the practitioners and forming a stepping stone from which to conduct future studies.

Literature by Henderson (2000) indicates that CAM therapies, such as reiki, are being accessed through social work services. As well, literature on CAM indicates an increased number of people using alternative therapies, including reiki, outside of the North American healthcare system. This suggests the usage of a therapy that is in the process of being measured but is not yet complete. This study will explore some of the reasons why a small group of counsellors would or would not use reiki in social work practice in the healthcare system. In the next two chapters, results of the interviews conducted in this study will be discussed and analyzed respectively according to themes 
related to the benefits of integration of reiki and social work (in general and in the healthcare system) and limits or barriers to such integration.

The topic of risks related to the integration of reiki and social work will also be discussed. Information obtained in this study will hopefully offer a starting point to better understand factors involved with the possible integration of alternative therapies such as reiki therapy and fields of practice such as social work in the healthcare system.

\section{Chapter 3: The Potential of Integration}

Not surprisingly, the practitioners who were interviewed for this study articulated a number of reasons why they thought there were advantages to integrating reiki with social work in the health care system. The organizational representative from the Canadian Reiki Association was also strongly in favour of incorporating reiki with social 
work, particularly when practicing within the healthcare system. In contrast, responses of the representatives from the College of Social Workers and Social Service Workers and the Ontario Health Department were neither for or against integration. Instead these participants focused on the standards and obligations in each field that would need to be met in order for integration to occur. In this chapter, I will explore the potential benefits that practitioners saw in integration.

Clearly a sample of individuals with both reiki and social work credentials is likely to focus on the advantages of integrating these modes of practice because such an integration would value the practitioner's particular combination of skills. However, what was interesting was how they articulated such support. The benefits described by the practitioners applied to both practitioners and clients. All of the practitioners felt strongly about how the benefits of reiki therapy, as well as components of reiki practice, complement treatment and practice goals in social work.

\section{Complementary Goals}

The primary reason that practitioners gave for integrating reiki and social work in the healthcare system is that the healing practices and benefits of both professional practices are quite similar. This integration was also understood as being consistent with the treatment goals and preventative health measures of the Canadian healthcare system. In summary, the benefits described by practitioners included:

1. relief of physical pain,

2. relaxation and stress reduction,

3. relief of emotional pain,

4. increased mental clarity, self-awareness, and increased receptivity to therapy, 
5. enhanced spiritual connection, and

6. a sense of empowerment.

While I will attempt to discuss each of these benefits separately, it is important to note that many practitioners described situations in which either they or their clients were experiencing a combination of difficulties that were interconnected and relieved simultaneously during reiki sessions or sessions that involved a combination of reiki and counselling. Many practitioners saw the benefits contributing to a holistic healing experience that is not easily re-organized into specific categories.

\section{Relief of Physical Pain}

The first benefit that practitioners explored was their sense that integrating social work and reiki would help relieve clients' physical symptoms. This was seen as important because pain can often present a significant barrier to emotional and psychological healing (Kabat-Zinn, 1990). The following discussion draws on excerpts from two separate interviews with practitioners who participated in this study. Beth and Ellen (names have been changed to provide confidentiality) both described their own experiences with reiki that in turn led them to learn and practice reiki. Both practitioners described experiences of chronic pain and illness that had not been addressed successfully with Western medical treatment. Drawing on their experiences, in addition to the experiences of clients, both practitioners were able to state first-hand, the benefits of integration. Beth and Ellen discussed these experiences as validating their support of both reiki therapy and the integration of reiki with social work practice. While initially expecting to only have data from the perspective of a practitioner, these stories of the 
practitioners' own experiences helped illuminate a number of the key intersections between reiki and social work.

Both practitioners discussed their experiences as having a life-altering impact that led them to incorporate reiki therapy into their personal and professional lives as counsellors and social workers. A number of the practitioners interviewed spent a significant portion of their conversation focusing on the merits of reiki therapy. This is likely connected to their concern that little is known about reiki, unlike social work, and that reiki therapy is rarely perceived as a credible form of healthcare. The following excerpt from Beth's interview is an account of her personal experience as a recipient of reiki therapy rather than as a practitioner. Although this does not speak explicitly to the integration of reiki and social work from the perspective of a practitioner, it illustrates the powerful and freeing impact of relief from chronic pain that is provided with reiki:

I didn't know anything about reiki, and about 1998 while I was in a bout of being quite sick with Lupus (which I personally think got brought on from my way of thinking and the way I was as a human being), I was quite ill. I was at a women's retreat in the Ottawa Valley and they were offering reiki as one of the afternoon options. I thought, "okay, why don't I take it, it looks kind of interesting. I don't know much about energy work and I would be interested in doing it." On that particular day, my hands were quite crippled in and I couldn't apply any weight on either knee and I couldn't use my left arm. I went for this reiki treatment and I got off the table and I was perfectly normal, completely normal. It kind of surprised the reiki practitioner as well and she said "you must have been working on some of the blocks to be unblocked if you're feeling as good as you are right now." I said to her, I had been. And I just said, "How would I prevent this from happening again or continuing to happen again?" I told her I've never felt better for even a week at a time for the last four years. She said very clearly "you have to be very aware of how you're blocking the energy in your life." Within two weeks, when I would have been due for another cortisone shot, didn't need it and continued to feel well, I said "there's something here, so I'm going to start learning how to do reiki." From that point on, I've basically been in remission because of reiki. That's been many, 
many years. Many years free of pain and all that stuff. It is because I started doing the reiki.

Physical pain can be debilitating and immobilizing. It can also be compounded with other issues such as emotional pain, trauma, anxiety, or spiritual distress (Wardell, 2001; Walsh, 1999). While Beth described the impact of reiki as relieving physical pain and difficulties with mobility, she also mentioned the oppression of living with years of chronic pain and how relief of this pain empowered her to reach further in managing her own healthcare needs.

Beth described the unique and intense nature of her healing experience as being enhanced by the personal cognitive work that she was doing in combination with medicine to meet her health and well-being needs. The value of tuning in to one's intuition and increasing self-awareness is acknowledged in social work practice (Canda \& Furman, 1999; Hancock, 1997). This internal approach to resolving problems is only part of the goals of social work practice that can be seen with the practice goals of providing education, encouraging self-reflection and self-awareness, and respecting the active participation of the client in the problem resolution process (Mullaly, 1993; Lundy, 2004). The use of these skills in problem solving allows for an increased awareness of oppressive conditions or psychological pain that may be contributing to the problem and interfering with the resolution. This in turn contributes to a better sense of direction in how to manage and proceed with such conditions.

Beth discussed working on her own "blocks", which was both validated and encouraged by her reiki practitioner. Although she was doing her own work in this area, Beth's description reflects the benefits that one could receive with the combination of 
working on one's problems by connecting to the inner self as one may do in counseling, and energetically with respect to reiki therapy. In combination with the pain relief provided through reiki therapy, Beth's internal work was brought to a new level as she opened to the possibility of managing her own healthcare needs. Beth also described her observation that tuning in to her inner self facilitated the intensity of healing that she experienced during the reiki session. This description illustrates the possibilities regarding mutual benefits involved with the integration of reiki and social work, with the relief of physical and emotional pain and distress, and with the facilitation of overall problem solving in a positive manner. It also demonstrates the relevance of the contemplative approach and concept of detachment valued in Buddhism, Taoism, and transpersonal theory, and the fit between Buddhism, Taoism, and transpersonal theory as the theoretical framework for exploring the integration of reiki and social work. In another interview, Ellen described a very similar and intense first experience with reiki therapy that demonstrates how she experienced a relief of physical, mental, emotional and spiritual pain:

I had fibromyalgia and went to the doctors. There was nothing they could do for the pain. I was taking 9 ibuprofin a day. I took a yoga class, the teacher also happened to be a reiki master and told me about reiki. I did level 1 and 2, and found that the energy helped me. I didn't learn a lot at that time because it was way too quick and I was stressed from the physical pain, but okay because the energy was so fantastic. I was emotionally numb because of the pain. All of a sudden I could experience emotion. Reiki brought me back to my spiritual self with gentle mind, body, spirit integration. After that, I went back to learn again, more thoroughly. I found that then the fibromyalgia was so well managed. 'It brought me to my spirituality and out of my fear'. 
The above experience described by Ellen is holistic in that it attends to emotional and spiritual healing benefits as well as stress reduction and relief of physical pain. These benefits enabled Ellen to move forward and assume more of an active role in meeting her healthcare needs, as well as reconnecting with her spirituality. Ellen's experience illustrates the immobilizing impact of chronic physical pain and conjunctive problems of anxiety, repressed emotions, and spiritual disconnection. With the exception of addressing physical pain, the above-mentioned problems are usually presented in social work practice and approached with counselling and skills such as active listening, empathy and reflecting back to the client. The relief of physical pain involved with reiki would allow a social worker integrating reiki in their practice to mitigate the barrier of intense and prolonged physical pain and provide a more in-depth and holistic service.

Ellen's example demonstrates the difficulties involved with one's ability to address problematic issues while also suffering the negative impacts of chronic pain. Ellen exemplified the empowering effect of direct pain relief, as well as the subsequent relief of emotional and spiritual trauma. Given the holistic nature of healing described in Ellen's example, one can see the potential assistance that the incorporation of reiki therapy could provide to people receiving social work services. Both Ellen and Beth have social work education and both function as counsellors who offer an integration of reiki therapy and counselling. They commented that integration of services is a natural and logical step to take due to the connections between physical, emotional, and spiritual problems and anxiety. Ellen described that "the two hats are always integrated".

All of the practitioners interviewed discussed that relief of physical pain was a benefit of reiki therapy. They also discussed that relief of physical pain is often 
accompanied by an emotional breakthrough or release that requires the use of counselling skills. Practitioners described that they all employ their counselling and active listening skills during reiki therapy and thus saw a natural fit between the fields of social work and reiki, particularly with regards to counselling that addresses issues about physical, mental, emotional, and spiritual health. The following quote from Dan illustrates his thoughts on the incorporation of reiki and social work and how he sees reiki contributing to the fields of mental health, healthcare, and social work based on his experiences with private practice and volunteer work:

Dan: Well, people with mental health problems, addictions, homelessness, or you know, social problems certainly benefit. There are also benefits to physical health, with regards to those with HIV and physical ailments. People do derive a lot from it [reiki and social work], the immune system is boosted, it promotes deep relaxation, which I can attest to, and promotes healing on all levels, including mental and emotional. It [reiki and social work therapy] can promote physical pain relief on a deep cellular level, it can address trauma, which is very important in terms of social and psychological health, as well as provide stress and tension relief. Invariably a lot of clients fall asleep on the table and it [reiki] still works through that. I think it can even help empower people with regards to their goals, even if they don't realize it at the time.

Q: what are your thoughts on the incorporation of reiki and social work?

Dan: Reiki will pick up emotional components in the client so I think it would be very very complimentary to do counseling after a reiki session or within the next day or something because people may not want to stay right away... but it does pick up on the emotional body so I can see it being very akin to the counseling.

While listing the numerous observed benefits of both reiki and the integration of reiki and social work practice, Dan made the link between mental, emotional, and physical pain 
and the relief of related symptoms. He then noted more explicitly the natural and relevant fit between reiki and counselling.

While social workers cannot provide direct relief of physical pain, they are often presented with people in situations that involve a number of problematic issues that include physical pain and illness. In some cases, people may not be able to move past their physical pain in order to address other problems, leading to a cumulative "mountain" of issues that seems insurmountable and contributes to feelings of powerlessness (Kabat Zinn, 1990). It could be hypothesized that the incorporation of reiki, with its ability to relieve and heal physical pain, can potentially provide enough relief to allow for the processing of psychological, social and economic concerns.

We know that physical illness is not always isolated from emotional or mental health (Ell, 1996; Loveland Cook, Becvar \& Pontious, 2000; Finger \& Mayfield Arnold, 2002; Henderson, 2000; Walsh, 1999), and that many who are seeking care through the healthcare system may be able to have their needs met more appropriately through services that meet emotional and spiritual as well as physical health needs (Miles \& True, 2003). Providing services such as integrated reiki and social work therapy could alleviate concerns regarding the high volume of need within an already burgeoning healthcare system (Coyte, 2001).

\section{The treatment of emotional trauma}

Practitioners in this study clearly articulated that the use of reiki in combination with social work would be helpful in the treatment of emotional trauma. In particular, 
Beth discussed the positive working relationship that she has with both the counsellors and the clients at a shelter for abused women where she volunteers and provides a combination of reiki and counselling. Beth discussed that the benefits of this combined approach are helpful to both counsellors and clients alike. It provides clients relief from minor physical ailments, emotional pain, and anxiety. Such findings are supported in the literature (Miles \& True, 2003; Miles, 2003; McDermott and Epstein, 2001). McDermott and Epstein (2001) explored the Effects of Reiki in Addressing the Major Consequences of Sexual Abuse (2001). The study was conducted with participants in a community program designed to provide holistic healing services for individuals dealing with the impacts of childhood sexual abuse. One-hour reiki sessions were conducted on a weekly basis over a period of 9 weeks. Participants were also able to partake in any of the ongoing services at Tamara's House, such as the Healing Centre, and had the additional support of a safe care worker. Findings indicated a remarkable improvement in participants' sleep, eating, level of anxiety, physical pain, and overall feeling or wellbeing (MacDermott \& Epstein, 2001). These improvements were seen as greater than those that had been found with more traditional interventions.

In the context of treating extensive emotional issues, Ellen described providing counselling and reiki to a woman who had been suffering from a "complicated grief reaction":

I saw one lady regarding a complicated grief reaction, four years post-trauma. She had been in group treatment with psychotherapy but was still struggling. She initially came to me for counselling but after being introduced to reiki became a "reiki junkie". To this day, she comes for reiki and wants to learn it - we were done with the counselling 6 months ago. 
Ellen's description of her client's response to the combination of reiki and social work allows one to see the potential for a form of therapy that more intensely helps clients to progress towards healing their emotional issues and empowers them to take a more selfdirected role in maintaining their well-being.

Not all people who experience emotional trauma are conscious of its impact on other areas of their lives, particularly when the trauma is sustained during childhood and effectively buried or only partially addressed (Herman, 1997). All of the practitioners participating in this study described situations where, during reiki sessions, clients would experience a sudden surfacing, or re-surfacing, of an emotional disturbance or past trauma that had not been disclosed as a presenting issue and that was unexpected by the client. Beth described these occurrences and drew on images of the practitioner as psychiatrist in order to highlight the intimate nature of the situations:

Certainly when they're on the table, there are some that will feel the reiki energy and the heat and the tingling, some that will just find some deep buried emotion is all of a sudden coming up to the surface. I always give anyone an option- you can talk to me the entire time I am doing these treatments, especially if something comes up and you want to share it, or you can stay perfectly quiet. So, I think that as soon as they end up talking about something that is emotional and is building up for them, you're pretty much like the psychiatrist. If they're on the table and they're laying there and they have trusted you, they will start opening and sharing.

In the above description, Beth demonstrated one of social work's goals, client respect, by creating an environment where it was safe to either share or not share, leaving the choice to the client. Beth described the impact of the combination of being vulnerable, lying on the reiki table, and feeling the effect of the energy therapy as facilitating an emotional release. In combination with the safe and respectful environment, she observed clients opening up and sharing the emotional issue. Beth likened the position of the practitioner 
to that of the psychiatrist providing active listening and guidance via counselling skills as well as reiki therapy. Interestingly enough, this same practitioner-psychiatrist analogy was also articulated by Ellen:

A lot of the time the reiki table becomes a psychiatrist's couch, amazing stuff happens, background stuff, childhood trauma stuff, negative stuff just seems to come up. Social work values are always there: client-centered; client-safety; client autonomy; and client respect.

Ellen described the surfacing of disclosures of emotional trauma, which she likened to that which would occur on a couch in a psychiatrist's office. As much as the above analogies paint a picture of a therapeutic environment that involves the client lying down and the facilitation of relaxation and conversation, the similarities to psychiatry end here. Psychiatrists also diagnose and evaluate, operating from the medical model approach, which are neither goals of reiki therapy (http://www.reiki.ca/faq.htm). In addition, a psychiatric approach does not tend to take into account the aspect of spirituality or connection with self or a divine or natural order as part of a framework for identifying or resolving problems (Cowley, 1993). With regards to talking, emotional releases, and disclosures that facilitate therapeutic rapport, a more fitting analogy would be that of counselling, a parallel that all practitioners discussed.

Ellen was clear to differentiate the psychiatrist analogy from that of social work in the context of client relationship and goals of practice. In this manner, she also referred to the overlapping of, or similarities in, professional codes of ethics and conduct for the fields of reiki and social work. In an environment that fosters respect for the client's personal needs for safety, autonomy, and values, it is not surprising that a therapeutic rapport or relationship can develop, particularly after there has been an emotional release 
or disclosure from the client. An important benefit of integration that is being described here is that of the facilitation of therapeutic rapport or the enhancement of client's receptivity to therapy. With the relaxing physical effects of reiki and ensuing relaxing atmosphere, an environment is created where, with the appropriate counselling skills, emotional disclosures can occur that can enhance the relationship between practitioner and client and increase the client's receptivity to and progress with therapy.

The following quote from Anne provides more context to the enhanced therapeutic relationship that both Beth and Ellen allude to as occurring through integration. Anne described her feeling that reiki therapy adds a depth to the healing and counselling experience that goes beyond active listening and "straight talk therapy":

I feel that this sharing, or sense of communion from reiki, is significant as clients report they have never before felt that someone really saw them in the way they have in their own mind. Having done straight talk therapy, I know the value of empathy and active listening and I feel that a counsellor can be really skilled and empathetic, but it's not the same mingling of mind and heart. Reiki goes beyond active listening, that's why it's so healing.

The description of this depth in the reiki healing process as going "beyond straight counselling" or "beyond straight talk therapy" was echoed by all of the practitioners in their argument towards the benefits of integration. All practitioners discussed the natural fit between reiki and social work practice with regards to the emotional releases that they described as occurring for clients while receiving reiki and the relevance of having the appropriate counselling skills to assist that person in navigating the feelings and issues that are coming up for them. 
Although Cynthia does not utilize reiki therapy in her counsellor role, she acknowledged the importance, relevance, and use of counselling skills during reiki sessions, particularly in the context of emotional issues:

I think why reiki and counselling are so complementary for me is because I can't imagine how you would approach some of the stuff that comes up during a reiki treatment without having some of those skills. I mean sometimes they're not going to want to talk and they're fine and they go and have their own experience but then for those who want to know and want to explore or have had a release on the table and want to talk about it, I'm very thankful that I have these skills in some other departments that I can pull on. It's very short term and it's going to ensure the person is comfortable leaving, but I don't consider that my hat when I'm in that mode.

The above description reflects the view of all of the practitioners regarding the practicality and necessity of counselling skills when practicing reiki. Again we see the description of a phenomenon whereby emotional issues surface for the client while receiving reiki therapy. A likely contributor to this surfacing of emotions evolves from the process of slowing down, relaxing, and focusing awareness inward, while receiving energy therapy that works to resolve blockages in the energetic layers and channels surrounding and running through the body (Miles, 2003; Miles \& True, 2003; Kabat Zinn, 1999). Energy therapy such as reiki can facilitate not only a release of emotion but an increased awareness of unresolved issues or challenges faced by the client that in many cases requires further processing. It is when feelings and information are shared between the reiki practitioner and client that counselling skills are used and a therapeutic relationship is formed. With respect to the healing of emotional trauma, the environment that practitioners describe involves the facilitation of facing, feeling, and disclosing the experience of trauma in an environment that is safe and respectful.

\section{Facilitating Relaxation and Stress Reduction}


Research has demonstrated a significant link between anxiety and emotional, mental, and physical health problems (Ell, 1996; Loveland Cook, Becvar \& Pontious, 2000; Finger \& Mayfield Arnold, 2002; Henderson, 2000; Walsh, 1999). As such, benefits of stress reduction are integral to social work practice and healthcare and are relevant to this research project in the context of benefits involved with incorporating reiki and social work.

Every practitioner discussed the benefits of both reiki therapy and the combination of reiki and social work of reducing anxiety and enhancing a relaxed state within the client. The following quote from Anne is her description of how incorporation of reiki therapy into mainstream services would benefit society, particularly in the context of how anxiety affects people:

For the most part in Western society we live with low-grade anxiety to the point that we're so used to it and minimize its impact. We would be a much kinder, gentler society with reiki. If people could have increased awareness about the level of anxiety they have and of the stress reducing impact of reiki and what contributes to their stress, it would be so helpful to their own healing and what they would want for others.

In discussing the pervasive impact of anxiety, Anne also pointed out that we live in a society that allows for and minimizes the importance of the detrimental effects of stress and anxiety, which is concerning in light of the research that indicates that many people suffer from anxiety in our society (Kabat-Zinn, 1990). One of the hallmark features of reiki therapy is relaxation, attracting many who wish relief from the impacts of stress and anxiety. This is also the goal of some people who seek social work or counselling services. In many cases, people may be aware that they are experiencing problems and aware that they are stressed, but due to the extent that Western society minimizes the 
impacts of stress on everyday living, they may not be able to fully realize the extent of their anxiety and how that stress is impacting them on multiple levels (Kabat Zinn, 1990; Walsh, 1999). Anne discussed one client who was suffering from the negative impacts of anxiety, and how an integration of reiki and counselling was used to assist this client in resolving the problems related to the anxiety:

I had one client, an administrator with a large organization, who was stressed, had problems sleeping and waking up at night and then at 5 a.m., etc. I can't say that reiki alone solved the issue because the client also had not been utilizing any other stress reduction strategies, so I would do reiki and also tell her to do other things such as meditate, and place her hand on her third chakra before she goes to bed at night. We did 3 reiki sessions - her headaches were gone and she was sleeping better. I haven't seen her again as she was feeling so much better, she planned a vacation with her husband. We discussed that she'd come back if she needed it. The client was more light-hearted - there was a big shift.

While Anne did not explicitly describe provision of counselling services in the above example, she identified herself at the beginning of this interview as having a private practice that integrates counselling and reiki therapy. She described the relaxing effect of reiki as integral to the healing and assistance of many of her clients. The above quote is a clear example of how the physical and emotional impacts of stress can be resolved with a combination of reiki and counselling that focuses on returning to the self. Anne educated the client about reiki concepts and meditation so that the client could focus on relaxing the areas of her body that needed the attention, which also helped to raise awareness of the factors that contribute to the tension. Social workers may be able to assist people in unraveling the many conditions that contribute to a person's emotional state and challenges that they face in everyday living, or in situations of crisis, but their ability to do so would be enhanced with the integration of a therapy that effectively reduces anxiety 
during the session, facilitating in-depth conversation regarding the person's situation and how they are responding to problems.

Such therapeutic treatment is particularly relevant in the healthcare system where stress is described as having a degenerative effect on biochemical process and changes (Miles and True, 2003; Wardell, 2001). Miles (2003) discusses the important role that reiki plays in stress reduction, particularly during the time that patients in the medical system are awaiting test results or a diagnosis. She describes the impact of stress as aggravating medical conditions and reducing the patient's ability to carry out self-care and make appropriate decisions about their lifestyle. This is significant in times of physical health crisis when people are asked to make important decisions regarding their healthcare (Miles, 2003). In a similar context, Beth described her experiences helping people with managing long-term or terminal illnesses:

I've used reiki and counselling working with people that are dying of cancer. And if it's just to help them have a better perspective on what is going on for them, to have a calm mind in dealing with what they're dealing with, it's just as important. But I would say that a lot of people, the moment they get off the table, feel extreme relaxation, there's no doubt, even some who say they have never relaxed before.

Beth described the benefit of putting the disease and mortality into a context that enables the client to better cope with and manage their living experience in light of pain, illness, and anxiety. In addition to this, Beth saw that stress reduction helped patients achieve the clarity, composure, and confidence that positively contributed towards the patient's perception of their healing and improved medical outcomes (see also Miles, 2003). Beth is describing a benefit of integration that involves the enhancement of a client's ability to cope with terminal health issues by shifting the way they perceive and think about their current situation and possible outcomes. 
Wardell (2001) clarifies the interconnected physical and emotional impact of stress by explaining that anxiety is the cognitive result of stress while physical symptoms of stress are represented in the motor system as muscle tension. The relaxation response in the body and brain shows a reversal of such complex stress response symptoms as high blood pressure, lowered skin temperature, and elevation of cortisol (Wardell, 2001). Social workers are able to work with people on multiple levels, emotionally, mentally, through advocacy, and with provision of resources to assist with stress reduction and identifying issues that are problematic (Canda \& Furman, 1999). While these forms of intervention may help to alleviate some of the physical symptoms of stress, the addition of a therapy that simultaneously addresses these physical symptoms at an energetic level could enhance existing social work and healthcare services (Miles \& True, 2003), particularly in the healthcare system where many health complaints are connected to the impacts of anxiety. Wardell's (2001) study found decreasing levels of perceived anxiety, increasing signs of relaxation, and increasing immunological function after a single session of reiki, that speaks to the benefits that stress reduction therapies involving reiki might have in the healthcare system.

\section{Benefits of Increased Mental Clarity, Self-Awareness, and Increased Receptivity to Therapy}

Another outcome of the healing process described by practitioners is that of increased mental clarity. This particular benefit speaks to the relevance of integration in terms of facilitating problem resolution, increased self-awareness, and a clearer sense of direction in terms of how to address problematic or unclear situations troubling the client. The benefits of these outcomes to social work practice, as opposed to solely reiki therapy 
or only counselling, is described by Ellen, who related her observations regarding the need for both services to effectively assist clients:

Using reiki in social work brings better clarity to a client situation. It enhances their talk therapy and way of looking at things- they are more relaxed and more receptive. This combination of therapy shifts clients, particularly with regards to the level of anxiety and stress. This is most important because if you are doing social work and trying to help clients put things in perspective, it could lessen time in therapy.

In this quote, we begin to see the possibilities for enhancing the effectiveness of social work interventions through integrating reiki practice. In general, social work interventions are geared towards helping clients cope more effectively. This is true in health care settings where one aspect of increasing a client's ability to cope is to reduce anxiety and to increase a client's ability to hear and understand their healthcare options (Miles, 2003, Kabat Zinn, 1990). Reiki facilitates relaxation, a condition that is conducive to increasing receptivity to therapy. In addition to this benefit, practitioners reported the benefit of increased mental clarity that facilitates empowerment of the client to make choices, which facilitates self realization, self-actualization, and selfdetermination.

Several practitioners discussed that both they and their clients felt this increased mental clarity and a clearer sense of direction from receiving reiki that assisted them in coping with their healthcare issues. A more specific example depicting the benefit of perceptual change through reiki is demonstrated in the following story by Beth, who described a situation in which someone had been referred to her to address the issue of oncoming blindness: 
I told her not to expect that what I was going to do today would change her blindness, at that moment, but might change her perception of her blindness. And I clearly wanted her to hear that from me. About a month later, she contacted me and told me that she had been going for reiki treatments at this center in exchange for volunteer work. She said "I can't thank you enough". And I knew I wasn't going to hear from her "I can see better." She said "my blindness is still continuing to progress in a way that I'll go blind, but my understanding and my acceptance of it changed so much in the last month."

In this quote, Beth provided a perfect example of the ways in which reiki can be combined with social work to increase one's ability to cope. Social workers are rarely able to resolve the chaos and struggle in the lives of people with whom they work. Social workers in health care can not cure cancer or prevent death. Neither can reiki practitioners, but both professional interventions are focused on increasing a client's ability to cope with the health crises they are facing. Social workers often do this by providing people with increased resources and information. Reiki practitioners tend to intervene at another level. For the woman in Beth's story, an intervention that focused upon changing the energy fields that were shaping this woman's relationship with her blindness led to a change in the experience of blindness.

As a therapy, reiki does more than facilitate the flow of energy to assist with the goals of obtaining balance and clearing blockages in a person's energy system. The philosophy behind reiki also emphasizes the participation of the client in terms of tuning into the self as a whole - body, mind, and spirit. This act of tuning in allows one to connect with their inner self and with how they are both impacted by, and reacting to, the problems they are facing. This is similar in effect to that of the education, self-reflection, and consciousness-raising utilized in social work practice. Also similar is Kabat Zinn's 
(1990) discussion of mindfulness-based therapy to manage the impact of stress and related health problems. Kabat Zinn discusses that a successful way to manage feelings such as powerlessness and anxiety is to understand thought patterns and the connections between body, mind, and spirit. By better understanding the impact of thought patterns on overall functioning and well-being, people can see where they need to focus their efforts on changing their relationship to themselves, reshaping their perceptions and responses to problems (Kabat Zinn, 1990). This increased clarity of self allows for more acceptance, patience, and confidence about the ability to manage problems in all areas of their lives. Given the connection between emotional and physical illness, particularly with regards to anxiety, one may be able to see the impact that their way of thinking about their illness has contributed to the illness itself or to increased stress. Incorporating this philosophy, with the anxiety-reducing effects of reiki therapy and counselling skills to guide clients regarding their perceptions, integrated services could assist in facilitating the increased awareness necessary for the client to change the way they think about themselves and their illness.

Practitioners in this study consistently described reiki as inducing or facilitating relaxation and a meditative state. It is this state that is key to developing mindfulness or increased awareness (Kabat Zinn, 1990). Kabat Zinn (1990) describes that committing to a process of tapping into a problem to become aware of your body and cognitive responses to situations provides a sense of clarity and direction as to how your energy is being used, or is scattered, and how to channel your energy to be more effective. The combination of reiki and social work can assist a person to relax and reach a meditative state. It also assists with increased awareness about the self and how one is both impacted 
by and impacting their situations, allowing for the person to connect with and become aware of their ability to manage difficult issues. In integrating professional responses that add resources and supports with those that change ones relationship to their health crises, practitioners saw the potential for even greater changes in a client's ability to cope.

Increased mental clarity is also an important benefit to clients when the source of their distress is not clear. Anne described:

One man came to me initially because he felt that things were not right in his life. Eventually he came to realize that this was due to marital difficulties. People tend to come to me and describe that they are not happy, or have anxiety or mild depression.

Anne further articulated that she feels that reiki benefits mainstream practices such as social work with regards to facilitating clearer perceptions of self:

I feel that reiki really helps people to unfold what the barriers are to their own well-being. Through reiki, I get a sense of the person as a loving, whole person, and I try to help them see this image and the barriers to them being that person. I feel that this raises their awareness as to what beliefs keep them from seeing themselves as whole and loving. I feel a great compassion and that this process is very confirming to them that they are better than they think they are. I think it also makes them feel safe- not judged, not "bad people".

In the above quote, Anne described that she helps to provide clients with the image she sees of them as a whole person in light of their struggles. She concluded that using reiki therapy with counselling skills in this manner increases the client's self-awareness as to what beliefs keep them from seeing this positive and whole image. Anne discussed the benefit involved with the combination of reiki and counselling to help guide the client in the processing of their view of self. In this example, benefits of integration would include educating clients regarding the external influences that impact the client's view of 
self and the provision of resources that could assist the client in changing or managing those external influences to support the strengthened internal resources.

Another example from the interviews that illustrates the beneficial impact that integrated services can have with respect to increasing mental clarity involves people with complex and difficult life situations. During my interview with Dan regarding his experience and perspective on integrating reiki with social work, he discussed his volunteer work with community social work services that assist people suffering from HIV/AIDS, and their family members, as well as those generally struggling with physical, emotional, mental health issues, and drug addictions:

I could see progress in their journey, more confidence and a better sense of direction as to where they were going....so, I think, you can't plan as to where it's going to take people and they can't really either, but then it's always good to have a person say how they're doing and what they're hoping to achieve during a session. I think that in itself can be very therapeutic too, there's a lot of listening at first.

This excerpt reflects the impact of reiki therapy used in a social work setting to address situations that are not as clear and direct as a patient attending a hospital or healthcare clinic for physical health issues. Dan discussed the importance of allowing space for the client to describe where they are at and what they are hoping to achieve during a session, which can also be beneficial to the client as they hear themselves processing their issues and desires.

The above example speaks positively to the possibilities of integration between reiki and social work in the healthcare system, particularly with marginalized people. Social workers can help such clients to achieve more clarity through the combination of counselling and education regarding the impacts of the organization of society and 
systems specific to the client's situation. They can also provide support through active listening and the provision of material supports such as temporary shelter or assistance in obtaining housing, financial assistance, or food.

Social workers cannot directly have an impact upon the physical health issues that often occur in combination with the above-mentioned problems. While reiki cannot provide material resources to assist people with housing, food, or money, the effects of reiki can provide some relief of physical and emotional pain related to those problems. It can also assist the client in reaching a state of clarity so they can be better able to think about their problems and the help they could receive to manage their situation. An important precept of structural social work is that people are affected by many personal and societal or environmental factors that affect their well-being and daily functioning (Mullaly, 1993). While many people in the above-described situations may not be able to mobilize the energy to advocate for themselves or get involved in social action, with integrated services they could potentially become more open and clear towards attending services to address or manage their situation. Such integration would also be ideal given the links to physical health and relief of chronic physical pain and anxiety.

\section{Enhanced Spiritual Connection}

I have discussed the practitioners' views on the benefits of integration to physical and emotional health. Incorporated with these benefits is the aspect of spiritual connection and ensuing growth and development that all practitioners noted as part of the healing process. All practitioners discussed the powerful impact of feeling a connection to the spiritual self for both practitioner and client. This connection was described as validating a more positive view of self and as validating the ability to view and manage 
problems from a perspective that enhances internal strengths and resources. In this context, the practitioners also identified that the addition of reiki to social work services provides the missing element of spiritual connection and development that they feel is necessary to the human personality and healing process. The following statement by Cynthia reflects the sentiment shared by the practitioners regarding the importance of spirituality to both reiki and social work practice:

I think that spirituality is left out of a lot of [social work] practice. I think because reiki is not considered "spiritual" practice or that it's non-denominational, that that has a lot of power and a lot of place in social work for sure. Again it's going back to the fact that people can heal themselves and that's a huge part of social work in terms of empowering that, whether or not it's hands on touching, talking, sitting and being quiet. I mean whatever method it is, that's reiki energy being present.

Cynthia's discussion of spirituality as an aspect of the person that affects their life and their ability to problem solve as a missing element of social work practice is an argument that has been successfully made and supported by authors such as Edward Canda (Canda, 1999; Canda \& Furman, 1999). One of the benefits of reiki in this context is that although it enhances a sense of spiritual connection or sense of spirituality, it is not a practice that claims to be spiritual in the context of being a religion.

Despite its Taoistic and Buddhist influences, there is no specific denomination identified with or encouraged in reiki practice. Cynthia noted that this is particularly beneficial to social work practice because it does not enforce a particular religious or spiritual stance, which would serve to marginalize or discourage people that do not identify with particular religions from connecting with social services. Walsh (1999) discusses the importance of a neutral or impartial position of the social worker regarding 
their own particular religious or spiritual affiliation. A social worker may be able to effectively communicate about their spirituality or religious beliefs with a client in an open and non-judgmental manner. However, Walsh's position reminds us that it is important to be aware of the impact that a social worker's level of authority can have on the therapeutic relationship, particularly if the social worker in question discusses an affiliation with a belief system that is culturally predominant and differs from that of the client (Walsh, 1999; Canda \& Furman, 1999). With this in mind, Walsh also endorses operating from a perspective that allows for the sharing of spiritual stories, where appropriate, to support the spiritual growth and development of the client regardless of their religious or spiritual belief systems (Walsh, 1999; Canda \& Furman, 1999). The neutrality of spiritual support that Cynthia described as occurring through reiki would naturally sustain the type of social work practice described by Walsh and serve to facilitate the spiritual growth and development necessary to meet and validate the spiritual and well-being needs of clients.

Similarly, Beth differentiated religion from the spirituality involved in the healing process and stated that the inclusion of spirituality as an aspect of healing can assist people who are confused about their purpose in life or contribution to society. This is a similar concept to the lack of meaning discussed in transpersonal psychology as a source of distress for people:

Some are just really distraught with life, depressed, feeling overwhelmed with what they do in their life, and just would like to have some direction. I don't think the religions that are out there right now seem to be answering the difficult questions for them. I think there is certainly a purpose for every single religion that's out there, but what I'm finding is that, especially when somebody is quite sick or dying, is that they're not feeling as much comfort in their particular religious practice, and that the reiki (and I suspect 
some of my spiritual beliefs) are quite comforting for them. I don't expect anyone to have the same spiritual beliefs that I have, but living these beliefs and incorporating them into my life, made the concept of suffering very different for me. I'm not as reactionary to it. I feel compassionate about it, but it doesn't have the same impact it had before...

Beth raised the issue of the importance of spirituality for people who are dying or experiencing a terminal illness, which is relevant to a social worker's role in the healthcare system. Beth's belief system, as described earlier, includes the Eastern philosophies that are inherent in reiki. Her description of how this spirituality impacts both her perspective, and ability to resolve problems connects with literature supporting the idea that spirituality provides an internal framework of strengths and resources from which to draw from in times of distress (Barret, 1999; Kabat Zinn, 1990). We see in this situation how reiki and social work can work together to enhance the development of such a framework for people.

The following quote reflects Anne's personal and professional observations about the sense of spiritual connection felt in her reiki and counselling sessions with clients:

Practicing reiki is almost an experience of a meditative state and a tremendous state of intimacy with the client, as well as a general sense of satisfaction of progress with the client after the session either feeling the progress/energy change, or physically seeing or hearing the results that that person feels better or has increased awareness. It also creates a balance in my life of working with both heart and mind, not just intellectually. Reiki is calming for me as well. It's a reminder that the world exists beyond the five senses. There's a real sense of communion- of mingling that's hard to describe- it's hard to know what language works for people, in terms of what I see or feel.

The above quote nicely encapsulates the spiritual atmosphere and increased awareness that is often felt, but difficult to articulate, by both practitioner and client during a reiki session (Miles, 2003; Miles \& True, 2003). The description of the session as inducing a 
meditative state and facilitating balance for the practitioner through the mind-heart connection conveys an Eastern spiritual and philosophical flavour that corroborates the theoretical influences of Taoism and Buddhism inherent in reiki therapy (Miles, 2003; Miles \& True, 2003). The meditative state allows for connecting inward and tuning into the interconnection between body, mind, and spirit, contributing to a focus towards wholeness and balance for optimal well-being (Kabat Zinn, 1990). Anne described this type of intimate experience as enhancing the therapeutic relationship with the client. In combination with counselling skills and resources offered in social work practice, there is great potential for increasing the connection to one's spirituality and receptivity towards intervention in a holistic manner.

The following quote from the interview with Dan also touches upon the experience of spiritual connection, again reflective of Eastern spiritual and philosophical influences, in the reference to accessing a "higher self" through reiki:

It's totally different because it's accessing an individual's higher self and it's also working through my higher self, so the help that I'm providing is more on the surface, but it's in another category. As far as health goes, we're not doctors or qualified in that way, but reiki certainly benefits the immune system and facilitates healing. People will have stress, tension, and illness as a component of their situation in most cases. So if a person can really, really deeply relax- go into deep relaxation, that can be healing. Actually, we don't do any diagnosis or anything but I recall one client coming out of the session and saying, 'oh I totally forgot to mention that I had a really sore back before we started but now I don't have it anymore', so it's just an example.

The concept of a "higher self" is represented in transpersonal psychology with regards to the personal goal of transcendence, it is also alluded to by Miles in her description of the spiritual component of reiki therapy (Miles, 2003). Leight (2001) argues that the transpersonal model is relevant to social work practice in that its holistic approach, 
including the aspect of spirituality, is a logical extension of the inclusive perspective valued in the social work profession. This inclusion of spirituality as an important aspect of human functioning and development, in addition to the concepts of detachment from, and the transcending of, negative and oppressive conditions influence the adoption of a framework, like that described by Walsh (1999), from which to resolve problems. This framework would also serve to assist with the achievement of a more genuine identification of, and connection with, self. The integration of a model that encourages dis-identification with internalized oppressive conditions and ensuing marginalization allows for a cognitive shift to occur within the client, facilitating self-awareness, selfdetermination, and empowerment (Leight, 2001; Kabat Zinn, 1990). This argument can be extended to the benefits of incorporating reiki and social work in the healthcare system with regards to the value and emphasis placed on holistic healing and the importance of acknowledging and maintaining a state of well-being.

All of the practitioners discussed the importance of feeling an enhanced spiritual connection during reiki therapy, which was said to benefit both the practitioner and client individually, as well as to enhance the therapeutic relationship. In particular, Ellen described "what we get out of it is the sense of connection - to ourselves, higher selves, Creator, and the client". She described how her use of reiki and counselling skills really helped a lot of people in palliative care who couldn't relate to either religion or the medical model: "they were being treated with the medical model and these people were outside of the medical model".

This again relates back to the previous discussion about the importance of providing an atmosphere that supports spirituality but that does not relegate or contain 
this to any particular religious denomination. Providing service in this manner allows for a person to draw strength and meaning from their situation by connection to their own belief system and internal resources. At the same time, this service helps to highlight for clients the limiting thought patterns that need to be addressed to increase the ability to cope with stressors in a positive manner.

\section{A Sense of Empowerment}

The benefit of empowerment is perhaps the most relevant argument in support of incorporating reiki and social work practice. All practitioners discussed this benefit as occurring through the aspects of reiki practice that overlap with social work: client respect; client as expert; and active participation of the client. As well, practitioners discussed a benefit exclusive to reiki therapy regarding the option of being attuned to the first level of reiki in order to perform self treatments. While empowerment ensues from mental clarity, education, and self-awareness, it also facilitates a process of selfdiscovery, self-determination, and self-realization, allowing one to address a range of issues from those that are personally relevant to those that are for the benefit of the community and larger society (Lee, 1996; Kabat Zinn, 1990). The following quote is from my interview with Cynthia, who described coming from an empowerment approach when working with people:

A lot of empowerment comes from talking about the problem before either treating somebody or when I'm teaching people about using their own intuitive sense. One of the things I find really neat is when somebody gets off the table and they want to know what you felt about the session. I tell them "tell me what you felt, where are your questions coming up because you know better than I do." Even though I will pay attention to any stuff that comes up for me, it's not my place to know whether or not they are ready or not to hear that stuff. 
Q: Do you share that with them at any point in time?

Yeah, if they have asked, it is part of my practice for me to empower them to move forward. If they're open to that they'll always say the same thing, in a bit of a different context, but they'll have the same areas and images that I will. Even my table treatments have a lot about education about bodies, and body-mind memory as a power that exists for us, so it's allowing individuals to tap into that and let them have the session the way they need to.

Cynthia described empowerment in her reiki practice where counselling skills are used in the context of encouraging the client to use the session to reflect inward and tune into an awareness of self in a holistic manner. This "tuning in" allows one to be knowledgeable about what is happening in their own bodies and psyches, and to draw upon this knowledge to become more aware of their well-being needs to make choices accordingly. Cynthia discussed her preference in operating under the assumption that although she is the practitioner trained in reiki practice, the client is the expert as they know themselves best and would therefore be best able to tap into what they need to move forward. This is also reflected by Kelner and Wellman (1997) in their discussion about how alternative practitioners encourage patients to play an active role in their healing based on the premise that they know their own body best and trust their own judgment most.

At the same time, Cynthia stated that she respects her clients' requests with regards to her sharing her own perspective on the session and any observations she would have made. Cynthia consistently experienced her clients as having the same observations and conclusions that she had from their sessions, further validating their experiences and demonstrating the intimate connection between client and practitioner in the healing process. However, this client response could also reflect the client's deference to the practitioner as an authority figure and thus someone to agree with, fearing that their own 
insights are not valid enough to discuss, particularly in the event that they differ from the practitioner's. One of the main goals of the empowerment approach in social work is to remove the barrier of power that is obtained with knowledge, which occurs through providing information to the client and respecting their ability to understand and manage that information (Lee, 1996). Cynthia described trying to mitigate the power imbalance between herself and her clients by encouraging clients to discuss their thoughts and observations of the session versus hearing hers.

Cynthia emphasized that educating clients regarding their bodies and abilities enhances their capacity to relax and allows them to tune in to themselves, which, in turn facilitates the capacity for increased awareness. Education, increased awareness, and active problem resolution are also important components that characterize empowerment from a structural social work perspective, again demonstrating parallels between reiki and social work practice.

Similarly, Kabat Zinn discusses the relevance of respecting, validating, and supporting the belief that the client is the best person to manage their own distress as they know themselves best and can access the inner recourses they need in order to move forward. He states that being an active participant in their own healing process helps to address counterproductive feelings or beliefs of powerlessness or loss of control to their problems (Kabat Zinn, 1990). The validation that occurs through the belief and encouragement of the practitioner in the client's ability to play an active role and contribute to their own healing sends a message of value to the client that they can do something very important for themselves (Kabat Zinn, 1990). 
The success of mindfulness therapy depends on the level of commitment and conscious effort of the client to move forward with the healing process and the goal of attaining inner peace (Kabat Zinn, 1990). Similarly, the benefits of reiki, particularly in the contexts of increased mental clarity and empowerment, are positively correlated with the level of commitment of the client to facing their stressors and discovering their strengths and limitations which will enable them to move forward in their healing process (Miles, 2003; Miles \& True, 2003).

Miles (2003) discusses the factor of empowerment as an important aspect and benefit of reiki therapy, particularly in the context of learning reiki. Empowerment was discussed by all practitioners in the context of self-treatments and in the provision of clients with the first level of reiki training to conduct these treatments. Again we see an emphasis on active participation in the healing process. Beth discussed her belief that a key value of incorporating reiki with counselling is the ability to teach people to use reiki on themselves to facilitate their own healing:

But you know what's just as valuable, is teaching- teaching $1^{\text {st }}$ level reiki to these people who are people we could be potentially counselling. You know, to teach a one day class on first level reiki would be remarkable because you know that if somebody starts to feel that they have some control and can do some self healing on their own, the empowerment there is incredible. So I wouldn't just say that giving treatments, the thing that moved me into further health, was me being able to treat this on myself. I'd love to see that it be offered sometimes for the women that are abused at the center, they may offer them a day of how to be less/ stress free, or [do] relaxation or meditation [exercises].

In the above quote, Beth linked the benefit of feeling an increased sense of control in responding to problems as being particularly helpful for women who have been abused and who still may feel a sense of powerlessness or lack of control in their lives. 
Involvement in an abusive relationship may take years to face or change. Women who have experienced violence are often disconnected from their bodies, emotions, and sense of spirituality (Marshall \& Vaillancourt, 1993). The concepts of relaxation, redirecting stress and connecting to the body, mind, and spirit, can help women identify what they need for their healing. It can also help them to identify with the concept that they already have the strength within themselves to face and address adverse situations. It could be hypothesized that, given the sense of empowerment that can stem from reiki and social work practice, women who are able to use reiki for themselves are likely to further their sense of self-worth and efficacy - feeling an increased sense of control and competence in knowing themselves and facilitating their own healing. Integration of reiki therapy into social work practice can also enhance concurrent social work services in this context, building trust and therapeutic rapport and increasing receptivity to intervention. Integration of the concepts and the relaxing effects of energy therapy with social work skills and techniques such as counselling, active listening, and education can work well together to assist the client in identifying and challenging thought processes that contribute to their fears or inability to leave abusive relationships on a permanent basis. For those that have made the actual separation, next steps can feel very daunting. Integration of services could also assist the client in building on their strengths, personal value, and sense of self-efficacy, contributing to the choices they make in moving forward with their lives - more aware of themselves and the impacts of the society they live in (Miles \& True, 2003; Miles, 2003).

It is for this reason that Miles incorporated first degree training for healthcare patients, their caregivers, and their families in the reiki programs that she created and 
established in several New York hospitals (Miles, 2003). Miles states her belief that empowering patients with this simple tool can not only address anxiety, pain, and medical treatment outcomes, but it can also impact the quality of interaction with the care-provider, which is integral to the patient's receptivity and perception of treatment (Miles, 2003). In addition to these benefits, the client's ability to play an active role in meeting their healthcare needs would also enhance overall well-being and selfdetermination, which are important goals of both reiki and social work practice. Practitioners also discussed the provision of other techniques such as meditation for the client to work on for themselves. Ellen always teaches meditation to help clients quiet themselves and always provides techniques for them to take home. "Once people can do self-treatment, it's so beneficial". Corroborating this, Anne finds incorporating reiki empowering as with reiki "you can give the tools to someone to use for their own healing".

Frank also confirmed the benefit of empowerment that is enhanced by combining reiki and social work:

Whether it's somebody who wants to learn themselves, for their own healing, and they don't have to rely on anyone else; or if it's just giving that other strong spiritual view. It can be another whole piece that nobody's ever thought about in their life. And then they can change their whole life because of it.

Frank's comment about people being able to change their life with regards to taking on their own healing, particularly through learning to do reiki themselves, touches upon the relevance of thought patterns that dictate one's relationship to the world. The way we perceive reality includes our beliefs about our position in the world and our ability to make changes (Kabat Zinn, 1990). Changing these beliefs can have life altering effects 
which would definitely be of benefit in the context of struggles with anxiety and physical and emotional health issues. Being able to alter self-limiting thought patterns and beliefs has profound implications.

Based on the interviews with the practitioners in this study, there is a natural fit between the practices of reiki and social work. When used together, they facilitate selfrealization, self-determination, and empowerment of the client to move forward to address problematic issues experienced in the areas of mental, emotional, spiritual, and physical health. Addressing such issues has a relevant and beneficial place in the healthcare system, especially if this can be facilitated by non-medical professionals such as social workers. Expanding on this concept, benefits of increased self-awareness and enhanced spiritual connection could allow for the development of an internal framework that can be drawn from to resolve problems (Walsh, 1999). With this type of framework, problems could be resolved in a manner that reduces feelings of powerlessness, encouraging more reliance on inner resources and likely less reliance on services in the healthcare system as these measures move into more of a health maintenance and prevention of illness mode.

\section{Conclusion}

Overall, the benefits of integration of reiki and social work reported by the practitioners are reflective of goals in the healthcare system such as relief of physical pain and mental distress, stress reduction, clarity, and increased receptivity with respect to treatment interventions. The ultimate difference between social work practice with or 
without the integration of reiki therapy is the element of physical and mental relaxation facilitated through the channeling of energy involved in the healing process. The other key factor involves the commitment and active participation of the client to healing, highlighting practice goals that connect both reiki and social work and ultimately benefitting the healthcare system with respect to enhancing service provision and addressing concerns about the ability to meet the increasing healthcare needs of the public. While benefits of reiki therapy are important to consider for the argument towards incorporation of reiki and social work practice within the healthcare system, one cannot ignore the possibility of dangers or risks involved with reiki that would lend to the inappropriateness such of incorporation. There are also other factors to consider with regards to barriers that would impede or prevent any incorporation of the two practices within the healthcare system to occur. The following chapter will address information regarding risks of reiki and barriers to incorporation as obtained from the perspectives and experiences of the people interviewed and from the literature reviewed for this study. 


\section{Chapter 4: Barriers to Integration}

In this chapter I will explore the six main barriers to integration that were raised and discussed by practitioners in their interviews. These include financial, cultural, and administrative barriers. Following this I will explore the barriers to integration raised by organizational representatives and discuss their responses in relation to that of the practitioners' concerns. I will also discuss the overall impact of such responses to the question of possibilities and risks involved with the integration of social work and reiki in the healthcare system.

None of the practitioners interviewed saw reiki therapy as harmful or as presenting danger to clients, so they did not see any risks of harm involved with the integration of reiki and social work practice. In response to concerns from medical professionals about the possibility of harm involved with reiki, Miles (2003) explains that these fears stem from a Western mind-set that reflects dualistic thinking about a help/harm dichotomy. She identifies that reiki is not a medical intervention and has no contraindications due to the fact that the body is not manipulated, therefore it does not fulfill the dichotomy of having the power to harm in order to be able to help.

None of the practitioners argued against the merits of social work as an established field of practice. Barriers to integration mainly revolved around barriers with respect to how perceptions of and responses to reiki practice might negatively impact social work practice if integration were to occur. Interview responses clearly fell into themes regarding types of barriers. Discussions about barriers were easily organized into the following themes: 
1. Lack of Standardization of Reiki Training and Issues of Credibility

2. Money/ Financial Costs of Reiki

3. Lack of Awareness and Scientific Research about Reiki

4. Western Mind-Set

5. The Issue of Touch

\section{Lack of Standardization of Reiki Training and Issues of Credibility}

The concerns that the participants in this study raised about the quality of reiki services focused on the lack of standardized practitioner training. They saw this lack of standardization as resulting in practitioners having varying degrees of depth or ability to assist clients with processing any emotional issues that might surface during a session. The following quote by Anne provides an example of how this problem can affect clients:

I had a client who commented that he came to me because he trusted me as a professional. He commented on being skeptical about reiki because he has seen a range of reiki practitioners offering reiki services and described that many people are drawn to reiki and desire to be a practitioner to help others without having dealt with their own issues first. They may take a weekend course and think they are masters of reiki/reiki professionals.

The concern this client has with reiki practice speaks to the failure to design practitioner training that consistently ensures that those trained in reiki have engaged in serious selfreflection and have done some self healing before they begin to work with clients. In addition, it reminds us of the importance of ensuring that practitioners do ongoing work to maintain boundaries between their practice and their personal experiences. This type of self-reflection and boundary maintenance is a significant component of social work education (Hancock, 1997). 
Miles (2003) also discusses the dangers that emerge when reiki practitioners do not receive sufficient training. In particular, she worries about practitioners who hope to "fix" or cure clients. Miles sees this as a problem because this need to fix becomes the focus, as opposed to the healing process which includes respect of the client's needs and their ability to contribute to their own healing. Similar to social workers and psychotherapists, there is a need for the professional to take the time to heal their own issues and achieve balance so that appropriate boundaries are maintained between practitioner and client (Miles, 2003). As noted in the previous chapter, participants discussed not only the importance of self-awareness and clarity for both practitioner and client, but also the value of empowerment.

In addition to concerns about standardization, participants also worried about credibility. Participants linked the issue of credibility to research, which relied upon scientific evidence of outcomes for there to be acceptance by mainstream professionals. Practitioners in this study discussed the need for other professionals, particularly those in the medical community, to experience reiki in order to facilitate acceptance of integration and also lend more credibility to the practice. Ellen discussed wanting to see more integration of services, particularly with social work, in a manner that enhances rather than detracts from credibility:

I would like to see more social workers doing reiki. [I] would like to see more credible reiki too as a lot of people mix it with "New Agey" stuff, I'm not against it but I have seen too many "flakes" they get perceived as "weird" vs. professional.

Here, Ellen raised concerns over the lack of standardization and credibility. Although she discussed not having a personal bias against New Age theories and techniques, Ellen's statement was reflective of the societal stigma around the New Age movement. The New 
Age movement brought advantages such as the opening of Western doors to the concept of holistic healing (Canda and Furman, 1999). However, New Age thinking also conveyed the concept of naïve acceptance of metaphysical laws that have not been "proven" in the Western world. This naïve acceptance included some beliefs and practices that fall outside of the traditional Eastern practices and beliefs which are becoming more palatable in the Western world (Taylor, 1992). Despite the fact that traditional Eastern practices are becoming more acceptable, current Western societal reservations are likely affected by the generalization of Eastern world practices as being New Age.

In the following quote, Beth outlined the steps that she feels would have to be taken to establish reiki as a credible intervention:

I think that it [reiki] should be taught, and I think that it has to be shown as a course that can be taught at college or universities, and you could say you had a diploma in reiki, or whatever it would be called, certified, that you're certified in reiki, would be big. But I think that, mind you, the schools of massage aren't going through universities or colleges themselves, it's just a program right on it's own. I think that most medical doctors think that what we're [reiki practitioners] doing is, voodoo is a strong word, but you know, but we're not far off from voodoo.

Beth draws upon fairly traditional ideas about education and the value of teaching reiki through respected educational institutions. Clearly, such a shift in training would help address problems of credibility and standardization. At the same time, such an integration is likely to mean a reframing of reiki in terms of Western models of service provision. The problem with this is that it extends the risk of extinguishing the original principles and practices of the Eastern roots of reiki practice, some of which have already been lost in the splintering of the practice that occurred in the process of introducing reiki to the 
Western world (Miles, 2003; Miles and True, 2003; Lubeck, Petter and Rand, 2003). It also runs the risk of limiting the spiritual and individualized nature of reiki therapy, affecting the level of intimacy in the client-practitioner relationship, and of containing the value placed on the intuitive knowledge of both client and practitioner (Lubeck, Petter and Rand, 2003; Kelner, Boon, Wellman \& Welsh, 2002).

Given the established education programs and practice standards in the field of social work, the issue of lack of standardization in reiki with respect to both education and practice would have to be addressed to ensure that not only the standards of social work practices are maintained, but that reiki is viewed as a valid, credible, and safe tool to use in social work practice. The tension between integrating a practice that has a rather tenuous hold on Western professional credibility, with one that is outside of this system of credibility remains a significant barrier to integration. The vulnerability of social work in itself makes it likely that social workers will experience some anxiety that such integration will push them further to the margins and possibly threaten their hard won place within the healthcare system.

\section{Money/Financial Costs of Reiki}

All practitioners interviewed in this study acknowledged the impact of having to pay out of pocket for reiki therapy as presenting a barrier to integration. One of the most significant barriers to integration that was raised by practitioners in this study was the cost of reiki services. Such costs make it unlikely that reiki will be accessible for people who are economically marginalized. Given that people dealing with economic constraints are the primary group of people who engage with social work, this is a significant barrier to integration. As a result, reiki practice has become a service for people with mid to high 
range incomes. Here, Beth speaks of the problem of paying for reiki treatment and some of the ways she has worked to try to decrease costs:

Do you know what's also probably another barrier is the finances of it [reiki]. I mean, I know that a lot of people couldn't necessarily afford an hourly rate because it's not covered by OHIP. I've ended up looking at various alternative methods. [Reiki is] an expensive thing to think of doing, if you want to do [it] even once a week, and I don't know what the charge is, $\$ 45-\$ 50$ for a treatment, it's expensive....massage is covered, you know by some people's health plans, but reiki would take a lot, I would think before OHIP would cover anything like that, or even a portion of it, or before some office would cover that in their health plans.

Beth noted the particular problems raised by the lack of Ontario Health Insurance Plan (OHIP) subsidies provided for CAM therapies. Kelner, Wellman, Boon and Welsh (2004b) have done an extensive review of healthcare funding priorities and allocations. It is noted that current government personnel and healthcare leaders continue to insist on scientific evidence to demonstrate the safety and efficacy of CAM therapies before such services could be incorporated into and funded through the mainstream healthcare system (Kelner, Wellman, Boon and Welsh, 2004a; Kelner et al., 2004b; Coburn, Rappolt, and Bourgeault, 1997; Coburn, Torrance, Kaufert, 1983; http://www.hcsc.gc.ca/healthcare/cahc/index.html). The problem with such a demand is that the nature of reiki therapy is based on Eastern beliefs and practices that are philosophical and spiritual in nature, and thus not easily measurable within the context of the scientific principles that are valued in the West (Miles, 2003; Miles and True, 2003; Kelner, Wellman, Boon and Welsh, 2004 a). In part, Kelner, Wellman, Boon and Welsh (2004 a; 2004 b) see the problem of funding CAM services as also linked to competition for healthcare dollars and a fear of expanding the healthcare system given rising costs. This pressure against integration is offset by public pressure for CAM services (Kelner et al., 
$2004 \mathrm{~b}$ ). When considering the responses of practitioners in this study, it is clear that the feasibility of integrating reiki with social work depends largely upon various levels of government funding CAM therapies.

While it remains clear that the cost of reiki services is a barrier to integration, a number of practitioners discussed a variety of strategies they used to help moderate costs, suggesting that there are possibilities of negotiating this particular barrier to integration.

As Dan stated:

I think, well, I have volunteered [in social services] where [reiki] it's free, and I have repeat clients [in my own practice] and there's a donation but so in those cases I think people who can have it for free, they may never have gotten it, what would the barrier be there? I think it would be what prevented them from coming forward...I think, not knowing what it is, and probably that as well for people who are donating something, materials, not knowing what [reiki] it is and also maybe a financial barrier to ... What I do is I encourage people to come forward four weeks in a row...and there's a reduction if you do, I find it is more useful and beneficial if they come regularly for a period. A lot of times I'll just offer it for free.

In this quote, Dan described the possibilities for providing services free of charge or for a significantly reduced fee. Despite these innovative practices, it is clear that until both CAM and social work practices are fully funded by the state, the possibility of integration would only be available for people with some disposable income.

\section{Lack of Awareness and Scientific Research about Reiki}

Another key barrier to integration is the lack of awareness and scientific research into the effectiveness of reiki. While most people know about social work services, few are aware of what reiki involves or the possible benefits one might secure through reiki. As Anne noted: 
There's not enough education out there for people to even know about reiki. Most of the time I talk to people about reiki and they've never even heard of it- I don't think it is well known yet. Some of my cancer clients were introduced to reiki in the hospital, not sure which hospital, but it's in Ottawa- possibly one that deals particularly with cancer.

Reiki has been identified in the literature as one of the most unconventional and least well known therapies within CAM (Kelner and Wellman, 1997; Kelner, Boon, Wellman and Welsh, 2002). While some of Anne's clients did know about reiki, she didn't think that this was representative of the general public. In an interview about reiki therapy, Pamela Miles (2003) explains that the teaching of reiki is passed down from person to person by way of an attunement process that cannot be obtained on one's own or by reading a book. She also states that in the transition of reiki therapy from East to West, the teaching and practice of reiki became splintered as people offered varying interpretations, or "hybridization", of the original teachings. Miles described that "Westerners changed the practice without ever having done the practice" (2003, p. 78). Although she does not explicitly make the connection, it is highly likely that the exclusive tradition of learning the practice of reiki, combined with the splintering and hybridization of reiki teaching and practice that has occurred, has contributed to the fact that the therapy is not very well known among the general population. In the process of this splintering and hybridization, reiki practice became even more individualized, resulting in a broad dissemination of practices that come from similar roots but have been changed to the point of being viewed as separate practices altogether, making traditional reiki practitioners seem like a smaller and possibly more exclusive group.

Cynthia, another of the study's participants, had a more optimistic view of public education about Reiki: 
There's a lot of consciousness- raising that needs to happen that comes along with some yoga and breathing meditation. I think that the yoga movement that is pretty strong right now is opening the doors for a lot of other practices to become more accepted. Whether or not you'd call them relaxation techniques or meditation in that way, the doors are slowly opening.

Cynthia suggested that the popularity of the yoga movement and the Eastern concepts of health and holistic healing may increase people's awareness of reiki. However, she also noted that general awareness and acceptance will require a transition in how we establish clinical validity and credibility:

Well, probably, I would have to imagine, the College, and the associations will start to come out with reiki statements or clarification or defining terms and the way that reiki is defined, that is the first thing. Depending on how reiki is defined and explained because reiki is a threat to scientific methodology, it's a threat to theological methodology, and to our lifestyle...just in terms of the connotations of that word, so as a community we need to find ways that are quick and simple in defining what reiki is that doesn't threaten any of those methodologies. I'm always laughing with somebody that when somebody asks what reiki is I do a quick assessment of, ok should I give them the scientific version or ...... what is going to work best because you only have that moment and those first impressions are very important and people form their ideas pretty quickly on that stuff.

Cynthia's statement about reiki being a threat to scientific methodology is corroborated by Kelner, Wellman, Boon and Welsh (2004a) who discuss the response by medical healthcare leaders to the professionalism of CAM as defensive. Kelner et al. (2004 a) state that the emergence and growing popularity of CAM therapies such as reiki threaten the authority and primary status of medical professionals in the healthcare system, who do not wish to have to compete for funding for medical-based research and education. Despite the fact that there are medical interventions which have not satisfied the "gold 
standard" of evidence-based medical practice, this established standard of science and medicine and demand for scientific research may also act as a barrier against general education and accessibility to alternative therapies such as reiki (Kelner, Wellman, Boon \& Welsh, 2004a; Straus \& McAlister, 2000; Kelner and Wellman, 1997, Hirshkorn and Bourgeault, 2007; http://www.hc-sc.gc.ca/healthcare/cahc/index.html). Kelner, Wellman, Boon and Welsh (2004 a) propose that the demand for scientific research is a strategy by medical professionals to contain the acceptance and integration of CAM into the healthcare system. This conclusion reflects one of the critiques about evidence-based medical practice with regards to placing economic boundaries on research and restricting the clinical autonomy of clinicians even within the medical model (Coborn, Rappolt \& Bourgeault, 1997). In accordance with this demand to meet the standards of evidencebased medical practice, most of the study's participants stated that in order for integration to occur they felt there needed to be more scientific research into the effectiveness of reiki. They stated that the credibility of reiki as a valid form of healing therapy and as a profession is negatively impacted by this lack of scientific research regarding the benefits of the therapy.

Frank raised concerns that until reiki is found to have some scientifically-proven benefits, integration may actually pose a threat to social work, which is already precariously situated in the health care setting:

Well I think there is still a very old-school type of thought with social work. First of all, we're trying to have social work become a profession. You know, where it's sort of recognized, so now we're stepping up with that, with registering to make it more important. I think it [integration] is [possible], but it has to be in a realm where people are aware of it, because the barrier that presents with reiki is that a lot of people don't know much about it. So it's something hidden. Like it's this art, or this new, spiritual type of healing that 
nobody knows about. So until mainstream society starts to understand that and the true effects. Almost like it needs to be scientifically accepted too, in a different type of way, but I mean, that's the only way, and then suddenly people would truly accept it, although it's hard to prove in a sense.

Frank makes visible the almost impossible bind that reiki finds itself in. Scientific evidence is needed to provide credibility and acceptance, but the very nature of reiki defies scientific quantification. Miles and True (2003) challenge that the Western requirement of evidence to confirm the success of alternative therapy as either true or false precludes any validity of Eastern beliefs and "requires the abandonment of scientific knowledge" (p. 65). They argue that this view effectively shuts down "all inquiry before it begins" (2003, p. 65). While not completely excluding the possibility of quantitative research about reiki, Miles and True (2003) also discuss the value that qualitative studies add to promoting a better understanding of, and credibility in, reiki practice. In addition to this, Miles cites that a small number of studies that have been conducted about reiki and other energy healing modalities with the use of randomized control studies, exploratory studies of physiological changes, and descriptive and phenomenological studies (Miles \& True, 2003), demonstrating the possibilities of scientific or evidencebased research as well as qualitative research.

Additional critiques of the evidence-based approach within the medical model include the practical limitations of time and resources for clinicians who have to meet the increasing needs and high demand for healthcare services and the dehumanizing effect of randomized control studies that exclude meaningful and narrative information about individual patients' stories (Straus \& McAlister, 2000; Mykhalovskiy \& Weir, 2004; Tataryn \& Verhoef, 2001). This exclusion of rich, contextual information conflicts with 
the holistic approach to knowledge and practice inherent in CAM (Kelner, Wellman, Boon \& Welsh, 2004a; Tataryn \& Verhoef, 2001) which would not benefit the type of information that would be considered valuable to both reiki and social work practice.

Adding to the dilemma about scientific research is the fact that there are reiki practitioners who do not feel the need to conduct scientific research to conform to Western medical expectations (Kelner, Boon, Wellman \& Welsh, 2002). The lack of standardization in reiki contributes to a division between those practitioners who wish to professionalize and who acknowledge the need for scientific research and those who wish to remain in private practice, separate from the Western world of science. The proscience stance reflects a Western world view that conflicts with an Eastern approach due to significant paradigmatic differences regarding how life, functionality, illness, and healing are viewed. Unfortunately, the issue of science validating credibility within the healthcare system and on a professional basis also extends to and influences the perception of the general public regarding the legitimacy of alternative therapies such as reiki.

Similar to the view of reiki as non-quantifiable and as lacking in scientific research, the profession of social work, with its emphasis on understanding the humanities, is seen as a "soft science" (Neuman and Kreuger, 2006). This categorization has impacted the view of social work as a valid, well-researched profession in Western society where the understanding of science is related to physics, chemistry, and biology. Trying to combine this with alternative therapies such as reiki that operate from a different paradigm adds to the struggle of professions such as social work to enhance and 
maintain a credible status within a society operating from a science-based, medical model.

Ellen discussed her opinion of the need for more research to validate the relevance of reiki practice as having a "place" in western society:

I would like to see research that dispels the myth that reiki is voodoo and that would highlight the utility of blending fields. I believe there is a place for reiki, as it becomes more researched, if more medical people become aware of it.

In this quote, Ellen draws attention to the spiritual aspect of reiki that can be stigmatized as New Age or "flaky" in mainstream North American society. As much as practices such as yoga or meditation have increased in popularity and have opened the door a bit to alternative therapies, there remains a stigma attached to concepts perceived as New Age versus Eastern (Taylor, 1992). Interview responses from established healthcare leaders in a study by Kelner, Wellman, Boon and Welsh (2004 a) suggest that this stigma is particularly apparent amongst a number of professionals in the medical community. This forms an obvious barrier in terms of allowing for integration to occur in the healthcare system. Again, we see that any integration of social work and reiki in the health care system would require acceptance of reiki by the general medical community.

\section{Western Mind-Set}

The paradigm differences between East and West that contribute to the resistance of professionalization of CAM therapies such as reiki into the healthcare system present a barrier to integration. Practitioners involved in this study described a conservativism in Western mainstream services, including the field of social work, that they felt prevented the integration of reiki and social work practice. Studies exploring the possibility of 
incorporating CAM therapies such as reiki into the Western healthcare system identify that tensions around the East-West dichotomy play a significant role in barriers to such incorporation (Kelner et al., 2004 a; 2004 b). As we can see from Cynthia's quote in the previous section, reiki is a threat to both scientific and theological methodologies that predominate in the West. Standards in Western society have been shaped and established through both religion and science but it has been the world of science that has supported and maintained medicine as the predominant method of healthcare in North America (Kelner, Wellman, Boon and Welsh, 2004 a). The following quote by Dan illustrates his immediate response to the question of whether or not he incorporates reiki into social work practice:

No, you mean in my day job? I wasn't hired as a complementary therapist and I don't think it would be looked upon well because my role or job description hasn't got anything to do with complementary therapy so it's like a whole other mind-set, that's why it has to be something that I would do on my own and you have to have clients coming to you, you really just have to put up a shingle and say what it is, I'm not saying that it wouldn't help people, in the day-time job. I think the mind-set is that social work practice is confined to talking with people and counselling them and maybe helping them out with material problems and that whole thing, it doesn't include any other forms which could be beneficial, which include complementary therapies, that's what people need.

Dan identified his current social work position as entirely different and separate from the world of alternative and complementary therapies. This highlights the scientific and theological roots of the values and standards that Western social services are built from. He distinguished this entirely from complementary therapies and the benefits one can receive from them. Reiki can not provide material supports, while mainstream social workers have not typically been encouraged in their training to attend to a person's 
spiritual needs, or the interconnection between mind, body, and spirit (Canda \& Furman, 1999). It seems that an integration of the two practices in this context would be of maximum benefit to clients in terms of meeting their needs for overall functioning and well being. Dan was clear that, despite differences and barriers to integration of reiki in mainstream social work practice, he felt that integration would be both helpful and needed.

The paradigmatic barrier that Dan described was also observed by Anne who articulated it as "cultural" or linguistic barriers to integration:

I feel there's somewhat of a cultural barrier with regards to seeing something like "energy therapy" intervention as useful when there's not enough knowledge of this concept in mainstream Western Society, for example, acupuncture has only recently been accepted into mainstream. How do you find the right or acceptable language and get around the taboo?

Without a language to speak about practices such as reiki, Anne sees the possibility of integration as limited. Language is a key marker of the paradigms through which we make sense of the world. The discomfort with the notion of "energy therapy" speaks to the impossibility of such an idea within Western healthcare models. Kelner, Wellman, Boon and Welsh (2004a) describe that, in the healthcare system, stakeholders are skeptical of CAM therapies given that their origins and basis for practice falls outside of the Western medical model. As a field of practice, social work would have to decide upon a position with respect to the use of reiki therapy and its impacts in light of the apparent paradigm clash in mainstream society. Social workers integrating reiki and social work practice would have to demonstrate an acknowledgement of and comfort level with reiki therapy as well as the spiritual and healthcare beliefs of their clients.

Cynthia felt that the linguistic barrier to reiki had regional variations: 
I've only been in Ottawa for a couple years, so I'm coming from a different place, so in B.C. it's not a problem at all right, so I think I'm coming in with that confidence but I also really appreciate the process of being careful about using words like "energy" and "healing", but the more I use it, the more I find people are receptive to it. It's more my own barriers and my own concerns about how people are going to feel about it.

In this quote we see the ways in which messages about what language is possible or appropriate in a community is structured through subtle interactions. This type of embedded and ubiquitous response to alternative therapies tends to run quite deep in a culture and, as Cynthia said, will take time to evolve and transform. What is interesting in this quote is that Cynthia expresses the pressure she feels to break these norms. This type of burden can, in itself be a barrier to integration. Reiki therapists are expected to take risks in terms of negative social reactions in order to secure social acceptance for their work. However, the integration of more structural approaches to perceiving problems may be helpful for reiki providers who can instead reframe the problem in terms of social organization and values and develop more of a political approach to challenging the barriers to integration. The challenge to find the right language to speak about reiki is not only important at the level of creating the necessary social policy to facilitate integration, but also to facilitate effective practice (for example, increasing client comfort and reducing the power differential between client and practitioner) and the comfort of other health care professionals.

\section{The Issue of Touch}

One of the issues of concern that are predominant in the fields of psychology and social work is the use of touch in practice (Stenzel \& Rupert, 2004). Generally the use of touch is viewed in Western therapeutic practice as inappropriate (Tune, 2001; Maidment, 
2006; Pinson, 2002). However the issue of touch in practice, despite the above view, is not always so clear-cut for social workers. The following statement by Cynthia exemplifies the tensions felt by many social workers and counselors with regards to the use of touch in a therapeutic manner:

About the fact that the field of helping is far away from touching, it's hard because I can be in this sort of environment and someone can just let it all out and I want to touch, I want to hug I want to console, and I can't, I really can't for many reasons that are listed, and ones that are fear-based and institutionalized and that kind of stuff. But on the flip side of that, that's ok because people need to have that permission before they sort of feel that and I'm very conscious of that.

Cynthia also raised the point that fears about touch in Western society limits the extent of a genuine and compassionate response by the social worker towards the client. Pinson (2002) discusses that the predominant view of touch in psychoanalytic therapy as inappropriate and possibly harmful is due to the recognition of the power and sexual connotation that touch conveys in Western society. Literature reviewed for this study indicates that therapists who use supportive touch with their clients believe that longings for touch do not necessarily have to be driven by sexual desire, rather may also reflect a need for attachment, self-calming and regulation of excitement (Tune, 2001; Maidment, 2006; Pinson, 2002). Arguments promoting the use of touch describe benefits such as the provision of comfort and a feeling of safety for individuals who have experienced trauma, a sense of connectedness, opens the door to further exploration of issues, and assists a client to integrate parts of themselves that were previously alienated (Pinson, 2002; Horton, Clance, Stark-Elifson \& Enshoff, 1995). Horton et al. (1995) discuss that patients tended to view touch in therapy as positive when feeling that emotional and physical 
intimacy proceeded appropriately and congruently and when they were able to stipulate boundaries with their therapist around touch.

Given the taboo around touch in Western society and the nature of touch involved and associated with reiki therapy, I anticipated that this issue would be raised as a barrier to integration. Surprisingly, the issue of touch was not explicitly raised by the practitioners during the interviews, as such, I probed the issue with more direct questions.

In response to my probing, the participants in this study did not see touching in reiki as a barrier to integrating reiki and social work practice unless the integrated service was to be used in a position that was authoritative, such as work with children or with people who are vulnerable as a result of abuse. For example, Dan explained:

Touch as a barrier? It could be yeah, I think reiki could help children too but I'd always want the parents to be sitting there because there's so much concern about abuse. Every time I have a new client I always make sure they know that there's no touching of private parts [during treatments].

Here the contemporary anxiety of the sexual abuse of children raises its head as a barrier to integration. In a world where the sexual abuse of minors in the hands of professionals is regularly projected across our newspapers and televisions, it seems unlikely that parents or practitioners will be comfortable having children work with a professional whose job involves touching them. With regards to ethical concerns, the controversy of touch centers around the potential for harm and exploitation, particularly if the touch could be misinterpreted as a sexual overture or that the physical contact would blur the boundaries between therapist and client, leading to sexual activity (Pinson, 2002; Stenzel and Rupert, 2004). It is clearly stated in the social work code of ethics that there is to be no sexual contact or related inappropriate activity between the social worker and the 
client, including any inappropriate conduct on the part of the social worker. Such boundaries would ensure a management of the power differential between the practitioner and client, as well as ensure that the client is respected throughout the therapeutic process.

As such, the issue of touch in reiki therapy would need to be addressed with the same boundaries, given the fact that a reiki session usually involves the client lying on a reiki table, and the practitioner providing reiki through light touch. Prohibition against sexual or inappropriate touch during reiki therapy is explicitly stated in the CRA code of ethics. Lack of adherence to this standard results in the loss of licensing as provided by the Canadian Reiki Association. Unfortunately one does not need to be licensed with the Canadian Reiki Association, or any other institution of reiki professionals, to practice or teach reiki. The fact that this safety factor cannot be ensured with regards to reiki practice is an issue that will need to be addressed in order for any integration to occur with social work practice, particularly in the healthcare system.

Beth discussed her work with abused women in a shelter and how she mitigates the potential concern about touch during reiki by being conscious about the potential impact of touch to abused women, and by offering healing via hands over the body but not touching the body:

The women that are in the shelters, we [reiki practitioners] have experiences where they are apprehensive because, maybe some of it is their religious beliefs to what we're doing. If they, I think at least the counselors would have the [knowledge], they may be aware of therapeutic touch, or they're open, they're definitely open to it. I don't know if it's necessarily [an issue about] education, because I know some educated people I've spoken to, it doesn't matter so much about education, as much as some of them are a little overwhelmed. They're in an overwhelming situation already because they're in that shelter. And when we introduce it to them, we try not 
to present any of the overall theories behind reiki and this universal energy coming in. I think that's maybe too much. It's just that it's a relaxation technique and we're not trying to do anything here that is, you know, we'll only touch a part of your body if you're comfortable with that. Otherwise, our hands can be much higher up, because you can imagine if they've come from an abusive situation, we can't just assume they mind the touch.

Here Beth mitigates anxiety about touch by adapting her practice and her introduction to reiki treatments. Beth also raised the importance of advising the client about touch prior to the session and giving the client a chance to respond and set limits regarding the extent of touch involved. This allows for the empowerment of clients during therapy.

Pinson (2002) and Maidment (2006) in their respective studies, discuss the use of touch in the treatment of patients who have experienced a history of sexual abuse, sexual problems, or fears and phobias around sex. Clinicians who work with sexually abused clients have to be especially sensitive to boundary issues and readiness for touch with these patients, however these patients also appear to particularly need and are helped by touch. Literature suggests that this may be due to the fact that touch helps these patients to trust, build self-esteem, and feel empowered in setting limits and asking for what they need (Lawry, 1998; Pinson, 2002). As well, it may be that touch frees the adult survivor of sexual abuse from fear and shame and helps them to be able to receive nurturing and affection.

Ellen also articulated the healing or therapeutic impact of touch as being lost in mainstream helping systems such as counselling or social work. She described that when given the choice, clients, including survivors, choose touch:

I do not feel that touch is a barrier - I offer non-touching but clients all like the touch, including the survivors- they loved it in the hospital. People want to be touched, with all the stuff that we're going through, nobody touches us in a good way anymore. 
Again we see confirmation of the fact that touch can be viewed as positive, nurturing and healing which can be quite effective in enhancing a therapeutic rapport and trusting relationship between a practitioner and client. Ellen's statement links back to literature confirming that sexual abuse survivors can be positively impacted by the use of appropriate touch in therapy. Current mainstream fears around touch may have acted to obscure this helpful information. Integration of social work and reiki could help to highlight the benefits of touch and promote additional research. Such research could be used to further clarify boundaries around appropriate versus inappropriate touch and to achieve a balance between enhancing therapeutic rapport and reducing the power differential between client and practitioner.

\section{Conclusion}

As discussed previously, there are several layers of barriers to the integration of CAM therapies such as reiki with social work practice in the healthcare system. Barriers observed by practitioners in this study regarding the integration of reiki and social work included: financial costs of reiki, lack of awareness and scientific research about reiki, a Western mind-set (reflecting an East vs. West dichotomy), lack of standardization in reiki training and related issues of credibility, and the use of touch with regards to mainstream social work practice.

The main issues of concern are the current lack of standardization in reiki training and practice, and the credibility of reiki as a valid form of healthcare or therapy. These issues become complicated in light of the paradigmatic tensions in the West about Eastern-based therapies. Lack of standardization of training and practice in reiki 
contribute to concerns in Western society because of the individual differences in the competence and service provision of reiki practitioners. Stemming from the abovementioned lack of standardization are concerns about a lack of accountability in terms of ensuring that ethical standards are adhered to in reiki practice. This is particularly important to both fields of social work and healthcare in the context of the use of touch and respect of the power differential between therapist and client. Although arguments were made about the benefits of the use of appropriate touch in therapy, it is clear, in light of concerns about lack of standardization and the need to ensure the safety of clients that additional efforts to standardize reiki training and practice need to be continued by such agencies as the Canadian Reiki Association. Consultation with mainstream services such as social work could also be beneficial in order to establish boundaries required for facilitating integration of reiki services into both social work practice in general and in the healthcare system. However, such efforts could place limits on the individualized and intimate nature of the healing process involved with both reiki and social work practice. Other concerns include the possibility of increased tension between medical professionals and social workers in the healthcare system who could become further marginalized due to the association with reiki therapy. Alternatively, there is a risk to the field of reiki that reiki therapy could be assimilated into a more Westernized and scientific approach and practice. In addition, there is the possibility that more limits and boundaries would be placed around the use of touch and intuitive knowledge in therapy, limiting both the potential for an increased therapeutic rapport between practitioner and client and a respect for the self-determination of the client. Furthermore, issues of funding and decision-making would have to be resolved which would affect the balance of power and 
the construction of policies and processes around the provision of integrated reiki and social work services in the healthcare system.

Despite the fact that reiki was not considered dangerous or harmful by either practitioners or organizational representatives interviewed for this study, a significant barrier is still present with respect to societal and mainstream professional reservations around Eastern-based practices and the demands of the medical community for scientific research to prove the safety and efficacy of reiki therapy. This barrier also includes the need to conduct this research in order to meet approval standards of the government to ensure the safety of the public. Until a paradigm shift occurs with respect to the EastWest dichotomy and power imbalances within the healthcare system, the possibility of integration of reiki in the healthcare system, and thus reiki with social work in the healthcare system, will remain in limbo with some acknowledgement given to the statement that reiki is not harmful, but no official position regarding the safety of reiki in order to permit any type of integration to occur. Further research in this area is definitely needed in order to satisfy concerns regarding safety and to maintain ethical standards in the context of integrating the practice of reiki with other fields such as social work and the healthcare system. To address the dilemma around the difficulty of meeting demands for scientific research, future research may need to be focused on obtaining quantitative data through single-subject research design, mixed-methodological studies, and on generating a number of qualitative studies including long-term studies that measure the perspectives of clients on differences in their emotional and physical health before and after reiki and integrated reiki and social work sessions. Other studies that would be of benefit would include those that provide further exploration of the cost-effectiveness of 
reiki therapy as part of a person's healthcare regime versus a regime of solely conventional medicine. 


\section{Chapter 5: Conclusions Regarding Integration}

The purpose of this project was to explore the perspectives of individuals in Ottawa with both reiki and social work credentials regarding the benefits, risks, and barriers involved with the integration of reiki therapy and social work practice in the healthcare system. An organizational representative from each, The College of Social Workers and Social Service Workers, The Canadian Reiki Association and The Ontario Health Department respectively, was also approached to obtain perspectives regarding any benefits, risks, and barriers involved with integration in order to provide an organizational context to the responses of the above-mentioned practitioners interviewed for this study. This type of research is relevant at this time due to the increasing popularity of complementary and alternative services (CAM) that are offered outside of the mainstream healthcare system. This trend in CAM use raises questions as to the effectiveness of current mainstream healthcare and social services offered in Western society to address both the physical, emotional, mental, and spiritual health needs of the general public and the need to explore possibilities to enhance mainstream services.

While this thesis does not directly address many of the concerns of structural social work, I would argue that it does fit within the Carleton School of Social Work's frame of reference because it begins to open new directions for structural social work research. Some particularly relevant ideas are those concerned with people's views about the accessibility of particular healthcare and social work services, as well as the exploration of societal, economic, and systemic barriers to people receiving reiki. Future studies stemming from this research could provide a more in-depth analysis of these 
barriers and recommendations for change that may need to occur to better ensure that people's needs are met in an equitable manner.

My interest in pursuing this area as a topic for study pertains to my education, practice experience, and observations made in both fields of social work and reiki practice, namely regarding any parallels between the two fields and the prospect of better service provision in social services and the healthcare system. Being a graduate student, an employee in the field social work, and a reiki practitioner contributed to the desire to research this topic. I believe in the aim to strive towards better service provision and believe that parallels between the benefits and goals of both reiki and social work practice warrant further exploration in this context. My experience and observations in both fields of practice contributed to my enthusiasm to embark on a project that could contribute to further exploration of integrating tools such as reiki therapy into social work practice within the healthcare system.

My position as both practitioner and researcher also contributed to my commitment to exploring possibilities for expanded social work practice and better service provision to meet client needs at a holistic level. However it is also important to note that, because of my experience in both fields of practice and position as the researcher for this study, it is possible that I may have presented or encouraged a bias towards the integration of reiki and social work practice. As well, in recognition of my own bias and the clear support of the practitioners with regards to integration, I asked probing questions regarding the possibility of barriers to integration in the effort to correct this bias, possibly creating another in that certain barriers may not have been 
identified in the study, or may have been reported by practitioners as benefits to integration (such as in the case of the issue of touch).

This research project is informed by a conceptual framework that consists of transpersonal theory, emphasizing the importance of spirituality to human well-being and functioning, and the Eastern philosophies of Taoism and Buddhism that underpin reiki practice and ground the concepts of holistic healing known to most CAM therapies. This framework is relevant in that the holistic approach to health and well-being has been identified in literature as being one of the major reasons why people are using CAM services versus conventional healthcare. The aspect of spirituality has been identified as largely missing from both fields of healthcare and social work practice (Cowley, 1999; Canda \& Furman, 1999), indicating the need to explore how integrating a practice that incorporates spirituality with social work could impact both the practices of social work and mainstream healthcare services.

Due to the abstract nature of reiki therapy, difficulties regarding the ability to obtain quantitative data and limited research about both reiki and the possibilities of incorporation with social work, it was decided that a qualitative, explorative approach was necessary in order to gather descriptive information, look for possible themes in information, and generate ideas for future research. The use of interviews to gather personal and professional perspectives of individuals who have education and experience in both fields was chosen in order to capture the stories and intimacies involved with providing reiki and social work services to individuals and to lend context to the perspectives regarding integration. 
Participants were obtained through use of advertisements placed in newsletters pertaining to the fields of reiki and social work. Community social service agencies were also contacted with the request to post the advertisement in their staff rooms. It was anticipated that participants would also be recruited through word of mouth referrals about the project to other potential participants, thus creating the type of recruitment known as snowball sampling.

Unfortunately, my efforts did not generate the number of participants that were initially aimed for, likely due to the short length of time that advertisements were posted. As well, there were difficulties with regards to obtaining participants with the specified credentials (ie: participants with counselling versus social work, and participants in Ottawa with both reiki and social work credentials). This resulted in the expanding of research parameters to allow for counselling and reiki credentials and to allow for the involvement of one individual outside of Ottawa who had both reiki and social work credentials. There were also difficulties in navigating systems of both the College and the Ontario Health Department to speak to a person about the possibility of participating in the project, and then to obtain their responses via telephone interviews due to the need for administrative approval to participate in the study and to time constraints. As a result, participants from the College and the Canadian Reiki Association sent their responses to interview questions via email, while the representative from the Ontario Health Department responded to interview questions over the telephone.

Participants discussed counselling as being the natural venue for incorporating reiki into social work due to its complementary nature with reiki therapy and emphasis on guiding clients in the areas of emotional, mental and spiritual healing. Practitioners 
described several benefits that they observed with regards to their experiences with both reiki and social work, or counseling, that would lend to the success of integration of the two practices in the health care system. Of particular relevance are the benefits of stress reduction, empowerment of clients, and the facilitation of client reception to therapeutic intervention. Other benefits included physical pain relief, relief of emotional trauma, increased mental clarity and self-awareness, and the encouragement of connecting to one's spirituality. These benefits were also supported in the literature on reiki practice reviewed for this study (Miles, 2003; Miles \& True, 2003; MacDermott \& Epstein, 2001; Wardell and Engebretson, 2001). Overall, practitioners reported that integrated services facilitate a holistic healing experience for both client and practitioner that enhances physical, mental, emotional, and spiritual health and well-being. They also stated that offering these services in the healthcare system would improve concerns around credibility and accessibility. However literature indicates that CAM practices have to meet the challenge from the medical professional community to prove that their services are safe and effective before there can be any integration of CAM services within the Canadian healthcare system (Kelner, Wellman, Boon \& Welsh, 2004a; Tataryn \& Verhoef, 2001).

Although there were no reported concerns of risk or danger that arose in our discussions of the integration of reiki and social work in the healthcare system, practitioners were concerned with the lack of standardization in the field of reiki. Practitioners reported that this lack of standardization contributed to varying levels of competency of reiki practitioners, particularly in the context of their ability to appropriately manage the emotional issues that can present for clients during a reiki 
session. This issue was raised in both the interviews and the literature reviewed for this study. The credibility of the field of reiki continues to be questioned by skeptics in the Western medical professional community. Although the issue of credibility of reiki therapy may be alleviated with association to the already established field of social work, one practitioner proposed that this could also be a barrier to integration at this time in light of social work's efforts to enhance credibility and regulation of standards within its own profession.

Surprisingly, practitioners did not initially discuss touch as an issue of concern or as a potential barrier to integrated practice until probed further. Even with further probing, the issue of touch was seen as a potential barrier by only some of the participants in the context of fears around touch in mainstream social work practice. Others maintained that mainstream practices are limited in that they do not allow for the healing potential of touch. Responses from the organizational representatives were similar to the practitioners in that there were no reports of concern that reiki therapy and thus integration of reiki and social work would be dangerous. However representatives from both the College of Social Workers and Social Service Workers, and the Ontario Health Department were careful to point out that issues of safety, adherence to ethical standards, and professional competence needed to be ensured if any such integration of reiki and social work were to occur in general or in the context of the healthcare system. Explanations for this position have been described in the literature as ranging from containment strategies from the medical professional community, to the influence of the government in terms of how funding is determined given concerns about rising costs in the healthcare system. Naturally, the representative from the Canadian Reiki Association 
was supportive of the integration of reiki into other fields of practice such as social work and particularly the healthcare system. The Canadian Reiki Association has been making efforts to establish increased standardization and structure regarding ethical and professional practice. There seems to be a general accordance between the three organizations regarding expectations around the need for professional competence and ethical standards to be in the provision of integrated service.

Societal and structural barriers to integration were described by practitioners in this study. Although an analysis of these barriers was not the focus of this study, addressing macro-level concerns and challenging the status quo of mainstream health and social services to reduce the barriers to integration that stem from barriers such as the East-West dichotomy fits with principles of structural social work theory in the context of identifying a resolution to mental, emotional, spiritual, and physical difficulties faced by people.

The participants in this project found reiki to be a natural complement to social work and are already incorporating the two practices to some extent on an individual basis, or in full or part-time practice as an adjunct to their full-time "day jobs" in the social work field. This view towards the benefits of integrated services is also supported in literature by Henderson (2000) who indicates that social workers are already incorporating reiki therapy into their practice, either directly or by way of referral.

This study aimed to explore the perspectives of reiki and social work practitioners to the benefits, risks, and barriers of integrating reiki and social work within the healthcare system. Due to the small number of participants in this study, and the purpose of this study to obtain the perspectives of practitioners who participated in the study 
about the benefits, risks and barriers to the integration of reiki and social work in the healthcare system, the above- mentioned results cannot be generalized. The rich, contextual information contained in the study results can however be used to generate further discussion around issues that were raised and topics to consider for future research. Reiki is reported to be beneficial in reducing anxiety and physical and emotional pain (Wardell \& Engebretson, 2001; Miles, 2003; Miles and True, 2003), which is valued in the healthcare system and in promoting a sense of clarity and selfawareness that is valued in social work. Reiki can also facilitate spiritual connection and growth. Reiki was described by both participants in this study, and in the literature (Miles, 2003; Miles and True, 2003) to empower individuals with regards to encouraging self-reflection, awareness, and determination. This is particularly so with regards to the benefits of self-treatment in reiki, and the ability to make choices about healthcare based on an increased awareness of one's well-being needs. Reiki is not seen as a harmful or physically intrusive act, unless proper protocol and ethical standards are not carried out with regards to parameters surrounding touch in therapy.

Reiki is currently not standardized and cannot be regulated under the Ontario Health Act due to the fact that it is not considered physically harmful to patients. Similarities in the codes of ethics in both reiki and social work, as well as the Ontario Health Department's regulatory guidelines, allows for the possibility of incorporating reiki and social work in the healthcare system as long as the practitioner is appropriately trained and adhering to the standards and guidelines within their established professions and as long as hospital policy allows for such as service to be provided. As mentioned earlier, barriers to this lie in the lack of standardization in reiki and the fact that the use of 
alternative therapies in the healthcare system is dependent on federal funding, provincial legislature, and individual hospital administration and policies. Established healthcare leaders in the profession continue to maintain jurisdictional boundaries, contributing to the barriers already present in a Western society. In addition to these barriers are the expectations of the government for evidence to prove safety and efficacy of CAM practices, such as reiki, and fears of the impact of integration on a system already struggling with rising healthcare costs.

Recommendations by participants include the need for more research that is credible (both anecdotal and scientific), increased standardization in the field of reiki practice (particularly in the context of integration with other services), and acceptance into the healthcare system. As mentioned by one of the practitioners, future studies may also be conducted that could speak to benefits, or concerns, and be measured in terms of symptom reduction, or how a client feels before and after receiving integrated services. Of particular relevance to the field of structural social work, future studies may also want to focus on the experience of empowerment, increased receptivity to therapeutic intervention, and the potential for this combination of services to address both personal coping mechanisms and the issue of external or systemic challenges such as accessibility to material resources.

Social work in hospitals is considered a self-monitored profession (Michalski, Creighton \& Jackson, 1999). The history of social work in healthcare reflects advocacy for change in the social worker's role in hospitals. Incorporating reiki with social work in the healthcare system may be the best method of achieving credibility and acceptance while simultaneously providing the necessary benefits to clients of stress reduction, 
increased clarity, relief of physical pain and trauma, and empowerment. To facilitate these services and benefits, concerns regarding safety, efficacy, accessibility, and adherence to ethical standards in the professions of reiki, social work, and healthcare would need to be addressed to increase acceptance by mainstream Western public and professional communities. 


\section{Reference List}

Anastas, J. W. (1999). Research Design for Social Work and the Human Services, $2^{\text {nd }}$ Edition. New York: Columbia University Press.

Anderson, R.M. (1995). Revisiting the Behavioral Model and access to medical care: does it matter? Journal of Health and Social Behavior, 36 (1), 1-10.

Antle, B. J. (2005, February). Ethics and Contemporary Social Work Practice: Highlights From the New CASW Code of Ethics. The Journal of the Ontario Association of Social Workers, 32 (1), 1-4.

Aponte, H. J. (1999). The Stresses of Poverty and the Comfort of Spirituality. In F. Walsh (Ed.), Spiritual Resources in Family Therapy (pp.76-89). New York, NY; The Guilford Press.

Astin, J.A . (1998). Why patients use alternative medicine: results of a national survey. Journal of the American Medical Association, 279 (19), 1548-1553.

Barrett, M. J. (1999). Healing from Trauma: The Quest for Spirituality. In F. Walsh (Ed.), Spiritual Resources in Family Therapy (pp.76-89). New York, NY; The Guilford Press.

Brennan, B. A. (1988). Hands of Light: A guide to Healing Through the Human Energy Field. Canada: Bantam Books.

Broom, A. (2005, March). Using qualitative interviews in CAM research: A guide to study design, data collection and data analysis. Complementary Therapies in Medicine, 13(1), 65-73.

Canadian Association of Social Workers (1994). Canadian Association of Social Workers Code of Ethics. Retrieved March 29, 2006, from the University of Manitoba Website: http://www.umanitoba.ca/faculties/social_work/code_ethics/code_ethics_full.html

Canadian Reiki Association Homepage (2003). Code of Ethics. Retrieved June 10, 2007, from the Canadian Reiki Association Website: http//:www.reiki.ca/ethics.htm

Canadian Reiki Association Homepage (2003). Disciplinary Action Policy. Retrieved June 10, 2007, from the Canadian Reiki Association Website: http//:www.reiki.ca/documents/CRA_Disciplinary_Action.pdf

Canda, E. R. and Phoabtang, T. (1992, January). Buddhism as a Support System for Southeast Asian Refugees. Social Work, 37 (1), 61-67.

Canda, E. R. (1998). Afterword: Linking Spirituality and Social Work: Five Themes for Innovation. In Canda, E.R. (Ed.), Spirituality and Social Work: New Directions (pp.97106). Binghamton, N.Y.: The Haworth Pastoral Press. 
Canda, E. R., and Furman, L. D. (1999). Spiritual Diversity in Social Work Practice: The Heart of Helping. New York: The Free Press.

Carniol, B. (2005). Case Critical: Social Services \& Social Justice In Canada, $5^{\text {th }}$ edition. Ontario: Between the Lines.

Carniol, B. (2001). Case Critical: Challenging Social Services in Canada. Ontario: Between the Lines.

Chan, C., Ho, P.S.Y. and Chow, E. (2001). A body-mind-spirit model in health: an Eastern approach. Social Work in Health Care, 34 (3/4), 261-282.

Cleary, T. (1998). The Essential Tao. New Jersey: Castle Books.

Coburn, D., Rappolt, S., and Bourgeault, I. (1997). Decline versus retention of power through restratification: the case of medicine in Ontario. Social Health and Illness, 19 (1), $1-22$.

Coburn, D., Torrence, G.M., and Kaufert, J.M. (1983). Medical Dominance in Canada in historical perspective: the rise and fall of medicine? International Journal of Health Services, 13 (3), 407- 433.

Coholic, D. (2002). Practice Principles for Social Work and Spirituality: A Focus on Practice Methods and Relationship. Currents: New Scholarship in the Human Services, $1(1), 1-13$.

Cowley, A. S. (1993, September).Transpersonal Social Work: A Theory for the 1990's. Social Work, 38 (5), 527-534.

Cowley, A. S. (1996). Transpersonal Social Work. In F. Turner (Ed.), Social Work Treatment: Interlocking Theoretical Approaches (pp. 663-698). New York: The Free Press.

Cowley, A. S. (1999). Transpersonal Theory and Social Work: Practice with Couples and Families. Journal of Family Social Work, 3 (2), 5-21.

Coyte, P. (2001, December). Reforming the NHS: Current trends and future directions for the Canadian Healthcare System. Economic Affairs, 21 (4), 24-27.

Creel, H. G. (1970). What Is Taoism? And Other Studies in Chinese Cultural History. Illinois: The University of Chicago Press.

Davidhizar, R. and Newman Giger, J. (1997). When touch is not the best approach. Journal of Clinical Nursing, 6, 203-206. 
Dilley, P. (2004). Interviews and the Philosophy of Qualitative Research. The Journal of Higher Education, 75(1),127-132.

Eden, D. (1999). Energy Medicine. New York: Jeremy P. Tarcher/Putnam.

Eisenberg, D.M., Kessler, R.C., Norlock, F.E., Calkins, D.R., \& Delbanco, T.L. (1993) unconventional medicine in the United States. New England Journal of Medicine, 328, 246-252.

Ell, K. (1996). Crisis Theory and Social Work Practice. In F. Turner (Ed.), Social Work Treatment: Interlocking Theoretical Approaches (pp.168-190). New York: The Free Press.

Ellis, R. (1999). Practical Reiki. New York: Sterling Publishing Co., Inc.

Epple, D. M. (2003, Summer). Encounter With Soul. Clinical Social Work Journal, 31 (2), 173- 188 .

Finger, W. and Mayfield Arnold E. (2002). Mind-Body interventions: applications for social work practice. Social Work in Health Care, 35 (4), 57-78.

Goldberg, C. (1980). In defense of narcissism. New York: Gardner Press.

Greene, G. J. (1996). Communication Theory and Social Work Treatment. In F. Turner (Ed). Social Work Treatment: Interlocking Theoretical Approaches (pp. 116-145). New York: The Free Press.

Hancock, M.R. (1997). Principles of Social Work Practice: A Generic Practice Approach. New York: The Haworth Press.

Henderson, L. (2000). The Knowledge and Use of Alternative Therapeutic Techniques by Social Work Practitioners: A Descriptive Study. Social Work in Health Care, 30 (3), 5571.

Herman, J. (1997). Trauma and Recovery: The aftermath of violence- from domestic abuse to political terror. New York: Basic Books.

Hirschkorn, K.A., and Bourgeault, I.L. (2007, February). Actions speak louder than words: Mainstream health providers' definitions and behaviour regarding complementary and alternative medicine. Complementary Therapies in Clinical Practice,13 (1), 29-37.

Holland, T.P. (1989). Values, faith and professional practice. Social Thought, 15 (1), 2840 . 
Horton, J.A., Clance, P.R., Stark-Elifson, C. and Enshoff, J. (1995). Touch in Psychotherapy: A survey of patients' experiences. Journal of Health and Social Behavior, 36 (1), 1-10.

Kabat Zinn, J. (1990). Full Catastrophe Living: Using the wisdom of your mind and body to face stress, pain and illness. New York: Dell.

Kelner, M., and Wellman, B. (1997). Healthcare and consumer choice-Medical and alternative therapies. Social Science \& Medicine, 45 (2), 203- 212.

Kelner, M.J., Boon, H., Wellman, B., and Welsh, S. (2002). Complementary and alternative groups contemplate the need for effectiveness and cost-effectiveness research. Complementary Therapies in Medicine, 10, 235- 239.

Kelner, M., Wellman, B., Boon, H., and Welsh, S. (2004a, September). Responses of established healthcare to the professionalization of complementary and alternative medicine in Ontario. Social Science and Medicine, 59, (5), 915-930.

Kelner, M., Wellman, B., Boon, H. and Welsh, S. (2004b). The role of the state in the social inclusion of complementary and alternative medical occupations. Complementary Therapies in Medicine, 12, 79-89.

Kilpatrick, A.C. and Holland, T.P. (1990). Spiritual Dimensions of Practice. The Clinical Supervisor, 8 (2), 125-140.

Kissman, K., and Mauer, L. (2002). East meets West: Therapeutic aspects of spirituality in health, mental health, and addiction recovery. International Social Work, 45 (1), 35-43.

Koenig, T. L., and Spano, R. N. (1998). Taoism and the Strengths Perspective. In E. Canada (Ed.), Spirituality and Social Work: New Directions (pp. 47-66). New York: The Haworth Pastoral Press.

Kohn, L. (1991). Taoist Mystical Philosophy: The Scripture of Western Ascension. New York: State University of New York Press.

Lee, J. (1999). The Empowerment Approach to Social Work Practice. In F. Turner (Ed). Social Work Treatment: Interlocking Theoretical Approaches (pp. 218-249). New York: The Free Press.

Leight, A. K. (2001). Transpersonalism and Social Work Practice. In Canda, E. R. and Smith, E. D. (Eds.), Transpersonal Perspectives on Spirituality in Social Work (pp. 6376). New York: The Haworth Press.

Loveland Cook, C.A., Becvar, D. S., and Pontious, S. L. (2000) Complementary Alternative Medicine in Health and Mental Health: Implications for Social Work Practice. Social Work in Health Care, 31 (3), 39-57. 
Lubeck, W., Petter, F. and Rand, W. (2003). The Spirit of Reiki. Wisconsin: Lotus Press.

Lundy, C. (2004). Social Work and Social Justice: A Structural Approach to Practice. Ontario: Broadview Press.

MacDermott, Wendy E, and Epstein, Michael. (2001, April). Effects of Reiki- An Evaluation of Tamara's House: Reiki is Effective in Addressing Major Consequences of Child Sexual Abuse. Retrieved January 2006, from Tamara's House: Services for Sexual Abuse Survivors Inc. Website: http://www.tamarashouse.sk.ca.

Maidment, J. (2006). The Quiet Remedy: A Dialogue on Reshaping Professional Relationships. Families in Society: The Journal of Contemporary Social Services, 87 (1), 115-121.

Marshall and Vaillancourt (co-chairs). (1993). Changing the Landscape: Ending Violence- Achieving Equality: Final Report: The Canadian Panel on Violence Against Women. Chapter 1 (pp. 3-22).

Maslow, A. H. (1970). Motivation and Personality, $2^{\text {nd }}$ edition. New York: Harper \& Row Publishers.

Maslow, A. H. (1971). The Farther Reaches of Human Nature. New York: The Viking Press.

Michalski, J. H., Creighton, E. and Jackson, L. (1999). The Impact of Hospital Restructuring on Social Work Services: A Case Study of a Large University- Affiliated Hospital in Canada. Social Work in Health Care, 30 (2), 1-25.

Miles, Pamela. http://www.reikiinmedicine.org/index_flash.html

Miles, P. (2003, July/August). Pamela Miles Reiki Vibrational Healing. Alternative Therapies, 9 (4), 75-83.

Miles, P. (2004). Mind-Body Medicine News. Advances in Alternative Medicine, 20, (2), 30-31.

Miles, P. (2003). Preliminary Report on the use of Reiki for HIV Related Pain and Anxiety. Alternative Therapies in Health and Medicine, 9 (2), 36.

Miles, P. and True, G. (2003, March/April). Reiki- Review of a Biofield Therapy, History, Theory, Practice, and Research. Alternative Therapies, 9, (2), 62-72.

Moreau, M. J. (1989, May). Empowerment Through A Structural Approach to Social Work. Ottawa: Carleton University School of Social Work. 
Mullaly, R. (1993). Structural Social Work: Ideology, Theory, and Practice. Ontario: McClelland \& Stewart Inc.

Mykhalovskiy, Eric and Weir, Lorna (September, 2004). The problem of evidence-based medicine: directions for social science. Social Science \& Medicine, 59 (5), 1059- 1069.

Neuman, L. W., and Kreuger, L. W. (2003). Social Work Research Methods: Qualitative and Quantitative Applications. Toronto: Allyn \& Bacon.

Ontario College of Social Workers and Social Service Workers. http://www.ocswssw.org

Advisory Group on Complementary and Alternative Healthcare, Health Systems Division, Health Canada, (2001). Perspectives on Complementary and Alternative Healthcare, Retrieved March 2006, from the Health Canada Website: http://www.hc-sc.gc.ca/healthcare/cahc/index.html

Pinson, B. (2002, Fall). Touch in Therapy: An Effort to make the Unknown Known. Journal of Contemporary Psychotherapy, 32 (2/3), 179-196.

Pawluch, D., Cain, R. and Gillett, J. (1994). Ideology and Alternative Therapy Use Among People Living with HIV/AIDS. Health and Canadian Society, 2 (1),63-84.

Reese, D. J. (2001). Addressing Spirituality in Hospice: Current Practices and a Proposed Role for Transpersonal Social Work. In Canda, E. R. and Smith, E. D. (Eds.), Transpersonal Perspectives on Spirituality in Social Work (pp. 135-161). New York: The Haworth Press, 2001.

Reid, D. (1989). The Tao of Health, Sex and Longevity: A Modern Practical Approach to the Ancient Way. London: Simon \& Schuster.

Richmond, M.E. (1969). Friendly Visiting Among the Poor: A Handbook for Charity Workers. New Jersey: Patterson Smith.

Roof, W. C. (1993). A Generation of Seekers: The Spiritual Journeys of the Baby Boom Generation. San Francisco: Harper Books.

Rowe, W. (1996). Client-Centered Theory: A Person- Centered Approach. In F. Turner (Ed.), Social Work Treatment: Interlocking Theoretical Approaches (pp. 69-93). New York: The Free Press.

Royce, D. (1991). Research Methods in Social Work. Illinois: Nelson-Hall Publishers.

Rubin, A. and Babbie, E. (1997). Research Methods for Social Work, $3^{\text {rd }}$ edition. Toronto: Brooks/Cole Publishing Company. 
Saso, Michael and Chappell, David W. (Eds.). (1977). Buddhist and Taoist Studies I. U.S.A.: The University Press of Hawaii.

Schmehr, R., (2003). Case Report: Enhancing the Treatment of HIV/AIDS with Reiki Training and Treatment. Alternative Therapies in Health and Medicine, 9 (2), 120.

Smith, E.D., (1995, May). Addressing the Psychospiritual Distress of Death as Reality: A Transpersonal Approach. Social Work, 40 (3), 402-413.

Spencer, S.W. (1961). What place has religion in social work education? Social Service Review, 35, 161-170.

Stenzel, C. L. and Rupert, P. A., (2004). Psychologists Use of Touch in Individual Psychotherapy. Psychotherapy: Theory, Research, Practice, Training, 41 (3), 332-345.

Straus, Sharon, E, and McAlister, Finlay, A., (October, 2000). Evidence-based medicine: a commentary on common criticisms. Canadian Medical Association Journal, 163 (7). Retrieved from the Canadian Medical Association Journal website on September 12,

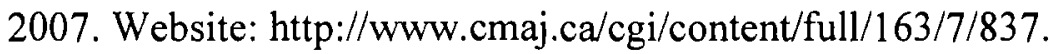

Strauss, A. and Corbin, J. (1990). Basics of Qualitative Research: Grounded Theory Procedures and Techniques. California: Sage Publications.

Tataryn, Douglas, J. and Verhoef, Marja. (2001). Combining Conventional, Complementary, and Alternative Healthcare: A Vision of Integration. Perspectives on Complementary and Alternative Healthcare, Retrieved March 2006, from the Health Canada Website: http://www.hc-sc.gc.ca/healthcare/cahc/index.html

Taylor, E., (1992). Transpersonal Psychology: Its several virtues. The Humanistic Psychologist, 20, 285-300.

The National Center for Complementary and Alternative Medicine, National Institute of Health, U.S. Web site: http://www.nccam.nilh.gov/health/.

Tune, D. (2001). Is touch a valid therapeutic intervention? Early returns from a qualitative study of therapists' views. Counselling and Psychotherapy Research, 1(3), $167-171$.

Walsh, Forma (1999). Religion and Spirituality: Wellsprings for Healing and Resiliance. In F. Walsh (Ed.), Spiritual Resources in Family Therapy (pp. 3-27). New York: The Guilford Press.

Wardell, D.W., and Engebretson, J. (2001). Biological correlates of Reiki Touch healing. Journal of Advanced Nursing, 33 (4), 439-445. 
Welch, H. (1965). Taoism: The Parting of the Way, Revised Edition. Boston: Beacon Press.

Wills, G. (1992, Winter). Values of Community Practice: Legacy of the Radical Social Gospel. Canadian Social Work Review, 9, (1), 28-40.

Wright, L. M. (1999). Spirituality, Suffering, and Beliefs: The Soul of Healing with Families. In F. Walsh (Ed.), Spiritual Resources in Family Therapy (pp. 61-75). New York: The Guilford Press.

Wuthnow, S. (1997, Fall). Healing Touch Controversies. Journal of Religion and Health, $36(3), 221-229$.

Yegidis, B., Weinbach, R., and Morrison- Rodriguez, B. (1999). Research Methods for Social Workers, $3^{\text {rd }}$ Edition. Toronto: Allyn and Bacon.

Yip, K. (2005) Taoistic Concepts of Mental Health: Implications for Social Work Practice with Chinese Communities. Families in Society: The Journal of Contemporary Social Services, Vol. 86, No. 1, 35-45. 


\section{Appendix A}

Canadian Reiki Association: Code of Ethics 


\section{The Canadian Reiki Association Code of Ethics (Must be signed by ALL Members)}

1. The health and well being of the client/student is the prime consideration of the member.

2. The client is entitled to truth, confidentiality, and the respect of their human dignity.

3. The client has the right to accept or refuse any form of treatment.

4. Members shall not refuse a client on the basis of sex, race, religion, sexual orientation, or political belief. However, notwithstanding this clause, members reserve the right to refuse a client for reasons of personal safety and/or other reasons, which do not contravene the aforementioned item.

5. Members should retain accurate and up-to-date records on their dealings with the client. These records should be maintained in a secure location and must be considered confidential. No information contained within the records should be released without the written consent of the client.

6. Members shall dress in a professional manner conducive to the holistic service being provided and be neat and clean in his/her own personal hygiene.

7. Members shall ensure that their professional conduct is beyond reproach. They shall not take physical, sexual, psychological or financial advantage of the client. They must not interfere in the client's personal affairs.

8. Members shall not practice or teach Reikj if they are in any condition, which compromises the quality of their services, such as inebriation, or if their mental faculties are lessened for any reason whatsoever and they shall never offer liquor to their clients.

9. Members will never ask a client to disrobe and will not allow such action to take place, nor will the member touch the genital area or anal area or the breasts or areola of their client, nor will the client be allowed to touch the practitioner in such a manner.

10. When the client has given permission for "hands on" therapy, members shall use light hand pressure when placing hands on the client's body There will never be a need to rub or manipulate of any body part. If the client has not given permission for "hands on" therapy, the member will complete the entire Reiki session with hands above the body at all times.

11. Members shall not refuse or withdraw services without justifiable cause. Such reasons include but are not limited to conflict of interest between the member and the client that jeopardizes the professional relationship or illegal or unjust or fraudulent actions taken or proposed by the client.

12. Members must recognize their limits of competence and must not undertake issues for which they have no training. Members will not claim that Reikj can cure, nor will they diagnose any medical problems or prescribe, nor will they ever advise a client to stop taking medications, unless qualified to do so. When it is in the client's interests, members should refer the client on to another practitioner or organization that has the training appropriate to the client's needs.

13. Members should continually make an effort to improve their knowledge and professional skills. They should also encourage the public to become educated and informed about the practice and teaching of Reiki and about the development of a health-enhancing lifestyle in general.

14. Teaching members should not encourage the practice of Reiki by persons who are not competent or who have insufficient training or certification. They should not grant certificates of attendance or competence to anyone whose skills and/or ethical conduct they have a valid reason to doubt. Teaching members should report any such cases to the CRA.

15. Members are responsible for reporting any member of the CRA who does not respect this code of ethics. This requirement aims to ensure the protection of the public interest and also to protect the good name and professional reputation of the CRA.

16. Members agree that failure to abide by the terms, conditions, and stipulations of this code of ethics will leave them subject to action, whether legal or other, by the CRA. Action may include but is not limited to: temporary or permanent suspension of membership, public notification of a member's transgression, and/or suspension of membership, legal action. In addition, members understand that breaching any or all of code numbers $7,8,9$ and 10 will result in immediate termination of their membership.

17. Members acknowledge that a code of ethics cannot cover every case of what is ethical and what is not. Therefore, it is understood that members must behave in accordance with the ethical standards of the province and country in which they reside.

18. It is understood that the CRA is hereby saved harmless from liability of any kind whatsoever for the actions or lack thereof of its Registered Practitioners and/or Registered Teachers in fulfillment of their association membership.

I have completed the CRA Membership Application form accurately and honestly and I agree to abide by the CRA Code of Ethics listed on this form. I understand it is my responsibility to abide by any local or Provincial laws and rules, if any, regarding Reiki as well as any other complimentary integrative modality that I practice. I have no knowledge of any incident, suit, pending claim or license revocations or ethics hearing violation against me. I have never been the subject of any investigation in connection with any sexual misconduct or act, molestation or assault. I attest that no issued documentation for licensing, certification or registration has been revoked and no disciplinary action is pending against me in relation to my trade's specialty. I attest that I have completed all of the required training and certification for Reiki and the integrative modalities I have listed on this application and that I practice. I understand my signature is considered legal and binding and that it verifies I have completed this form completely and honestly.

Signed

Dated

\section{Reference Authorization - RP and RT ONLY}

I authorize the Canadian Reiki Association to give my name and phone number to members of the public.

I understand that any references made by the CRA to me are undertaken solely at my own risk and that the CRA is not responsible for the consequences thereof in any way whatsoever.

\begin{tabular}{|c|c|c|c|c|c|}
\hline $\begin{array}{c}\text { I will } \\
\text { treat at: } \\
\text { (RP / RT) }\end{array}$ & $\begin{array}{l}\text { Client's Location } \\
\text { (Travel = Yes) }\end{array}$ & My Location & $\begin{array}{l}\text { I will } \\
\text { teach at: } \\
\text { (RT only) }\end{array}$ & $\begin{array}{c}\text { Student's Location } \\
\text { (Travel }=\text { Yes) }\end{array}$ & My Location \\
\hline
\end{tabular}




\section{Appendix B}

Canadian Reiki Association: Disciplinary Action Policy 


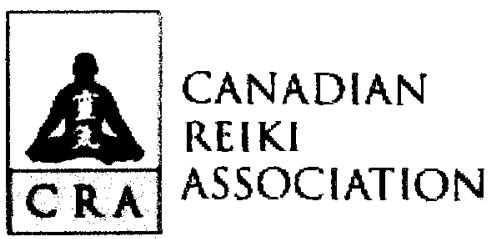

\section{Canadian Reiki Association Disciplinary Action Policy}

\section{Disciplinary Action}

1. Complaints and/or concems received via the Complaints \& Concems email address (complaints_concems@reiki.ca) located on the CRA website (http:/hww.reiki.ca/contact.htm) or by mail to Canadian Reiki Association PO Box 74072 , Hillcrest RPO, Vancouver BC V5V 5 C8 or by fax to 604.521 .9557 , will be processed by the President and Vice President of the CRA within three working days of the date the President and/or Vice President received the complaint and/or concem.

2. The complaint and/or concem will be investigated by way of contacting the originator of the email by telephone or if applicable and more efficient, by email. If the complaint or concem is with respect to a registered practitioner or teacher, the practitioner or teacher will be contacted and interviewed

3. If the complaint or concem does not involve a practitioner or teacher but does involve a procedure or function of the CRA, this will be brought to the attention of the CRA Board. If a change in procedures is required to satisfy the concem or complaint, it shall be brought forth and voted on by the Board of Directors.

\section{What action will be taken}

1. Upon investigation, if the allegation is without merit, no further action to be taken.

2. Upon investigation, if the allegation is with merit, and concems any one or more of codes 1 through 6 , and/or codes 11 through 18, of the CRA Code of Ethics, a written waming letter will be mailed to the offending member.

3. Upon investigation of a second allegation against the same member, if the allegation has merit, the result will be suspension of Membership with the CRA for a 6 month period and the members name will be added to the "Suspended and Expelled Members List" on the CRA website.

4. Upon investigation, if the allegation has merit and is a breach of codes $7,8,9$ and/or 10 of the CRA Code of Ethics, or is an allegation reported against any one member for a third time, permanent suspension of membership will result and the members name will be added to the "Suspended and Expelled Members List" on the CRA website.

\section{In addition to the above actions, the CRA will}

1. Add the Members name to a list of Suspended or Expelled members maintained on the CRA website.

2. In cases of serious misconduct, that represent potential serious risk to the public or practitioners, the information will be reported to the Police or other appropriate official authorities.

\section{The Suspended and Expelled Members List}

The Suspended and Expelled Members List is a text online list of all the individual practitioners or teachers that have been Suspended or Expelled from the CRA Membership.

Upon lifting of the 6 month suspension, that Member's name is removed from this list.

"Note: the Suspended and Expelled Members List is listed on the "Members Only" area of the CRA website and it is noted on the new membership application form that the members name would appear on this list if applicable and by signing the application form they are agreeing to this action.

Signed Member\#

Date 


\section{APPENDIX C}

Advertisement for Participants 


\section{CARLETON UNIVERSITY RESEARCH ON REIKI AND}

\section{SOCLAL WORK:}

I am an MSW student seeking individuals in Ottawa with both reiki and social work credentials to obtain perspectives on the possible barriers, benefits and limitations of incorporating reiki into social work practice. Please contact researcher, Cheryl Grant, by telephone: email: 


\section{APPENDIX D}

Interview Guide for Individuals with

Reiki and Social Work Credentials 


\section{INTERVIEW GUIDE:}

1. What level of reiki certification do you currently have? $(1,2,3,4)$

2. To what extent do you practice Reiki? (with family and friends; as a part-timeout of home practice; full-time- private practice)

3. What drew you to the practice of reiki?

4. How do you see the practice of reiki contributing to the individual; yourself; society?

5. How do you see the practice of reiki contributing to other fields of practice such as medical and mental health care and social work?

6. What are your views on the current use and knowledge of reiki therapy in mainstream society (such as in hospitals and health care settings).

7. Are you a registered reiki practitioner? How do you feel about registration and regulations in the field of reiki practice?

8. How accessible do you feel reiki is to people in the community at present? Do you think this should change?

9. Do you feel there is a need for reiki to be incorporated into other practices or remain private and separate from other domains?

10. What level of social work education do you have? (B.S.W., M.S.W., PhD)

11. To what extent do you provide social work services? (full-time employee of an agency; part-time employee of an agency; full-time private practice; part-time private practice).

12. Are you a registered social worker (R.S.W.)? How do you feel about registration and regulation in the field of social work. 
13. What social work services do you provide?

14. What drew you to social work practice, or the field of social work?

15. Do you offer both Reiki and Social Work services? (yes, no) How do you find they fit together? How do you see them working together?

16. What is your view of Reiki therapy? How would you describe Reiki?

17. What is your view of Social Work services? How would you describe social work services?

18. Do you see Reiki and Social Work services working together in other areas of social work practice?

19. If you have not practiced reiki and social work together to date, would you use Reiki in a social work session (s)? Why or Why not?

20. If you would not use reiki in a social work session, what would have to be different in order for you to do so?

21. What is your experience with being a reiki practitioner? How do you feel it benefits you and/or your clients? What experiences do you encounter as a reiki practitioner?

22. What type of issues do your clients describe as prompting them to seek reiki therapy? Do you notice any particular theme in terms of why clients come to you for reiki therapy?

23. What reflections or comments do your clients make to you after receiving a reiki session? 
24. Do the reiki sessions mainly involve the physical aspect of healing or do you find yourself also providing counselling services, either intentionally or unintentionally? How often would you say this happens with your clients?

25. Does your practice allow you to provide counselling services, or space to process with the client, regarding their experiences of the Reiki session?

26. Can you think of any experiences with Reiki where social work services (ie: counselling, psychoeducation, advocacy) would have been (or were) beneficial?

27. Can you think of any experiences with social work practice where Reiki therapy would have been beneficial?

28. What are your hopes regarding the future direction of reiki practice and social work practice?

29. What outcome would you like to see regarding research into the integration of reiki into social work practice? 


\section{APPENDIX E}

Thematic Guide

for Telephone Interviews 
Telephone Interview with a representative from the College of Social Workers and Social Service Workers:

1. What, if any, position does the College have regarding the use of reiki therapy in social work practice? What are the reasons for this position?

2. If the College does not support the use of reiki therapy in social work practice, what would have to change, or what conditions would have to be in place in order for this to occur?

3. Are there specific areas of social work practice that the College would be more likely to support the use of reiki therapy? Why?

Telephone Interview with a representative from the Canadian Reiki Association (CRA):

1. What, if any, position does the CRA have regarding the use of reiki in social work practice? What are the reasons for this position?

2. If the CRA does not support the use of reiki in social work practice, what conditions would be recommended, or necessary, in order for this to occur?

3. Are there any specific areas of social work practice that the CRA would more likely support the use of, or see the benefits of, reiki practice? Why?

Telephone Interview with a representative from the Ontario Health Department:

1. What, if any, position does the Ontario Health Department have with regards to the use of reiki therapy in the healthcare system; and in social work practice within the healthcare system? What are the reasons for this position?

2. If the Ontario Health Department does not support the use of reiki in social work within the healthcare system, what conditions would be required in order for this to occur?

3. Are there any specific areas within the healthcare system that the Ontario Health Department would be more likely to support the use of reiki? Why? 


\section{APPENDIX F}

Letter of Information for Individuals with

Reiki and Social Work Credentials 


\section{Reiki Therapy in Social Work Practice}

\section{Letter of Information}

My name is Cheryl Grant. I am a graduate student in the Master of Social Work program at Carleton University. I am also employed in a social service agency in Ottawa, and have credentials for practicing reiki. I am currently working on a research project to explore the possibility of incorporating reiki therapy into social work practice.

It is my intention to better understand the perspectives in Ottawa regarding the possible benefits and barriers to incorporating reiki therapy into social work practice. I am interested in speaking to 6-8 individuals in Ottawa who have credentials in both fields of social work and reiki therapy in order to obtain perspectives and experiences that would facilitate the exploration of the possibility (or impossibility) of utilizing reiki therapy in social work practice.

Each participant will be asked to participate in one interview that will be approximately 1-2 hours long. There is no remuneration for participation. The attached interview guide outlines the scope of the questions that I hope to explore in the interview. The purpose of the interview guide is to facilitate conversation regarding the exploration of incorporating reiki and social work, as such, the guide does not outline every specific question.

Interviews will be taped and transcribed by a professional transcription service. The participant's name and place of work will not be named on the tape, or in the final paper, and will thus remain confidential. If participants use any identifying information or language in their interview, the information will be removed from the data, and quotes will be paraphrased, for publication or research papers.

I hope that this study will contribute to the understanding of Complementary and Alternative (CAM) therapies, such as Reiki, and their relationship with fields of practice such as social work. However, it is unlikely that individual participants will receive any specific benefits as a result of participation in this research project.

While the risks of this type of research are minimal, it is always possible that the College of Social Workers and Social Service Workers could read the information in this study and act in any number of ways, positive or negative. That being said, all identifying information will be removed from any publications in order to ensure the anonymity of all participants. As a result, there are no foreseen risks to anyone participating in this study. 
All participants will be asked if they would like to receive a copy of their transcripts after the study has been completed. Any further findings may be published in academic journals and used to support further studies regarding CAM therapies, or reiki specifically, independently or in the context of the field of social work. While the researcher will not make a standard practice of making such publications available to participants, anyone who is part of this study can request copies of this information and the researcher will supply them.

This project has been reviewed and received ethics clearance through the Carleton University Research Ethics Committee and those participants with concerns or questions about involvement with the study may contact the ethics committee chair.

If, at any time before, during or after the interview participants have any concerns, questions, or want to withdraw from the study, they can contact me at , or Professor Sarah Todd, supervising professor, at 520-2600 ext. 4498. Alternately they may want to contact the Carleton Ethics Committee Chair, Antonio Gualtieri, at 520-2517, who will try to answer any of their questions and address any of their concerns. Participants are free to withdraw their agreement to participate at any time during the study data withdrawn without reprisal. Participants may also want to decline answering any questions during the interview.

Thank you for your time and cooperation,

Cheryl Grant 


\section{APPENDIX G}

\section{Letter of Information for}

Organizational Representatives 


\section{Reiki Therapy in Social Work Practice}

\section{Letter of Information}

My name is Cheryl Grant. I am a graduate student in the Master of Social Work program at Carleton University. I am also employed in a social service agency in Ottawa, and have credentials for practicing reiki. I am currently working on a research project to explore the possibility of incorporating reiki therapy into social work practice.

It is my intention to better understand the perspectives in Ottawa regarding the possible benefits and barriers to incorporating reiki therapy into social work practice. As part of my study I am interested in speaking to a representative from your organization regarding the organizational response to the possibility (or impossibility) of utilizing reiki therapy in social work practice.

You will be asked to participate in one telephone interview that will be approximately 30 minutes long. There is no remuneration for participation. The attached interview guide outlines the scope of the questions that I hope to explore in the interview. The purpose of the interview guide is to facilitate conversation regarding the exploration of incorporating reiki and social work, as such, the guide does not outline every specific question.

There is a risk that you will be identified as having participated in this research project. Your name will not be used unless specifically requested by yourself, however, due to the fact that you are being interviewed as a representative of your organization, anonymity and confidentiality will not be guaranteed.

I hope that this study will contribute to the understanding of Complementary and Alternative (CAM) therapies, such as Reiki, and their relationship with fields of practice such as social work. However, it is unlikely that individual participants will receive any specific benefits as a result of participation in this research project.

Any further findings may be published in academic journals and used to support further studies regarding CAM therapies, or reiki specifically, independently or in the context of the field of social work. While the researcher will not make a standard practice of making such publications available to participants, anyone who is part of this study can request copies of this information and the researcher will supply them.

This project has been reviewed and received ethics clearance through the Carleton University Research Ethics Committee and those participants with concerns or questions about involvement with the study may contact the ethics committee chair. 
If, at any time before, during or after the interview, you have any concerns, questions, or want to withdraw from the study, you can contact me at , or Professor Sarah

Todd, supervising professor, at 520-2600 ext. 4498. Alternately you may want to contact the Carleton Ethics Committee Chair, Antonio Gualtieri, at 520-2517, who will try to answer any of your questions and address any of your concerns. You are free to withdraw your agreement to participate at any time during the study, the data will be withdrawn without reprisal. You may also want to decline answering any questions during the interview.

Thank you for your time and cooperation,

Cheryl Grant 


\section{Appendix $\mathrm{H}$}

Standards of Social Work Practice Quoted in the Response of the College of Social Workers and Social Service Workers 
The Standards of Practice Handbook contains eight Principles. For each Principle, interpretations are provided as standards that guide College members. In the application of these principles to their own practice situations, College members should read and consider all eight Principles together as a whole. However, Principle II, Competence and Integrity appears to be very relevant to the issues you are considering. Interpretation 2.1 .1 states:

'College members are responsible for being aware of the extent and parameters of their competence and their professional scope of practice and limit their practice accordingly. When a client's needs fall outside of the College member's usual area of practice, the member informs the client of the option to be referred to another professional. If, however, the client wishes to continue the professional relationship with the College member and have the member provide the service, the member may do so provided that:

(i) he or she ensures that the services are competently provided by seeking additional supervision, consultation or education; and

(ii) the services are not beyond the member's professional scope of practice.

Recommendations for particular treatment services, referrals to other professionals or a continuation of the professional relationship are guided by the client's interests as well as the College member's clinical judgment and knowledge.'

Interpretation 2.2 Integrity is also of relevance:

'College members are in a position of power and responsibility with respect to all clients. This necessitates that care be taken to ensure that all clients are protected from the abuse of such power during and after the provision of professional services.

College members establish and maintain clear and appropriate boundaries in professional relationships for the protection of clients. Boundary violations include sexual misconduct and other misuse and abuse of the member's power'. 


\section{APPENDIX I}

Letter of Consent for Individuals with

Reiki and Social Work Credentials 


\section{Letter of Consent}

Cheryl Grant is inviting me, to participate in $\underline{\text { Reiki }}$ Therapy and Social Work Practice research project. This project aims to explore the possibility of incorporating reiki therapy into social work practice. Cheryl Grant is interested in speaking with individuals in Ottawa that have credentials in both social work and reiki therapy to understand their perspectives and experiences regarding the possible benefits, limitations, and barriers to incorporating reiki therapy into social work practice.

My participation will involve one interview that is approximately 1-2 hours in length regarding my perspectives and/or experiences of integrating reiki therapy into social work practice. The attached interview guide outlines the general questions that will be explored in our interview. The guide does not outline every specific question, but rather will be used to facilitate conversation regarding the exploration of incorporating reiki and social work.

Research interviews will be carried out in the location of my choice (i.e. workplace, coffee shop, home, etc.). While the risks of this type of research are minimal, it is always possible that the College of Social Workers and Social Service Workers could read the information in this study and act in any number of ways, positive or negative. Cheryl Grant will not use my name in the study and will ensure my confidentiality by using pseudonyms; removing any identifying information obtained during the interview; and by paraphrasing any distinctive language used in my interview. Transcripts and tapes will be stored in a locked filing cabinet in Cheryl Grant's home. They will be kept until June 30, 2006 and then destroyed. I can receive a copy of the transcript of my interview at my request, after the study has been completed. Any further findings of the study may be published in academic journals and used to support further studies regarding CAM therapies, or reiki specifically, independently or in the context of the field of social work.

My participation in this project is voluntary. I may withdraw at any time or refuse to answer any questions. Should I decide to withdraw from the study, I will decide at that time if the researcher may use any of the information I have provided.

I will have access to my transcripts and the summary of research results. 
This project has been reviewed and received ethics clearance through the Carleton University Research Ethics Committee and those participants with concerns or questions about involvement with the study may contact the ethics committee chair.

If I have any concerns, I may contact Cheryl Grant at Professor Sarah Todd, supervising professor, at 520-2600 ext. 4498. Professor Antonio Gualtieri, 520-2517, may be contacted with any ethics concerns or complaints.

Date:

Participant:

Researcher:

This signature documents that the participant has been informed about what the research entails and, on that basis, agreed to participate 


\section{APPENDIX J}

Letter of Consent for Organizational Representatives 


\section{Letter of Consent}

Cheryl Grant is inviting me, to participate in Reiki Therapy and Social Work Practice research project. This project aims to explore the possibility of incorporating reiki therapy into social work practice. Cheryl Grant is interested in speaking with a representative from my organization to understand the organizational response regarding the possible benefits, limitations, and barriers to incorporating reiki therapy into social work practice.

My participation will involve one telephone interview that is approximately 30 minutes in length regarding the response of my organization to the integration of reiki therapy into social work practice. The attached interview guide outlines the general questions that will be explored in our interview. The guide does not outline every specific question, but rather will be used to facilitate conversation regarding the exploration of incorporating reiki and social work.

There is a risk that I will be identified as having participated in this research project. Cheryl Grant cannot guarantee anonymity or confidentiality regarding my participation in this research project, however will not use my name without my permission. Information pertaining to my interview will be stored in a locked filing cabinet in Cheryl Grant's home, will be kept until June 30, 2006, and then destroyed. Any further findings of the study may be published in academic journals and used to support further studies regarding CAM therapies, or reiki specifically, independently or in the context of the field of social work.

My participation in this project is voluntary. I may withdraw at any time or refuse to answer any questions. Should I decide to withdraw from the study, I will decide at that time if the researcher may use any of the information I have provided.

I will have access to the summary of research results.

This project has been reviewed and received ethics clearance through the Carleton University Research Ethics Committee and those participants with concerns or questions about involvement with the study may contact the ethics committee chair. 
If I have any concerns, I may contact Cheryl Grant at : _ - or Professor Sarah Todd, supervising professor, at 520-2600 ext. 4498. Professor Antonio Gualtieri, 520-2517, may be contacted with any ethics concerns or complaints.

Date:

Participant:

Researcher:

This signature documents that the participant has been informed about what the research entails and, on that basis, agreed to participate. 